\title{
A MULTIMEDIA APPROACH TO IMPROVE READING INSTRUCTION OF FUTURE TEACHERS
}

\author{
A Dissertation \\ Presented to \\ The Faculty of the Curry School of Education \\ University of Virginia \\ In Partial Fulfillment \\ Of the Requirements for the Degree \\ Doctor of Philosophy \\ by \\ Emily Kathleen Ely, M.Ed.
}

January, 2014 
(a) Copyright by Emily Kathleen Ely All Rights Reserved January 2014 


\begin{abstract}
Teacher education efforts must successfully prepare future teachers to implement evidence-based vocabulary practices that are effective for all students. This research is composed of two experimental studies that investigate a multimedia-based intervention, which pairs a modeling video with a Content Acquisition Podcast (i.e., video plus CAP), to teach preservice teachers how to implement an evidence-based vocabulary intervention to students at risk for or with learning disabilities and/or with language learning barriers. The video plus CAP tool was created based on theories of multimedia and cognitive learning as well as the development of automaticity of practice. In Study 1, I used a pretest-posttest-maintenance design to examine the effects of video plus CAP on preservice teachers' $(N=101)$ knowledge of vocabulary instruction. In Study 2, with a posttest-only design, I investigated the effects of the tool on preservice teachers' $(N=49)$ teaching ability. Preservice teachers were randomly assigned to one of two treatment conditions to learn about evidence-based vocabulary instruction; the treatment group watched a video plus CAP and the control group read an informational handout. Results indicated no significant differences between treatment groups on a test of vocabulary instruction knowledge; however, those who watched video plus CAP used significantly more teaching behaviors associated with an evidence-based vocabulary intervention during instruction than the control group. The video plus CAP tool has promising implications for teacher education as a way of bridging research to practice and improving instruction for all students.
\end{abstract}

Keywords: evidence-based practices, multimedia, teacher education, video, vocabulary 


\section{Curriculum, Instruction, and Special Education \\ Curry School of Education \\ University of Virginia \\ Charlottesville, Virginia}

\section{APPROVAL OF THE DISSERTATION}

This dissertation, "A Multimedia Approach to Improve Reading Instruction of Future Teachers," has been approved by the Graduate Faculty of the Curry School of Education in partial fulfillment of the requirements for the degree of Doctor of Philosophy.

Chairperson, Dr. Paige C. Pullen

Dr. Michael J. Kennedy

Dr. Daniel P. Hallahan

Dr. Vivian Wong

Date 


\section{DEDICATION}

I dedicate this dissertation to my beloved twin sister, Arin Edythe Ely, whose selflessness has yielded endless support, love, and patience, not only throughout my doctoral program, but all aspects of life. Thank you for being my rock, inspiration, and source of happiness and laughter. I am so thankful to live life with you by my side. 


\section{ACKNOWLEDGEMENTS}

Thank you to my father - my anchor - a man of endless patience, love, and great advice on all matters practical, as well as a model of professional and moral excellence; to my beautiful mother who knew how important it was to read to us, and who is always in my corner; to my stepmother who reminds me to strive for excellence, not perfection, and who inspires me with her deep curiosity about the world in which she lives; and to my stepfather for his support and model of persistence and determination. Thank you to my siblings who have taken an active interest and supported me throughout my endeavors: to Trevor for letting me teach him in the basement before he was old enough to form words, and to Laura, Anne, and Vanessa, for remaining positive role models throughout my life. Thank you to my grandmothers: Kathleen, for whom I am named and love dearly, and Mary Lou, "Greaty," an inquisitive woman and voracious reader.

Thank you to my colleagues and mentors at the University of Virginia, including Dr. Paige Pullen, who had my back at every turn and served as an encouraging, warm advisor. It has been a pleasure getting to know you and Gabriel. Thank you also to Dr. Michael Kennedy for his unconditional support (and endless edits on drafts), which afforded me the skills and confidence to conduct high quality research. "MK" helped mold my career path and ensured that I was sufficiently prepared to reach my goals. Thank you to the members of my doctoral committee, Dr. Daniel Hallahan and Dr. Vivian Wong, and other professors who shaped my learning and growth at UVA; to Dr. 
Robert McNergney, Dr. John Lloyd, and Dr. Sarah Powell, for listening and providing trusted mentorship.

Thank you to my good friend and fellow doctoral student, Mira Cole Williams, who is a pillar of patience and peace. I feel fortunate to have learned beside you and from you throughout this program; to Andy Bruce and Nathan Dolenc for your patience and advice on statistics and life; to Dr. Kristen Ashworth for your comforting nature and willingness to answer all of my questions; and to my professors, doctoral friends, and students, who made my experiences at UVA positive and fruitful.

I am appreciative of the relationships formed at Kensington Park Elementary School in Miami, Florida, where my teaching career began and my desire to advance the field of reading and special education was sparked. Thank you to my former kindergarten students, families, and colleagues; I will always have fond memories and gratitude. Thank you to the faculty members at the University of Miami for encouraging and challenging me. In particular, thank you Dr. Mary Avalos for your consistent, gentle mentorship.

To Margy Taylor: Great teachers are like the beacon in the night shinning on the horizon. Thank you for guiding me along a new course, helping me rise to heights never imagined, and giving me the tools and confidence necessary to succeed. To Alice Kanack, my violin teacher: Thank you for encouraging me to find my voice and for giving me a gift in music that I turn to for peace and enjoyment. 
Finally, to my friends - near and far: You are generous, patient, fun-loving, intelligent, inspirational individuals who care about the community and world in which we live. Thank you for shaping my life in beautiful ways, helping me find balance, and for your enduring friendships. 


\section{TABLE OF CONTENTS}

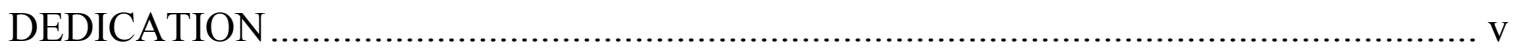

ACKNOWLEDGEMENTS ............................................................................... vi

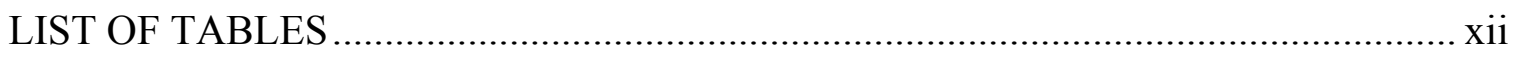

LIST OF FIGURES …...................................................................................

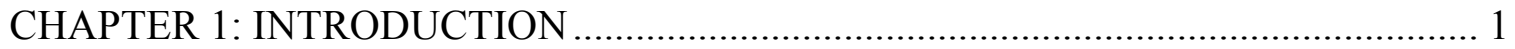

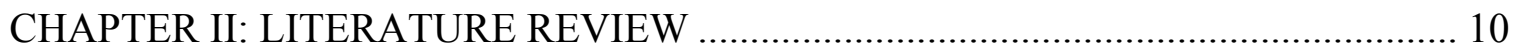

Teacher Preparation of Reading Instruction .......................................................... 11

Lack of Knowledge to Teach Reading..................................................................... 12

Reasons for Lack of Knowledge ................................................................... 18

Relationships Between Teacher Knowledge, Practice, and Student Learning ............ 21

The Current State of Reading Teacher Education ................................................. 32

Vocabulary Instruction......................................................................................... 34

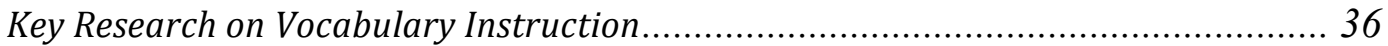

Vocabulary Interventions in General Education ............................................. 38

Vocabulary Interventions in Special Education ............................................ 43

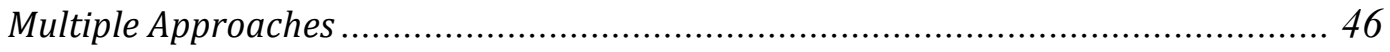

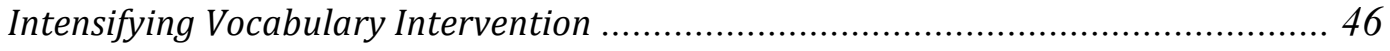

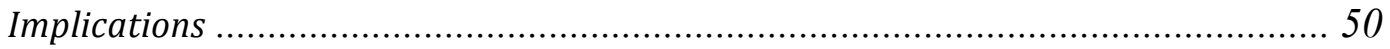

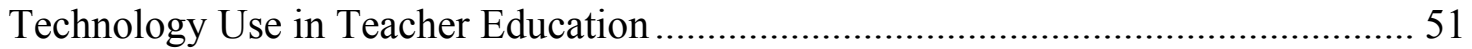

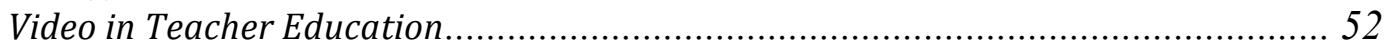

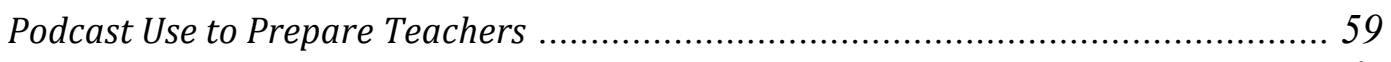

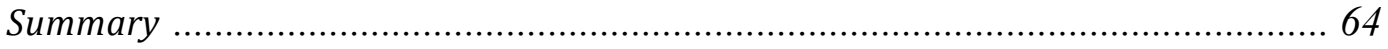

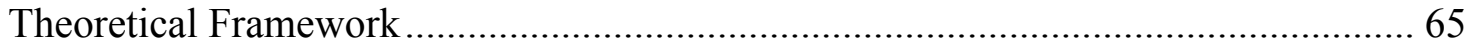

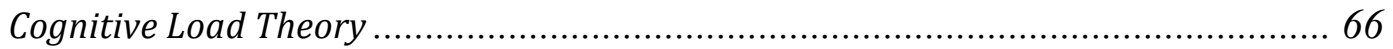

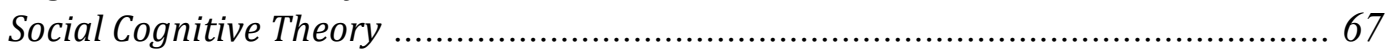

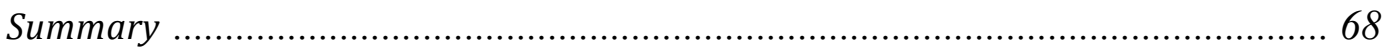

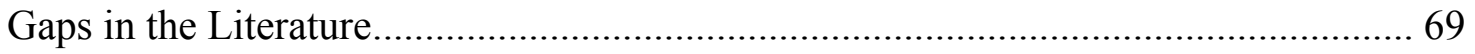

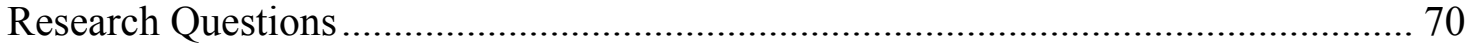

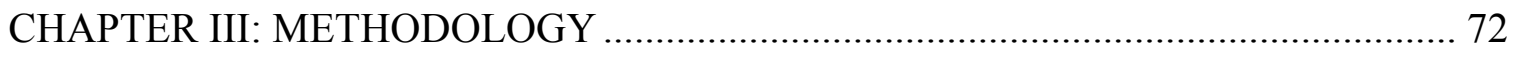

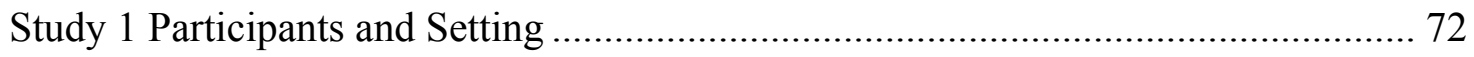

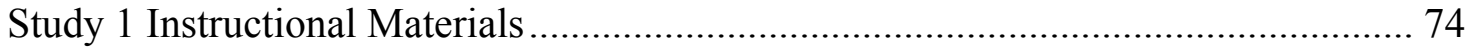




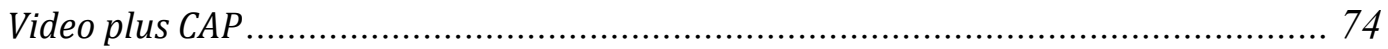

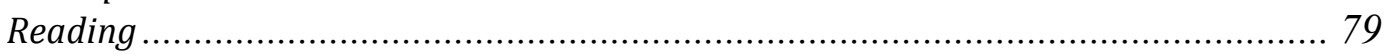

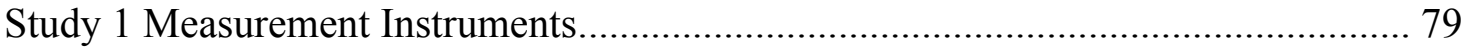

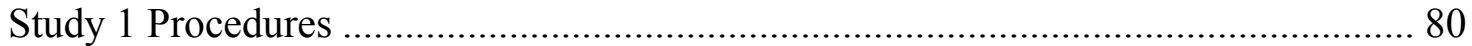

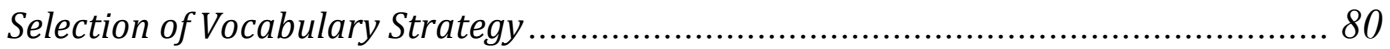

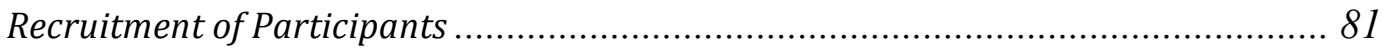

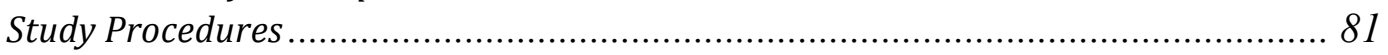

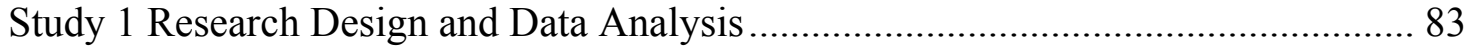

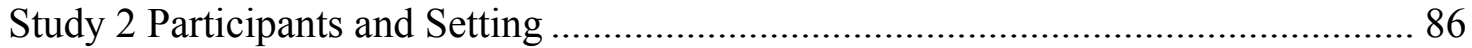

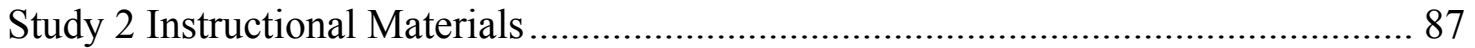

Study 2 Measurement Instruments...................................................................... 87

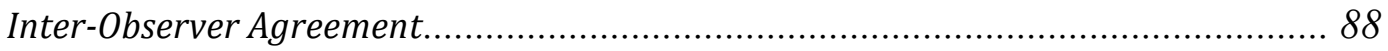

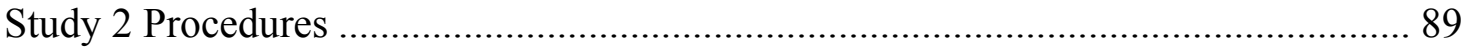

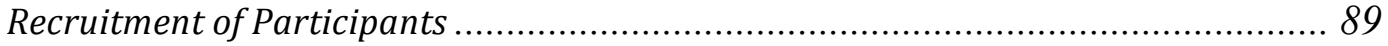

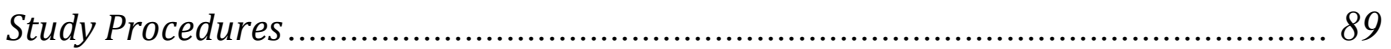

Study 2 Research Design and Data Analysis ....................................................... 91

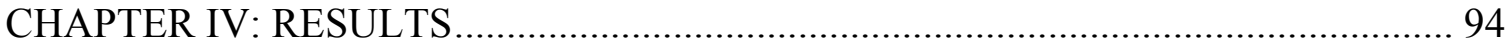

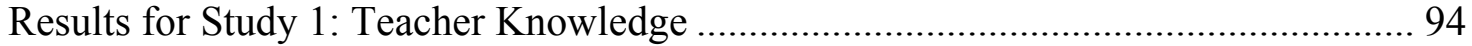

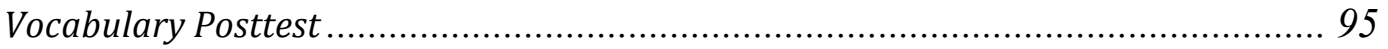

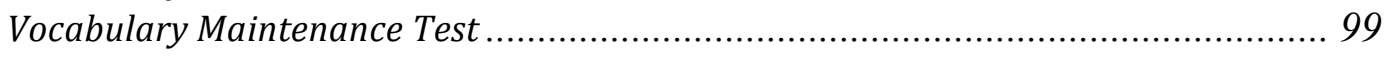

Comfort Teaching Vocabulary ............................................................... 102

Comfort Teaching Intensifying Vocabulary Intervention ................................... 104

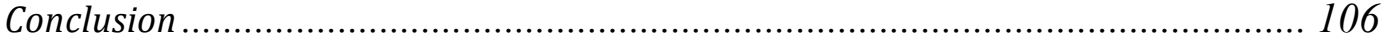

Results for Study 2: Teacher Practice .................................................................... 107

Percent of IVI Practices During Reading ........................................................ 108

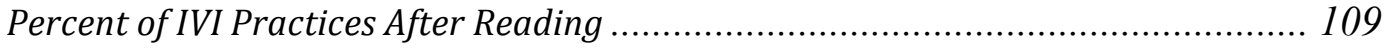

Percent of IVI Practices Total ................................................................... 110

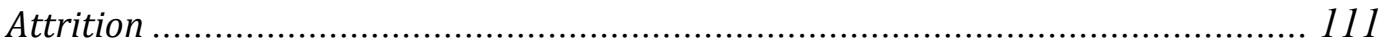

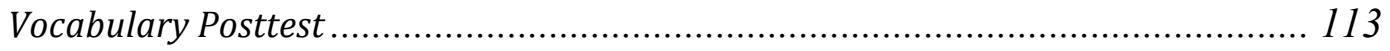

Comfort Teaching Vocabulary ................................................................ 113

Correlation Between Knowledge and Practice …........................................... 113

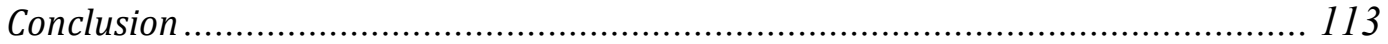

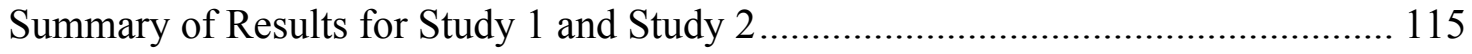

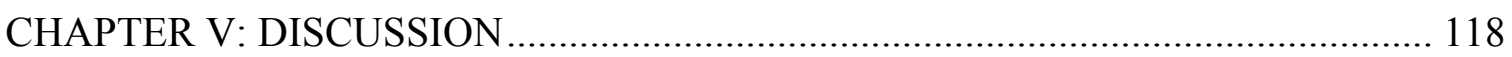

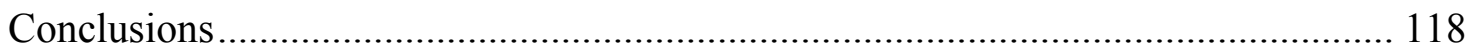

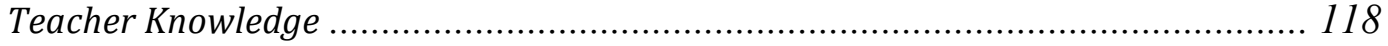

Comfort Teaching ..................................................................................... 120

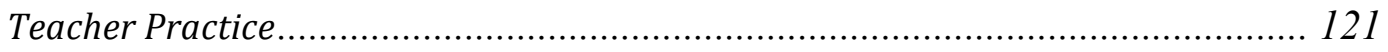


Overall Conclusions on Knowledge and Practice 122

Connections with Theory .......................................................................... 124

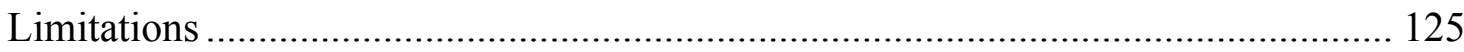

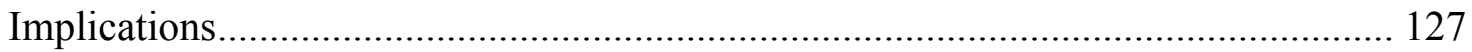

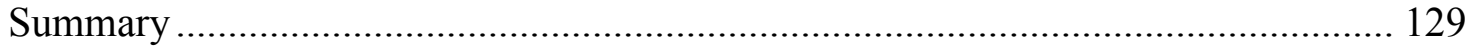

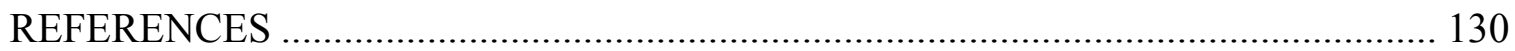

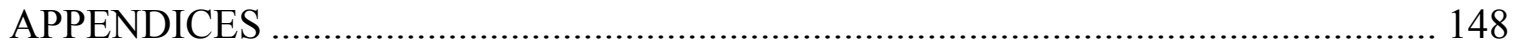

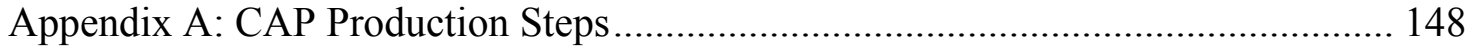

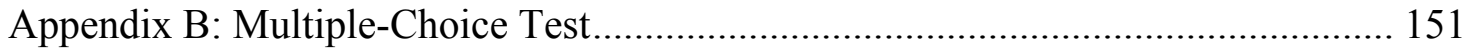

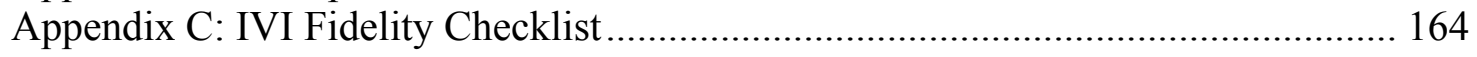

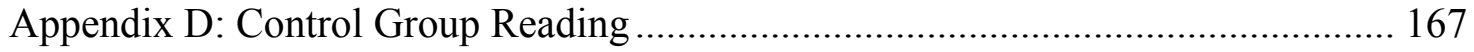

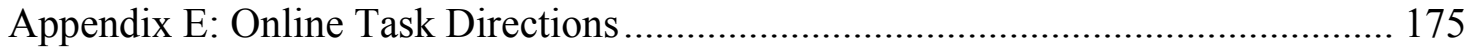

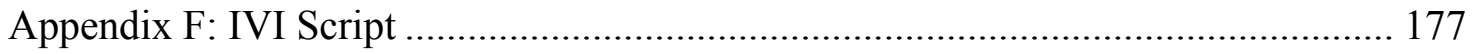




\section{LIST OF TABLES}

TABLE

Page

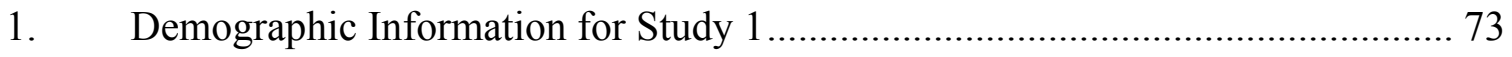

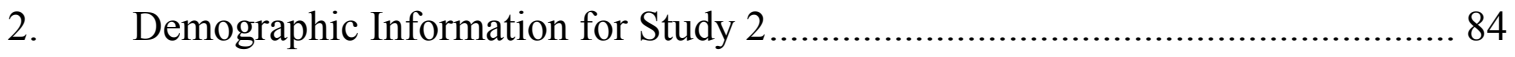

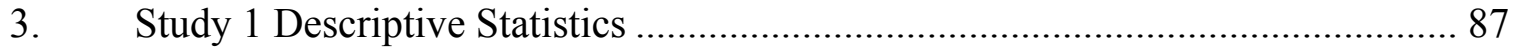

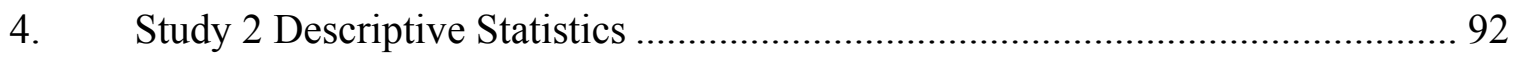

5. Study 1 [Posttest]: Coefficients from the Regression of Posttest on Group ......... 96

6. Study 1 [Maintenance]: Coefficients from the Regression of Maintenance on

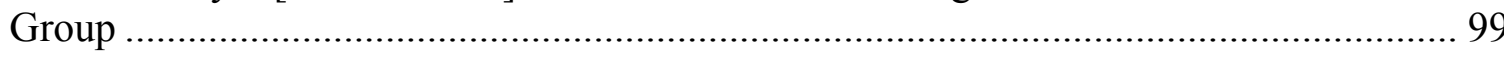

7. Study 1 [Comfort Vocab]: Coefficients from the Regression of Comfort Teaching

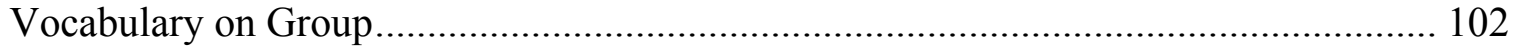

8. Study 1 [Comfort IVI]: Coefficients from the Regression of Comfort Teaching

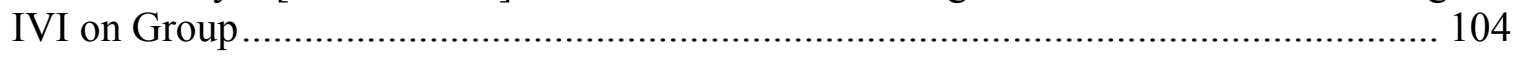

9. Study 1 Unstandardized Regression for the Prediction of Outcome Scores on

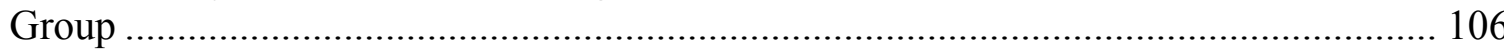

10. Study 2 [All Outcomes]: Coefficients from the Regression of Post Outcomes on

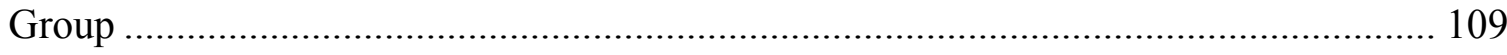

11. Study 2 Attrition Participant Comparisons ................................................ 111

12. Study 2 Comparison of Regression Results with and without Attrition ............. 112

13. Study 2 [All Outcomes]: Simple Regression Analyses and t-statistics ............. 114 xii 


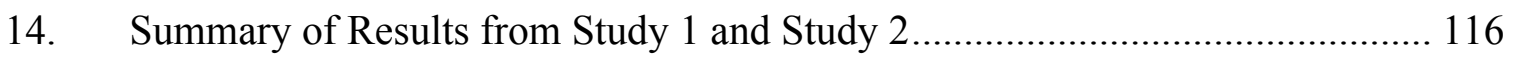




\section{LIST OF FIGURES}

FIGURE

Page

1. Graphic Representation of the Current Experiments .................................... 11

2. Mayer's Design Principles (Adapted from Kennedy et al., 2010)...................... 67

3. Brunvand's (2010) Video Production Strategies .......................................... 75

4. Video Production Steps that Follow Brunvand's (2010) Video Production

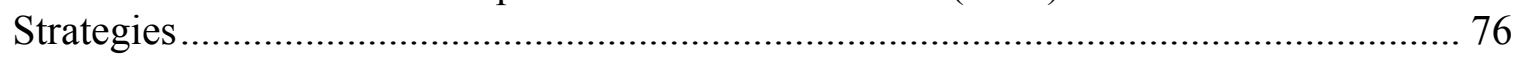

5. CAP Production Steps that Follow Mayer's CTML and Instructional Design

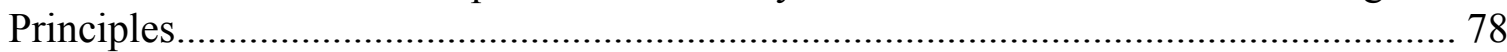




\section{CHAPTER I}

\section{INTRODUCTION}

The National Assessment of Educational Progress (NAEP) provides a view of how well America's students are reading. Results of the 2013 NAEP in reading revealed that $32 \%$ of fourth graders and $22 \%$ of eighth graders are below basic reading proficiency (NCES, 2013). Of fourth grade students with learning disabilities, 69\% scored below basic reading proficiency (NCES, 2013). Students who score below basic are not necessarily nonreaders, but are not able to complete enough tasks to demonstrate basic proficiency, which refers to "partial mastery of prerequisite knowledge and skills that are fundamental for proficient work at each grade" (p. 44). The NAEP measures students' reading comprehension (i.e., the ability to gather meaning from text; NCES, 2013). To convey students' ability to comprehend, NAEP tests word meanings in context to assess vocabulary knowledge.

Vocabulary is a fundamental component of reading that affects ability to comprehend text (Beck, McKeown, \& Lucan, 2002; Biemiller, 2001; Biemiller, 2005; Graves, 2006; Hazenberg \& Hulstijn, 1996; National Reading Panel, 2000; Stahl \& Nagy, 2006; Wagner, Muse, \& Tannenbaum, 2007). Research indicates that the predictive relationship between early vocabulary knowledge and later reading comprehension is robust (Biemiller, 2003; Cunningham \& Stanovich, 1997; Graves, 2006; Nagy, 2005). Many children, especially those from underprivileged backgrounds, begin formal schooling with limited oral language experiences and severe deficits in oral vocabulary 
(Biemiller, 2001; Coyne, Simmons, Kame'enui, \& Stoolmiller, 2004; Hart \& Risley, 1995). These struggles are difficult to remediate and frequently snowball into larger reading deficits (Biemiller, 2001). Educators can prioritize support for these youths by providing high quality vocabulary instruction (Beck \& McKeown, 2007; Graves, 2006). Thus, vocabulary instruction should be a priority within early childhood instruction, and continue throughout K-12 education to help students develop adequate vocabularies needed for reading comprehension and associated tasks (Pullen, Tuckwiller, Konold, Maynard, \& Coyne, 2010; Pullen \& Justice, 2003). However, on average, teachers spend less time explicitly teaching vocabulary compared to other literacy skills such as phonological and phonemic awareness (Maynard, Pullen, \& Coyne, 2010; National Reading Panel, 2000). Furthermore, recent studies show many teachers do not make sufficient use of evidence-based reading practices with students with and without disabilities (Klingner, Urbach, Golos, Brownell, \& Menon, 2010). The poor state of affairs in teaching reading poses the question: Why is effective vocabulary instruction lacking in primary classrooms? To answer this question, we look to research on (a) teacher preparation and (b) teacher views of evidence-based reading practices.

When it comes to preparing teachers to use evidence-based practices with fidelity through teacher education, limited empirical evidence to guide practice exists (Jones, 2009; Wayne, Yoon, Zhu, Cronen, \& Garet, 2008). Teacher preparation programs have a history of limited effectiveness (Darling-Hammond, 2010; Grossman, 2008; Hammerness et al., 2005), especially in preparing teachers to work with students with disabilities (Brownell, Ross, Colon, \& McCallum, 2005; Holdheide \& Clark, 2009). Many new teachers have reported graduating with inadequate training to meet diverse learner needs 
(Levine, 2006). Among several barriers expressed by teachers in implementing certain instructional practices, is inadequate understanding of such practices (Mastropieri \& Scruggs, 1998). Often new teachers can possess a fair amount of knowledge related to reading instruction, but lack engaged knowledge necessary to know how to operationalize such knowledge (Brownell et al., 2009). Engaged knowledge is developed when teacher learners are able to situate knowledge in the task of teaching children (i.e., situate principles of reading acquisition in real-life classroom scenarios; Phelps \& Schilling, 2004). Therefore, teacher educators are charged with the challenging responsibility of fostering situated knowledge and pedagogy for instruction to help teachers translate procedural knowledge into daily instruction (Brownell et al., 2009).

Another reason teachers may not use effective practices supported by research is that translating research into practice is challenging. Scientific studies are difficult to read, and making sense of research on evidence-based practices requires a basic knowledge of research that teachers may not possess (Landrum \& Tankersley, 2004; Snell, 2003). Furthermore, many teachers may not feel the need to turn to research based on their reports that special education research has little value to guide practice. On the other hand, some teachers professed importance of evidence-based practices, but were not observed implementing such practices (Jones, 2009). Moving effective practices out of researchers' laboratories and into teachers' daily repertoires has proven to be an exceedingly difficult mandate to fulfill (Desimone, 2009; Gersten, Vaughn, Deshler, \& Schiller, 1997; Heward, 2003; Jones, 2009; Landrum, Cook, Tankersley, \& Fitzgerald, 2007). Lack of knowledge and devalued views has resulted in teachers not implementing evidence-based practices, as demonstrated by a study (Jones, 2009) of novice special 
educators' views of evidence-based practices. Furthermore, evidence-based practices that are observed in schools are often implemented on a limited basis and without fidelity (Cook \& Schirmer, 2003; Landrum, Cook, Tankersley, \& Fitzgerald, 2007).

Teacher educators are in a position to address this challenge, and ultimately mitigate ill preparedness and help teachers overcome barriers to implementing evidencebased practices with fidelity (Gersten et al., 1997). In fact, significant federal funds and investments are spent on teacher preparation and professional development (Birman et al., 2007) with the understanding that teacher education can improve teaching ability and therefore improve student achievement (Carpenter, Fennema, Peterson, Chiang, \& Loef, 1989; Clewell, Campbell, \& Pearlman, 2004; Kennedy, 1998). To expand the use of evidence-based vocabulary practices and broadly affect student achievement, attention must focus on how teachers are prepared to use practices supported by research (Reschly \& Wood-Garnett, 2009).

Various research implications exist to support teacher development of evidencebased practices, or in other words to help translate research into practice (Gersten, Vaughn, Deshler, \& Schiller, 1997; Klinger, 2004; Wayne et al., 2008). Linking effective teacher education methods with educational research is necessary to foster teacher ability to provide appropriate interventions to students with learning disabilities (Klinger, 2004). Additionally, to encourage use of new practices, teacher educators need to provide (a) specific lesson procedures and concrete examples, (b) interventions that have significant effects on student performance, and (c) feedback and opportunities to discuss newly attempted practices (Gersten et al., 1997). 
These promising suggestions for teacher education are accompanied by barriers and unanswered questions that can impede teacher learning, and therefore deserve continued research (Klinger, 2004). Further research is needed to determine whether programs will be effective if adopted in a range of settings and ways, and what specific features matter (e.g., how much of a teacher preparation method is "enough" to produce effective teaching; Wayne, Yoon, Zhu, Cronen, \& Garet, 2008). Other necessary investigations are related to (a) the scope required for teacher change or adaptation of practice, (b) intensity levels of training required, (c) specificity of training, and (d) best ways to communicate research findings of interventions to teachers so that they find the practice essential, manageable, and rewarding (Gersten et al., 1997). Reviews in the field of special education teacher preparation (e.g., Leko et al., 2012; Sindelar et al., 2010) and general education teacher education (e.g., Grossman, 2005; Wilson et al., 2002) agree that research identifying effective teacher education methods to promote teacher candidate learning is limited. Teacher training will have limited effectiveness if they consist of methods that do not have solid empirical backing (Yoon, Duncan, Lee, \& Shapley, 2008).

Our field therefore needs continued programs of research that specify innovative methods to improve teacher use of evidence-based vocabulary practices in early years of schooling especially related to vocabulary instruction, considering the limited knowledge of successful teacher education practices (Beck \& McKeown, 2007; Biemiller \& Slonim, 2001; Gersten, Vaughn, Deshler, \& Schiller, 1997; Grossman, 2005; Klinger, 2004; Leko et al., 2012; Sindelar et al., 2010; Wayne et al., 2008; Wilson et al., 2002) and the need for early vocabulary acquisition in schools (Pullen et al., 2010). Designing teacher 
education methods that address, teach, and encourage long-term implementation of effective vocabulary practices, all while meeting cognitive demands of teacher learners, is complex.

Teacher education approaches should be created based on theories that support learning (Wayne et al., 2008). In addition to designing instruction according to theoretical principles, designers of instruction must also give careful thought to specific content to be delivered. It is most appropriate for teacher education efforts to incorporate practices that have shown prior evidence of efficacy (Saxe, Gearhart, \& Nassir, 2001). Emerging developments in the use of multimedia instruction to support cognition and delivery of effective instruction to future teachers is a solid starting point for this critical line of work (Kennedy \& Deshler, 2010).

Guidelines exist to design effective multimedia approaches (Mayer, 2009) that are based on cognitive learning theories. Researchers of cognitive processing provide guidelines for designing effective multimedia instructional approaches (Mayer, 2009) that are based on learning theories. Mayer's Cognitive Theory of Multimedia Learning (CTML) dictates that meaningful learning occurs when students are able to: (a) pay attention to relevant portions of words and graphics (i.e., limit cognitive load), (b) organize relevant words and graphics into cognitive structures in working memory, and (c) connect spoken and graphic representations with each other and relevant knowledge from long-term memory (Mayer \& Johnson, 2008). Mayer's CTML follows the (a) cognitive load theory (Chandler \& Sweller, 1991), which posits that cognitive processing is limited and can easily be overwhelmed by too much stimuli, as well as the (b) dual processing theory, which holds that human stimuli is retrieved through both visual and 
audio channels (DeLeuuw \& Mayer, 2008). These theories are incorporated in Mayer's roadmap for the design of multimedia instruction, which includes validated design steps that limit extraneous cognitive load and promote active cognitive processing (DeLeeuw \& Mayer, 2008). Multimedia instruction, created following theories of learning, is a promising approach for improving teacher use of evidence-based vocabulary practices (e.g., Borko, Jacobs, Eiteljorg, \& Pittman, 2008; Dieker et al., 2009; Friel \& Carboni, 2002; Santagata, 2009; Sherin \& Han, 2004).

In the present study, I created and implemented a multimedia-based tool consisting of a modeling video and Content Acquisition Podcast (i.e., video plus CAP) to teach an evidence-based vocabulary intervention to preservice teachers. I evaluated the effects of the tool on preservice teacher knowledge and teaching ability. The vocabulary practices embedded in the video plus CAP are referred to as Intensifying Vocabulary Intervention (IVI; Pullen et al., 2010). IVI is a scripted approach with components to directly teach word meanings within the context of a story to elementary students, including those at-risk for or with learning disabilities, and English Language Learners (Loftus, Coyne, McCoach, Zipoli, \& Pullen, 2010; Maynard, Pullen, \& Coyne, 2010; Pullen et al., 2010). Research supports shared storybook reading as an effective way to teach word meanings in context (Arnold, Lonigan, Whitehurst, \& Epstein, 1994; Coyne et al., 2004; Hargrave \& Senechal, 2000; Justice, Meier, \& Walpole, 2005; Pullen \& Justice, 2003; Wasik \& Bond, 2001; Whitehurst et al., 1994). In addition, vocabulary instruction is most effective when several instructional methods are used (Baumann, Kame'enui, \& Ash, 2003; Bryant et al., 2003; Ebbers \& Denton, 2008; Jitendra et al., 2004). After teaching words through storybook reading, IVI prompts teachers to use 
several after-reading activities to reinforce word meanings in varied, rich ways (Beck et al., 2002). IVI was chosen for this research because it includes direct explicit instruction of word meanings through context, as well as various strategy instruction methods.

The video plus CAP tool consists of a 30-minute two-part video. The first element of the video is a Content Acquisition Podcast (CAP; Kennedy, Driver, Pullen, Ely, \& Cole, 2013). CAPs are a form of enhanced podcasts in which still images are combined with on-screen text and audio (Kennedy, Hart, \& Kellems, 2011), and are generated in accordance with Mayer's CTML and accompanying design features. The CAP pre-teaches procedural steps and instructional practices within IVI, and sets the stage for what the viewer will see in the video clip. The second part of the video shows a teacher modeling IVI to struggling students. The video contains on-screen cues to help the viewer recognize when the teacher is using various parts of the intervention. Researchers have supported videos to model educational practices (Dieker et al., 2009; Dymond \& Bentz, 2006; Friel \& Carboni, 2000; Kent \& Simpson, 2010), as well as CAPs, to support learning of undergraduate students (Kennedy et al., 2011; Kennedy, Newton, Haines, Walthier-Thomas, \& Kellems, 2012; Kennedy \& Thomas, 2012; Kennedy et al., 2012); the current study attempts to expand this line of research.

The purpose of this experimental research is to explore use of multimedia instruction (i.e., video plus CAP) that adheres to theoretical design principles for learning to teach preservice teachers to use an evidence-based vocabulary intervention with struggling elementary students. To determine the efficacy of video plus CAP as a teacher preparation tool, I tested two forms of instruction that both teach IVI: (a) video plus CAP, and (b) a practitioner friendly reading (i.e., reading). In addition to addressing the need 
to determine effective ways to communicate and teach use of an evidence-based vocabulary intervention, the current study adds to the limited but growing evidence-base for the use of multimedia instruction in teacher education. 


\section{CHAPTER II}

\section{LITERATURE REVIEW}

It is important to critically examine the building blocks of various aspects that lead to the preparation of qualified and effective teachers of reading, and in particular vocabulary. This chapter is divided into four major sections. The purpose of the first major section is to provide an overview of the state of teacher preparation of reading instruction, the lack of preparedness that must be addressed, and existing suggestions to improve teacher preparation. This section provides support for the aim of this dissertation research to improve teacher education methods. There is a need to better prepare teachers of all components reading-related, but there remains an especially critical obligation to instill effective vocabulary practices in future teachers considering the dearth of classroom focus and research on this component. The second section addresses evidence-based vocabulary instruction. Specifically, this section addresses the importance of vocabulary instruction followed by a review of suggested vocabulary practices for all students, including those with exceptionalities. Empirical support for the specific vocabulary intervention (i.e., IVI) chosen for the current research is shared. In an attempt to prepare teachers to use effective vocabulary methods, we paired an evidence-based vocabulary practice (i.e., IVI) with a promising approach to teacher education: multimedia instruction. The purpose of the third major section is to provide an understanding of how multimedia has been used in teacher education. Use of video and podcasting have been supported with research to be effective instructional tools. 
Multimedia tools hold promise for learning to occur because of they can be created in adherence to cognitive learning processes. The last major section provides an understanding of the theoretical frameworks that were followed to create the video plus CAP tool. The chapter concludes with the need and promise for this research, as well as a statement of purpose and corresponding research questions. Figure 1 visually represents how the four major sections fit together to guide the current experiments.

Figure 1. Graphic representation of the current experiments
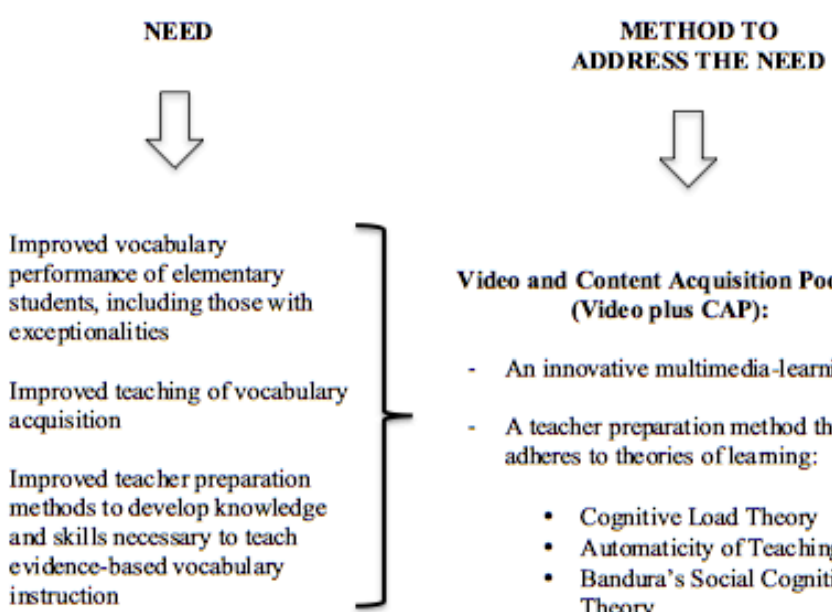

Video and Content Acquisition Podeast (Video plus CAP):

- An innovative multimedia-learning tool

- A teacher preparation method that adheres to theories of leaming:

- Cognitive Load Theory

- Automaticity of Teaching

- Bandura's Social Cognitive Theory

- Mayer's Cognitive Theory of Multimedia Learning

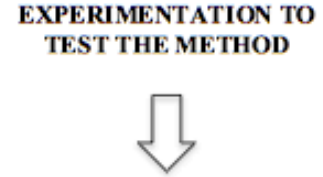

Research Question:

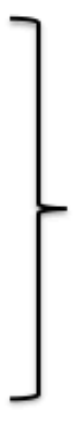

To what extent can video plus CAP on evidence-based vocabulary practices improve preservice teacher knowledge (study 1) and teaching ability (study 2)

Random Assignment:

- Experimental group: Watch video plus CAP

- Control group: Read informational packet

Design:

Study 1: Pretest-posttest-maintenance Study 2: Post-test/observation only

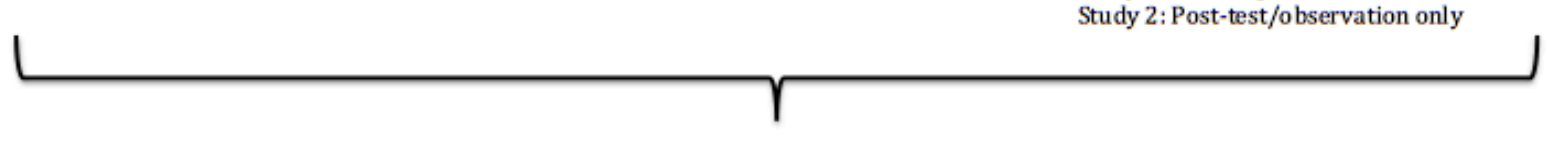

Project Aim:

To improve preservice teacher knowledge about effective vocabulary instruction as well as ability to effectively use evidence-based vocabulary practices with students with learning disabilities

\section{Teacher Preparation of Reading Instruction}

Reports on effective reading instruction have emphasized the importance of teachers' knowledge of reading (McCardle \& Chabra, 2004; National Reading Panel, 2000). After all, "teachers cannot teach well what they do not understand themselves" 
(Moats, 2009a, p. 387). The National Reading Panel (2000) found that most children benefit from systematic instruction in phonemic awareness, phonics, fluency, vocabulary, and comprehension, and difficulties in such areas can manifest into reading disabilities (Lyon, 1997). However, many reading education course syllabi do not reflect expectations that preservice teachers gain knowledge in the above-mentioned reading components (National Council on Teacher Quality, 2006; Steiner \& Rozen, 2004). The average preservice teacher is required to take only two courses in reading (Lyon, 1997). Most future teachers receive "little formal instruction in reading development and disorders during their undergraduate studies" (Lyon \& Weiser, 2009, p. 476). Coltheart and Prior (2007) noted from a report of the National Inquiry Into the Teaching of Literacy, established in Australia, that several preservice and in-service teachers were not equipped with linguistic knowledge necessary to foster literacy skills of children.

Therefore, many teacher education programs may not be providing pertinent information required to teach reading (Leko \& Brownell, 2011; Walsh, Glaser, \& Wilcox, 2006) and/or preservice teachers may not be learning what teacher educators are attempting to teach (Kosnik \& Beck, 2008). Possibly due to teacher education shortcomings, preservice and inservice teachers often feel ill equipped to meet instructional needs of children with language and literacy deficits (Moats, 2009b), and levels of reading content knowledge are found to be very low (Bos, Mather, Dickson, Podhajski, \& Chard, 2001; Cunningham, Perry, Stanovich, \& Stanovich, 2004; Moats, 1994; Spear-Swerling \& Cheesman, 2012).

\section{Lack of Knowledge to Teach Reading}


Several studies reveal that preservice and inservice teachers lack sufficient knowledge of reading instruction. The following section presents studies that portray the state of general and special education teacher knowledge related to reading.

General education in-service teacher knowledge studies. Moats (1994) administered a survey (i.e., Informal Survey of Linguistic Knowledge) to 52 graduate students enrolled in a Language and Literacy Foundations course to assess knowledge of spoken and written language structures necessary to teach reading. The graduate students were licensed and practicing teachers with varying years of experience. Results indicate that teachers possessed inadequate understanding of language concepts as well as spelling rules and conventions. Conclusions include a call for better instruction for all teachers in the foundations to teach reading.

Following Moats' seminal article, Bos, Mather, Dickson, Podhajski, and Chard (2001) gave questionnaires to 252 preservice teachers and 286 in-service teachers regarding perceptions and knowledge of early reading instruction. Data were collected through two measures: The Teacher Perceptions About Early Reading and Spelling measure, which was modeled after an instrument developed by DeFord (1985) and a 20multiple-choice assessment of teacher knowledge called Structure of Language, which was adapted from different sources (e.g., Moats, 1994; Rath, 1994). Participants reported a high need to teach certain reading skills, and the need to be competent to teach these skills; however, most teachers demonstrated little knowledge of children's literature, phonemic awareness, and phonics. Limitations exist that may affect the study's conclusions: The results are based on self-reports; no field-based observations exist to back up teacher statements. Additionally, collecting data in a face-to-face setting may 
have caused social desirability bias (i.e., tendency of participants to answer questions in a way that they feel will be viewed favorably by researchers) that could have resulted in agreeable ratings. Despite limitations, this study confirms Moats' (1994) finding: Many teachers have inadequate knowledge of beginning reading knowledge that limit their ability to teach struggling readers.

A survey study by Cunningham, Perry, Stanovich, and Stanovich (2004) assessed 722 kindergarten through third grade teachers' actual and perceived reading instruction knowledge. Researchers found that teacher ability to realistically estimate their strengths and weaknesses of reading instruction was often incorrectly aligned with their knowledge. Teachers lacked knowledge in reading areas (e.g., phonological awareness and phonics) that they rated as having high knowledge. In addition, teachers who perceived themselves as highly effective were more motivated to learn about and use new effective methods, which leads to a reality that teachers who overestimate their knowledge will not necessarily seek new effective practices.

Spear-Swerling and Cheesman (2012) administered a questionnaire and Teacher Knowledge Survey (TKS) to 142 elementary educators interested in measuring knowledge of response-to-intervention (RTI) models in reading. An extensive researcher-created questionnaire elicited background information such as preparation and teaching experience, as well as familiarity with reading assessments and interventions. The TKS models the multiple-choice section of a teacher licensure exam (i.e., the Foundations of Reading Test that many states require for elementary teacher licensure). The TKS included questions about the five components of reading, reading assessments, and RTI. Cronbach's alpha for the TKS as a whole (66 items) was .88. Mean scores of 
correctly answered items on the TKS were low, ranging from 58-65\% correct. The lowest scores were related to reading assessment and RTI practices. Questionnaire results indicated that teachers are unfamiliar with RTI research-based approaches related to reading.

Cunningham, Zibulsky, Stanovich, and Stanovich (2009) examined beliefs, literacy knowledge, and ways in which 121 first grade teachers structure and distribute literacy lessons. Teacher knowledge was found to guide teacher choice of instructional activities. To demonstrate, teachers with high knowledge of phonics tended to spend more time on explicit, systematic phonics practices rather than unstructured literature activities. Reports indicated a mismatch between many teachers' preferred reading strategies and those that are currently supported by research and policy. Fortunately, findings indicate that as teachers learned more about research findings related to instruction, beliefs on instruction shifted. This study did not examine whether changes in beliefs resulted in changed instruction. Cunningham et al. (2009) reinforced the need to effectively communicate recent research findings to teachers.

General education pre-service teacher knowledge studies. Washburn, Joshi, and Binks-Cantrell (2011a) surveyed 185 general education $\mathrm{k}-5^{\text {th }}$ grade teachers from different districts in the Southwest U.S. on basic language concepts, dyslexia, and perceived reading instruction ability. The same research team also examined 91 preservice teachers on the same concepts with identical measures (Washburn, Joshi, \& Binks-Cantrell, 2011b). Findings from the studies are parallel. Self-reports of participants demonstrated some knowledge of certain areas (e.g., implicit skills such as syllable counting), but deficiencies in others (e.g., explicit knowledge of phonics 
instruction). Interestingly, most perceived their ability to teach early reading skills to typically developing readers as moderate, and their ability to teach vocabulary as high. However, items related to vocabulary and morphology posed most challenging (e.g., only $40 \%$ correctly defined 'morphemic awareness'). Moats (1994) also found that teachers had great challenges with morphology. There was no significant relationship between perceived teaching ability and number of years teaching, however looking at knowledge of morphology specifically, first year teachers had significantly higher scores than teachers with $20+$ years of experience $(p<0.001)$. Participants did not correctly identify core deficits of dyslexia and also reported receiving little training in educating children with dyslexia, indicating that students with dyslexia (which make up one-fifth of the population) may not be receiving appropriate instruction (Hudston et al., 2007).

Special education in-service teacher knowledge studies. Bishop et al. (2010) conducted a mixed-methods study examining novice special education teachers $(N=25)$ who taught reading to elementary students with high incidence disabilities. The purpose was to determine potential factors (e.g., personal attributes, preparation, and school environment) that influence differences in teaching effectiveness. Data was collected through interviews, observations, and surveys. Analyses concluded that all factorsenvironment, teacher attributes, and preparation- contributed to either support or impede quality instruction. The least accomplished teachers seemed to have insufficient preparation, lack of knowledge, and hurdles in the workplace. Regarding preparation, when content was learned through applied experiences, teachers had a higher likelihood of successfully implementing practices. Regarding knowledge, participants reported feeling adequately prepared for the field of special education, but inadequately prepared 
to teach reading. Ultimately, teacher educators have no control over future work environments, but they can and must improve reading preparation.

Spencer, Schuele, Guillot, \& Lee (2008) surveyed 541 educators including reading teachers $(n=100)$, general education kindergarten and first grade teachers $(n=$ 221), special education teachers $(n=60)$, and speech-language pathologists (SLPs; $n=$ 160). Overall, educators had insufficient knowledge to accurately teach phonemic awareness. On a paper-pencil measure adapted from Moats (2000) that assessed phoneme segmentation, identification, and isolation, teachers struggled with phonemes in words and did not understand phoneme-grapheme structures. Specifically, SLPs performed below ceiling, with a mean score of 37.34 of a possible 47 points. Special education teachers, those required to educate students with highest learning needs, performed no better on the survey than reading or general education teachers. Three limitations were mentioned: (a) the data analyzed was collected over six years (20012006) from four states and it is possible data doesn't reflect recent educator knowledge, (b) the instrument was originally designed to assess knowledge changes after professional development, and not to answer the study's questions, and (c) a causal link between teacher phonemic awareness knowledge and practice or student outcomes cannot be supported and deserves future research investigation. Regardless, researchers stressed the need for effective training of educators to teach phonemic awareness.

Klinger, Urbach, Golos, Brownell, and Menon (2010) conducted 124 observations of 41 third through fifth grade special education teachers to determine the extent to which and how they promoted reading comprehension. Most participants were observed providing limited reading comprehension to students. Only 82 lessons addressed 
comprehension, and though these lessons addressed comprehension in some form, $40 \%$ of lessons included only nominal comprehension instruction (e.g., teacher questioning or review of vocabulary). It was also found that several comprehension-related lessons were not based on current research. Although, it is possible comprehension was taught at other times when researchers were not observing. Regardless, teachers were not spending much time teaching comprehension and when they were, many practices were not supported by research.

Special education pre-service teacher knowledge studies. Not only is there a disconnect between what preservice teachers should know and what they are being taught in teacher education programs, there is also a gap between what licensure tests assess and necessary knowledge to teach reading. Stotsky (2009) found that licensure tests for prospective pre K- $8^{\text {th }}$ grade special education teachers inadequately assessed knowledge needed to teach research-based reading practices. The tests included little content on the development of phonemic awareness, phonics, and vocabulary knowledge. Findings imply that preservice teachers must be provided adequate coursework in teacher education programs to teach research-based reading knowledge, as well as gain licensure by tests that measure their reading instruction knowledge adequately.

\section{Reasons for Lack of Knowledge}

It is clear that too many teachers are ill prepared to teach reading, but why, and what can teacher educators do to change this outcome? A few theories have surfaced to explain why: (a) there is simply not enough time in education courses to deliver information to teach the complex skill of reading, and more instructional time is needed (Kosnik \& Beck, 2008), (b) teacher education should be more closely and generatively 
linked with the field of practice, providing more authentic experiences (Cunningham, Perry, Stanovich, \& Stanovich, 2004; Sykes et al., 2010), and (c) teacher educators themselves may lack the knowledge necessary to teach reading instruction (Joshi et al., 2009).

Evidently, courses in teacher education programs are often deficient, which disable preservice teachers to learn the knowledge and skills necessary for effective reading instruction (Walsh, Glaser, Dunne-Wilcox, 2006). Even when courses are well designed with quality content, it is possible that the few hours spent teaching the content is simply not enough time to facilitate future teachers in reaching high levels of mastery (Spear-Swerling, 2009; Spear-Swerling \& Brucker, 2004). Teachers not only need to understand what reading related terms mean (e.g., phonological awareness, phonics, fluency, vocabulary, and comprehension), but also need to know how these components work together to promote reading competence and how to explicitly and systematically teach them (Lyon \& Weiser, 2009). High levels of content and pedagogical knowledge must be combined with engaging, motivating instructional interactions. In addition, teachers need to be able to differentiate instruction and know how to tailor instruction to meet individual needs. Clearly, preservice teachers must learn a profuse amount to teach reading, and often the minimum requirement of two courses (Lyon, 1997) is not enough.

Kosnik and Beck (2008) conducted a large-scale longitudinal qualitative study looking at views and practices of teacher educators $(\mathrm{N}=10)$ as well as graduates of the corresponding program $(\mathrm{N}=22)$ during their first three years of teaching. Along with course syllabi, semi-structured interviews were conducted with instructors of the program. Beginning teacher graduates were interviewed and observed twice each year 
exploring approach to reading instruction, reflections of preservice program, and challenges. Researchers found that "what was taught was not always what was learned" (p. 124). How can teacher educators fully prepare future teachers for the realities of the field? According to novice teachers, preparation could have been improved with clarified terminology (e.g., guided reading), aid in making links between topics, and addressing theory more fully and in a different manner. Since there is more to cover in teacher education than there is time to learn, focus must be on instructional priorities- appropriate and pertinent topics for quality instruction- with ample opportunities for future educators to develop understanding.

Teacher educators themselves may lack the knowledge of literacy skills that should be taught in teacher preparation courses (Joshi et al., 2009). Joshi et al. (2009) assessed 78 instructors of reading education courses on knowledge of language concepts with a 68 -item survey. The survey tested knowledge of phonemes, morphemes, vocabulary, comprehension, and meta-cognition. Instructors demonstrated weaknesses in several areas: closed syllables, open syllables, speech sounds, phonological awareness, phonemic awareness, and morphemes. Joshi et al. (2009) gave a different survey (with 12-items) to 40 instructors at 12 different universities. The survey measured knowledge on reading disability causes, philosophy of reading instruction, and effective practices in the five components of reading instruction (i.e., phonological awareness, phonics, fluency, vocabulary, and comprehension). No instructors mentioned low quality of reading instruction to be a possible reason for reading failure. Only $20 \%$ of instructors correctly defined phonological awareness. Last, a pertinent method for beginning reading instruction (e.g., synthetic phonics) was not mentioned. Ensuring instructors of 
future teachers possess the necessary knowledge of reading instruction is vital to integrate such knowledge into preservice reading courses.

\section{Relationships Between Teacher Knowledge, Teacher Practice, and Student}

\section{Learning}

Teacher knowledge. Teachers acquire initial understanding of reading instruction during preservice education. Although many teachers report feeling illprepared to teach reading, research indicates that what teachers learn prior to starting their career makes a difference in their quality of teaching (Bishop, Brownell, Klinger, Leko, \& Galman, 2010). Furthermore, a qualitative study by Leko and Brownell (2011) found that access to knowledge was a key influence on novice special educators adoption of conceptual and practical reading skills. Related, research indicates that knowledge of inservice teachers can also be improved. Spear-Swerling and Cheesman (2012) found that teachers who experienced-focused professional development were more familiar with research-based reading interventions that were effective in a response-tointervention model compared to teachers who did not take part in professional development. Educators who had higher levels of preparation, not only were more confident about their knowledge of literacy instruction but demonstrated higher knowledge compared to teachers who had lower levels of preparation (Spear-Swerling, Brucker, \& Alfano; 2005). A review of 82 studies on reading teacher preparation suggests that in recent years, teacher preparation programs have been relatively successful in changing teacher knowledge and though limited, some studies document the influence of pedagogical knowledge on teaching practice (Risko et al., 2008). Teacher knowledge of reading pedagogy can and should be improved. 
A study by Brady et al. (2009) enforced the basic notion that teacher understanding of reading instruction can be enhanced with adequate training. An intense form of professional development (i.e., in-class mentoring support, two-day summer institute, and monthly workshops) in the areas of phonological awareness and phonics was provided to 65 first grade teachers. All teachers made significantly large gains by the end of the year on a Teacher Knowledge Survey and according to a Teacher Attitude Survey, most felt the learning experience was valuable.

Teacher knowledge and teacher practice. Several studies further indicate that when teachers acquire knowledge required to teach reading, they are more effective reading teachers (McCutchen, Harry, et al., 2002). Just as students do, teachers learn at varying rates, and often teachers are unaware of what knowledge they have or have not learned (Cunningham et al., 2009). Therefore, constant progress monitoring and formative assessments are necessary along with extended time and mentoring to boost teacher knowledge to achieve high levels of teaching competence (Moats, 2009b). When future teachers respond to effective teacher preparation, a relationship has been seen between high teacher knowledge of reading and student ability to read (McCutchen et al., 2002; McCutchen, Green, Abbott, \& Sanders, 2009; Moats \& Foorman, 2008; Podhajski, Mather, Nathan, \& Sammons, 2009).

Dingle et al. (2011) investigated how three upper elementary special education teachers learned to implement word study and fluency strategies from a professional development model called Literacy Learning Cohorts (LLC). The professional development model, drawn from a conceptual framework of Desimone (2009), included an LLC institute, supportive monthly meetings, access to an online community, coaching, 
and opportunities to reflect on practice. Cross-case analysis of various data sources (e.g., interviews, observation notes, meeting transcripts, and knowledge surveys) indicated that all teachers changed their practices after professional development. Factors that influenced how teachers implemented learned knowledge included participant knowledge of reading instruction, participant motivation to change, and current curriculums used. Though findings support the notion that increasing teacher knowledge results in effective teaching, some limitations must be noted. Teachers exhibited changed practices, but not all were able to effectively implement strategies. Additionally, only a small set of teachers were examined, hindering ability to generalize to larger teacher populations. Relevant to the current experiments that use video to teach preservice teachers, one portion of the professional development included access to videos of teaching strategies. However, there is no mention if teachers actually viewed the videos, how the videos were structured, or what they entailed. Being only one small portion of the training, there is no way of knowing if and how video contributed to findings. This study did not examine student outcomes from changed practice. Last, further research is necessary to determine effects of changed instruction on student learning.

Teacher knowledge, teacher practice, and student learning. McCutchen, Abbott, et al. (2002) conducted an experimental study that examined a two-week training on systematic explicit instruction in phonological and orthographic awareness to 44 kindergarten and first grade teachers. Twenty-four teachers were given the two-week training and after the program were observed three to four times during the year. Student assessments varied per grade, but included a combination of some of the following: the Test of Phonological Awareness (Torgesen \& Bryant, 1994), Metropolitan Reading 
Readiness Test, a timed alphabet writing task (Berninger \& Rutberg, 1992), the GatesMacGinitie Reading Tests (MacGinitie \& MacGinitie, 1989), composition measure, and a spelling subtest from the Wechsler Individual Achievement Test (Wechsler, 1991). All teachers who received training exhibited deeper knowledge and changed behavior in their classrooms to reflect learned knowledge; the trained group exhibited more explicit instruction in aspects of literacy instruction compared to the control group. When teachers used more explicit instruction, students showed greater growth in phonological awareness, orthographic fluency, and word reading, and demonstrated higher results on writing measures. McCutchen et al. (2002) concluded that with changed instruction, student achievement can increase.

Spear-Swerling and Brucker (2006) studied the relationship between novice teacher knowledge (of word-structures) and learning of second grade students they were tutoring. This quasi-experimental study included a total of 147 novice teachers who were separated into three groups. Teachers in group 1 took a special education language arts course and were supervised while tutoring. Group 2 took the same course but did not have supervised tutoring, and group 3 served as the comparison consisting of teachers enrolled in a different course covering unrelated content. Group 1 and 2 improved teacher knowledge, and although not statistically significant, Group 1 who had supervised tutoring, outperformed Group 2. All children who were tutored showed significant progress from teachers in Groups 1 and 2. Though limitations exist (e.g., no random assignment to groups, an absence of tutored students in the comparison Group 3, narrow set of teacher knowledge measures, and low reliability on some student 
measures), overall findings propose that increased teacher knowledge can translate to student progress with reading.

Podhajski, Mather, Nathan, and Sammons (2009) researched the effects of professional development in scientific based reading instruction on teacher knowledge and student outcomes. Four first and second grade teachers were in the experimental group and received a 35 hour course with 10 mentorship visits as well as continuing education credits and $\$ 100$ worth of instructional materials. Three control teachers were given a \$25 gift card for participating. As demonstrated on The Survey of Teacher Knowledge, the experimental group had much higher understanding than the control group after professional development. Students in both groups were assessed with the Dynamic Indicators of Basic Early Literacy Skills (DIBELS), Texas Primary Reading Inventory (TPRI), and Test of Word Reading Efficiency (TOWRE). First grade students who were taught by experimental teachers had higher growth than control teachers' students on fluency, phonemic segmentation, nonsense word fluency, and oral reading. Second grade experimental group students exceeded control students in the area of phoneme segmentation. Though this study had limitations, including small sample size, results support that improved teacher knowledge can contribute to student progress.

McCutchen, Harry, et al. (2002) were interested in primary teacher knowledge of literature and phonology, philosophies of reading instruction, classroom practice, and student learning. Participants included 59 volunteer kindergarten through second grade teachers. Data was collected with assessments of teacher knowledge, questionnaires on teacher beliefs, and classroom observations of reading instruction, as well as tests of student knowledge. There were little relationships between philosophy and teacher 
knowledge as well as between philosophy and practice. Relationships were found between knowledge and instruction, and knowledge and student outcomes. Specifically, phonological and phonics knowledge positively affected reading instruction, which also predicted student outcomes of word recognition abilities at the end of kindergarten. However, there were much smaller correlations between teacher knowledge and student outcomes in first and second grade. Lack of relationships may be attributed to the study's limitations of restricted score ranges and low reliability on teacher knowledge assessments as well as reduced number of student test items. Overall, some evidence exists supporting the relationship between teacher knowledge, practice, and student learning.

Moats and Foorman (2003) also found that deepening teacher knowledge of reading instruction can result in changed practice and therefore, improved student learning. Researchers conducted a large-scale longitudinal study exploring teacher knowledge of reading and student achievement. Data was collected with a Teacher Knowledge Survey, standardized teacher observation checklist, as well as third and fourth grade students' scores on the Basic and Broad Reading scales of the WJR-Revised. After four years of the study, a regression analysis was conducted. Teachers who demonstrated higher knowledge also exhibited more effective practices and had students with greater achievement. At a second site, contrasting findings found less statistical significance in predictive relationships of teacher knowledge and student scores. Possible reasons are the restricted range of scores, which resulted in teachers scoring close to the ceiling at the second site; these teachers had different and more direct coursework that could have affected their scores. 
Al Otaiba and Lake (2007) conducted a mixed-methods pre- and posttest exploratory study to examine whether knowledge of undergraduate students enrolled in a special education program $(n=18)$ improved with multiple tutoring sessions and progress monitoring of struggling students, as measured by The Teacher Knowledge Assessment: Structure of Language (Mather, Bos, \& Babur, 2001). In addition, researchers looked at changes in student reading scores on fluency subtests of the Dynamic Inidcators of Early Literacy Skills (DIBELS) as well as subtests of the Woodcock Reading Mastery TestRevised (WRMT-R; Woodcock, 1998). Across a few classes, undergraduates were taught a specific evidence-based intervention (Tutor-Assisted Intensive Learning Strategies, or TAILS) that incorporated direct instruction in all five components of reading. Additionally, they were taught how to administer student assessments. By the end of the semester, participants described feeling better prepared to teach reading and demonstrated increased knowledge about the structure of language (effect size $=2.58$ ). Though student scores improved with alphabetic principle knowledge, most did not show significant improvement on WRMT-R. Specifically, students' comprehension did not significantly improve and actually fell below national norms. Several limitations may affect interpretations from this study. There was no control group of undergraduates or students, and with the small sample size, researchers did not test correlations between undergraduate knowledge and student outcomes. The fidelity with which all undergraduates provided tutoring instruction was not systematically documented and therefore this study does not reveal whether improved knowledge resulted in improved teaching. Al Otaiba and Lake (2007) suggest future research look at teaching fidelity of reading practices- supporting the need for the current study. 
Contradictions. Compared to the above-mentioned studies, a few researchers found mixed results that on the relationships between increased teacher knowledge, practice, and student achievement. Bos, Mather, Narr, and Babur (1999) used a professional development model consisting of an interactive course and collaboration with schools for one year. This model was called Reading Instructional Methods of Efficacy, or Project RIME, and was designed to support 11 elementary and special education teachers implement more explicit instruction for students with reading struggles. Teacher knowledge and attitude increased positively, but for the most part, their actual instructional approaches remained unchanged. In this case, simply changing teacher knowledge was not enough to alter instruction.

Kelcey (2011) investigated the relationship of reading knowledge and student reading ability. Knowledge assessments of teachers with analogous backgrounds and school settings were compared. Results showed reading knowledge to be significantly related to student achievement of some concepts (e.g., reading comprehension), but not others (e.g., word analysis). Despite mixed findings, Kelcey (2011) concludes that it is essential to develop specialized knowledge needed to teach reading.

Carlisle, Correnti, Phelps, and Zeng (2009) looked at the contribution of teacher knowledge of early reading on student improvement on tests of word analysis and reading comprehension. Teachers in grades one through three from 112 elementary schools filled out a questionnaire (i.e., Teacher's Quest) on reading knowledge and students completed two subtests on the Iowa Tests of Basic Skills (ITBS). Teacher reading knowledge did not account for differences in student achievement. A potential reason for this finding could be the context of schools that have chronic difficulty 
improving reading achievement (i.e., Reading First schools). Another explanation is the measure of teacher knowledge might not actually capture the knowledge that teachers use in their reading instruction. Actual teacher practice is a missing and important piece to this puzzle that could potentially explain student improvement.

Carlisle, Kelcey, Rowan, and Phelps (2011) developed and examined a survey (TKRRP) to measure teacher knowledge of reading instruction and the use of content knowledge to make instructional decisions. First through third grade teachers working in Reading First schools volunteered to complete the survey $(\mathrm{N}=1,101)$. Researchers analyzed the effect of teachers' reading knowledge on students' reading achievement. Results did not support a strong relationship between teachers' performance of knowledge on first through third graders' achievement. Limitations to the study may be attributed to the surprisingly small effects of teacher knowledge on student reading outcomes. Specifically, the unreliability in the measurement of teacher knowledge may have caused substantial underestimates of such effects. Carlisle et al. (2011) concluded that the study did not produce conclusive answers to their research questions and that results should not be taken to imply that teacher knowledge is unrelated to reading instruction and student outcomes.

Brownell et al. (2009) explored the role that teacher knowledge (about decoding and comprehension) and teacher practice have on special education teacher quality. Relationships between teacher knowledge, practice, and student achievement were examined. Participants included 34 novice special educators from nine districts in three states and their $3^{\text {rd }}$ through $5^{\text {th }}$ grade students $(\mathrm{N}=165)$ who had reading deficits or learning disabilities. Data was collected through observations of reading instruction, 
measures of teacher knowledge on the Content Knowledge for Teaching Reading Survey (Phelps \& Schilling, 2004), measures of student reading ability on the Woodcock Johnson Reading Mastery Test-Revised (WRMT-R; Woodcock, 1998), Oral Reading Fluency Test, and the Gray Oral Reading Test-Fourth Edition (GORT; Weiderholt \& Bryant, 2001). Results found that beginning special educator knowledge of reading instruction was average and that they struggled more with pedagogical reading practices. Knowledge did not contribute significantly to variance of classroom practice.

Hierarchical linear modeling (HLM) analysis revealed novice special educators rely more on classroom management and general practices rather than reading practices to influence student achievement. In fact, classroom management influenced student outcomes more than any other practice. Why didn't reading instruction knowledge significantly contribute to student gains in reading? Possible reasons for inability to establish relationships were described. First, novice special educators may rely more on general knowledge and classroom management than on any domain-specific pedagogy. Second, despite limited reading knowledge, many participating special educators used prescribed curriculums, a possible reason for successful instruction. Third, the measures of knowledge used in this study were originally created for general education teachers and may not sufficiently assess knowledge that special educators use when teaching reading. Last, the sample size may be insufficient to find significance of relationships. Findings enforce differences between general and special educators regarding preparation and knowledge they enter the field with. There is concern with how future special educators are prepared. Researchers hypothesize that novice special educators may not have had sufficient opportunities to deepen their knowledge of reading instruction, because even 
though they had a fair amount of reading instruction knowledge, they did not know how to translate knowledge into practice. Those who were able to translate knowledge into practice likely were provided with opportunities in teacher preparation to practice this. Brownell et al. (2009) support the current study's purpose by advocating for continued research to discover and create improved preparation of special educators to ensure they enter the field with knowledge and skills to be highly qualified teachers.

Summary. Reasons for findings of weak relationships between teacher knowledge and student learning could be due to inadequate research methodologies (Moats, 2009a), study limitations or insufficient professional development or training models. The argument that teacher knowledge is not always necessary to teach students to read, sides with the notion that some students require less instruction to learn. Though true in some cases, these arguments lose power when considering the plentiful studies that show explicit teaching results in improved outcomes for struggling students and those with disabilities (Moats, 2009a) as well as the previously mentioned studies (Al Otaiba \& Lake, 2007; McCutchen, Abbott, et al., 2002; McCutchen, Harry, et al., 2002; Moats \& Foorman, 2003; Podhajski, Mather, Nathan, \& Sammons, 2009; Spear-Swerling \& Brucker, 2006) that did find relationships between teacher knowledge and student outcomes.

Another reason for small relationships between teacher knowledge and student learning could be teachers who possess high knowledge do not necessarily apply such knowledge during practice; it cannot be stated that knowledge has a direct linear relationship with teacher practice (Moats, 2009a), but enough studies concur that teacher knowledge can be a vital component to increase student learning. Brownell et al. (2009) 
suggests that rather than simply possessing knowledge of reading instruction, teachers need to develop engaged knowledge. Specifically, teachers need opportunities to situate their knowledge of reading in the task of teaching. There is a need for research to discover effective teacher education models to instill engaged knowledge and skills that will translate into effective practice and therefore, improved student outcomes.

\section{The Current State of Reading Teacher Education}

Important implications emerged from studies mentioned and additional reviews of literature (Moats, 2009a). First, in general teachers are not prepared to teach reading. Teacher knowledge of early reading development is often underdeveloped, negatively affecting ability to teach basic literacy skills. Second, teacher preparation must be improved to enhance teacher knowledge and skills to teach reading because quality of instruction can result in student reading achievement. Furthermore, many future and practicing teachers need more practice teaching than most teacher education courses

provide in order to reach reading instruction mastery (Moats, 2009a). Preservice teachers must be given opportunities to apply what they learn and practice reading strategies in authentic ways.

Ways to improve teacher preparation. Much more needs to be done to ensure teacher preparation programs provide future teachers with the essential knowledge and skills to teach reading. Unless courses reflect research-based evidence from scientific research on reading, future teachers will continue to receive inadequate information about reading instruction (Lyon \& Weiser, 2009). Preservice teachers should be taught specific, evidence-based strategies beginning in teacher education courses and continuing through professional development. In addition, empirical findings (Darling-Hammond \& 
Bransford, 2005; Kosnik \& Beck, 2008) recommend that teacher educators transparently emphasize priorities, or put another way, disseminate the knowledge that is essential for beginning teachers. In addition to being selective about curriculum, teacher educators should carefully consider effectiveness of their pedagogical practices, since some methods confuse students and are highly ineffective (Kosnik \& Beck, 2008). A comprehensive review of research on reading teacher preparation (Risko et al., 2008) revealed that most effective teacher preparation provided explicit explanations and examples, demonstrations of practices, and opportunities for guided practice of teaching strategies in practical settings with students. Teacher education approaches must continue to improve if we are to address and mend our nations reading failure. The current study follows guidelines by Risko et al. (2008) by showing a video of a teacher modeling an effective practice and providing an opportunity for preservice teachers to attempt the strategy with elementary students.

Sykes, Bird, and Kennedy (2010) analyzed occupational competency of teaching (i.e., the availability of teaching knowledge and skills as well as existing adequate instructional practices) and based on the analysis, presented dilemmas and suggested directions for the field of teacher education. Innovative technology is acknowledged to play a progressively important role in teacher education. There must be standards of evidence from empirical studies that verify innovations to result in successful effects. Such evidence of technology in teacher education "has been absent for the most part," creating a gap and need for research (p. 474).

There are several endorsed suggestions for effective teacher education methods. Teacher educators are charged with not only choosing effective instructional methods, 
but also purposely and wisely determining critical content to disseminate. As vocabulary instruction has proved scarce in early elementary classrooms (Baker, Simmons, \& Kameenui, 1995), but is absolutely necessary for understanding reading, instructors of courses on reading education must ensure effective delivery of evidence-based vocabulary practices. The next section reveals the need for vocabulary instruction and empirical suggestions that exist to guide vocabulary instruction.

\section{Vocabulary Instruction}

Vocabulary development is not only crucial for reading, but pervades all subjects from science to physical education. The prevalent achievement gap in so many schools, especially poverty-stricken schools, is exacerbated by vast differences in children's vocabulary knowledge (Hart \& Risley, 1995). Vocabulary development is recognized as fundamental to comprehending text (Bos \& Anders, 1990) and as a necessary component in early reading curriculums, yet has not received nearly as much instructional attention as other literacy skills (such as early word recognition skills and phonics; Baker, Simmons, \& Kameenui, 1995). Teachers have been found to not spend much time on vocabulary (NRP, 2000)- possibly because they are ill-prepared due to lack of vocabulary instruction prioritization in teacher preparation. Much empirical work on reading pedagogy has focused on certain components of reading instruction, specifically, phonemic awareness and decoding (Maynard, Pullen, and Coyne, 2010), whereas less research exists to guide instruction in other areas such as vocabulary and comprehension. The current study is committed to increasing vocabulary growth of all learners by attempting to better prepare teachers to teach vocabulary. 
Typically developing students may be able to acquire vocabulary indirectly, through reading or conversations with adults (Hirsch, 2003). Many who struggle with reading will not necessarily acquire vocabulary indirectly and need direct, explicit instruction of word meanings (Penno, Wilkinson, \& Moore, 2002). Multiple direct instructional methods lead to increased word knowledge of both typically developing children and those with deficits much more than with incidental learning (Baker, Simmons, \& Kameenui, 1995). Students who have reading deficits tend to struggle immensely with vocabulary acquisition for several discernable reasons. First, children with reading disabilities do not engage in wide reading due to the difficulty they experience while reading; therefore they have fewer opportunities to learn words from reading (Graves \& Silverman, 2010). Second, limited engagement with storybooks also results in lack of practice with independent word-learning strategies, an important skill to learn vocabulary (Graves \& Silverman, 2010). In addition, children with reading disabilities often have "difficulty processing, retaining, and transferring information they have learned about words" (Graves \& Silverman, 2010, p. 324). Consequently, it is no surprise that children with disabilities tend to have limited vocabulary knowledge compared to typically developing peers and therefore are in need of prevention and remediation. Abundant instruction time with explicit instruction and opportunities for practice is necessary for vocabulary acquisition of students with disabilities (Bryant, Goodwin, Bryant, \& Higgins, 2003).

This section of the review draws on recent research of effective vocabulary instruction for elementary students with disabilities, as well as a review of research on a specific practice that was chosen for the video used in the current study. Components of 
the specific practice, Intensifying Vocabulary Intervention (IVI), are supported by recent research. Due to emerging research support, IVI can be a sought-after method by teachers to incorporate.

\section{Key Reviews of Research on Vocabulary Instruction for Students with Learning Disabilities}

It is established that vocabulary instruction is time well spent, but how to best use that time is not as certain (Ebbers et al., 2008). One quality review of the literature has been found in the area of vocabulary instruction to include interventions with elementary students with learning disabilities. The review by Jitendra, Edwards, Sacks, and Jacobson (2004) is a sound starting point to discuss existing knowledge in the field. Another review exists by Bryant and her colleagues (2003), which has important implications for older students in middle school.

Jitendra, Edwards, Sacks, and Jacobson (2004) review. Jitendra et al. (2004) reviewed nineteen studies of vocabulary interventions involving elementary, middle, and high school students with disabilities. All studies are published experimental, quasiexperimental, or single-subject designs. Studies are categorized into six intervention categories: (a) keyword or mnemonic strategies, (b) cognitive strategies, (c) direct instruction (DI), (d) activity-based method, (e) constant time delay (CTD), and (f) computer-assisted instruction (CAI). Keyword or mnemonic approaches investigated in five studies stressed the importance of "explicit phonetic and imagery links promoting definition recall of the target vocabulary word" (p. 312; mean ES =1.93). Ten studies examining cognitive strategy instruction involved use of semantic maps and semantic feature analysis to categorize vocabulary words (mean ES $=1.10)$. Three studies on 
direct instruction indicated that vocabulary performance improved with increased direct instruction on word meanings ( $\mathrm{ES}=9.78$ ). One study (Scruggs, Mastropieri, Bakken, and Brigham, 1993) found the activity-based approach to increase word knowledge of middle school students $(E S=0.45)$. Another study (e.g., Schuster, Stevens, and Doak, 1990) supported use of the constant time delay (CTD) approach. CTD occurs when the instructor gives a word and definition, then prompts the student for the definition and corrects him/her until the student can accurately state the definition. Results of six studies investigating computer-aided instruction $(\mathrm{CAI})$ had mixed effects $(\mathrm{ES}=.016, \mathrm{n}=$ 2), although four investigations had positive effects. Large effect sizes were found for most of the investigations with the exception of activity-based method and CAI. Though this review shows positive effects are associated with various vocabulary approaches, the review is also limited by nature; few studies were available to bolster effectiveness of interventions described. Conclusions from the review includes: (a) instructional methods must directly teach vocabulary, (b) selection of approach differs depending on instructional goals, (c) more research is needed in the emerging area of computer-aided instruction, and (d) continued investigation of vocabulary practices that are effective for students with disabilities is paramount.

Bryant, Goodwin, Bryant, and Higgins (2003) review. Bryant et al. (2003) reviewed six studies (Bos \& Anders, 1990; Condus, Marshall, \& Miller, 1986; Johnson, Gersten, \& Carnine, 1987; Mastropieri, Scruggs, \& Fulk, 1990; Mastropieri, Scruggs, Levin, Gaffney, \& McLoone, 1985; Stump et al., 1992) on vocabulary interventions for middle school students with learning disabilities. Intervention research variables of included studies were word selection procedures, materials, instructional design and 
procedures, duration of intervention, mastery criterion, measures of vocabulary learning, maintenance, and generalization to reading comprehension. Categories of interventions included computer-assisted instruction (CAI), fluency-building vocabulary practices, mnemonic strategy, and concept enhancement. Across all studies, students showed gains with relatively short instruction duration; vocabulary instruction does not need to take up large amounts of class time. Student learning may be optimized when multiple interventions are used (Mastropieri et al., 1990). Generalization effects were better from interventions that required deep processing of word meanings (i.e., mnemonics and concept enhancement; Bos \& Anders, 1990). Limitations suggest caution of results: (a) only six articles met selection criteria, denoting that research on effective vocabulary interventions for students with disabilities is limited, and (b) only half of the studies involved teacher implementation of interventions, and most that did involve teacher implementation had fidelity issues with implementation (Jitendra \& Xin, 1997). Overall, the studies reveal several interventions that can improve vocabulary for students with learning disabilities.

\section{Vocabulary Interventions in General Education}

Biemiller and Boote (2006) report two studies of primary vocabulary instruction embedded in storybook reading with general education kindergarten, first grade, and second grade teachers. Study 1, with a pretest-posttest design, examined effects of pretesting, reading books two or four times, and word explanations on word acquisition.

Participants included 43 kindergarten, 37 first-grade, and 32 second-grade students (about half were English Language Learners) and their teachers ( $n=6)$. A 40-item test of general vocabulary knowledge, an abbreviated version of Test B (Biemiller \& Slonim, 
2001) highly correlated with the Peabody Picture Vocabulary Test (Biemiller, 2005), matched cohorts of students. Similar items were created to assess learning of target words from storybooks. Repeated reading resulted in $12 \%$ gains of word meanings and adding word explanations added $10 \%$ gain. Kindergarten students benefited the most from four readings whereas first and second grade didn't have significant benefits with four compared to two readings. Pretesting did not have effects on word acquisition for any grade. Study 2 took place one year later (2003) with the same teachers and testing procedures, and looked at modifications to instruction (e.g., presenting words in new context sentences not taken from instructional storybook texts) to increase word learning, retention of word meanings, and transfer of vocabulary to new contexts. Participating students included 28 kindergarteners, 37 first-graders, and 42 second-graders. A simple pretest-posttest=delayed posttest design was used. A no-intervention group was included to compare vocabulary gains without storybook reading. Using repeated storybook readings with explanations of several words and reviews of words resulted in substantial vocabulary learning. This study showed that more words could be learned with added reviews during instruction and when more word meanings are taught each week. Word meanings were retained four weeks later and students were able to transfer vocabulary knowledge to contexts different than instruction. No limitations were reported though some exist such as no randomization and participants from one school, limiting generalizability of findings.

Beck and McKoewn (2007) conducted two studies involving rich vocabulary instruction to kindergarten and first-grade students. Study 1 had a between-subjects, quasi-experimental pretest and posttest design to examine student learning of words 
taught $(n=52)$ with Text Talk, a researched project based on read-alouds (Beck \& McKeown, 2001; McKeown \& Beck, 2003) compared to students who did not have instruction of words $(n=46)$. All participating children had relatively similar knowledge of vocabulary words prior to the experiment, with mean scores on the PPVT of 29.78 for experimental group and 34.36 for comparison group. Researcher-created pretests and posttests were developed to examine learning of 22 words and modeled the PPVT format of selecting from four pictures the one that showed a word. The experimental groups scored significantly higher on posttest than the comparison group (kindergarten: $F(1,45)$ $=15.93, \mathrm{p}=.000$, and first-grade: $\mathrm{F}(1,51)=7.25, \mathrm{p}=.010)$, suggesting that words of mature language users can be taught to young children. Study 2, which consisted of a within-subject, quasi-experimental, pretest and posttest design, was interested in learning the extent to which different amounts of instruction ( 3 or 6 days) affected learning of words. The same form of instruction, Text Talk read-alouds, was used for study 2 with 36 kindergarten students and 40 first-grade students. Researcher-created pretests and posttests had a similar format to study 1 . Students who had more rich instruction significantly outperformed students who had less (kindergarten: $F(1,35)=69.47, p$ $<.001$, and first-grade: $\mathrm{F}(1,39)=64.10, \mathrm{p}<.001)$, indicating that with more instruction vocabulary gains can be about twice as large. Though positive results are shown, this study did not compare Text Talk instruction to a different type of instruction and really just looked at instruction compared to none, and the types of measures used also cause limitations.

Coyne, McCoach, Loftus, Zipoli, and Kapp (2009) did compare two methods of direct instruction of word meanings to kindergarten students $(n=42)$ within storybook 
reading to a control group consisting of incidental exposure to words. This study was a follow-up of a related previous study examining the same times of instruction (Coyne, McCoach, \& Kapp, 2007) that found extended instruction to result in greater word learning than embedded and incidental exposure on expressive and receptive measures. The 2009 study used an experimental design with two within-subjects factors (type of direct instruction- extended and embedded) and time (posttest and delayed posttest). The direct methods varied in instruction time and depth. General vocabulary knowledge was assessed with the PPVT and knowledge of nine taught words was assessed with researchdeveloped measures. There were significant differences among the three conditions. Scores were higher for words taught with extended instruction, followed by embedded, and last incidental exposure $(\mathrm{p}<.001)$. Results support other findings that direct instruction (Justice et al., 2005; Penno et al., 2002; Walsh \& Blewitt, 2006) and more instruction time and increased exposure to target words produces greater learning (Beck \& McKeown, 2007; Biemiller \& Boote, 2006; Coyne et al., 2007). Limitations included short intervention duration with only three taught words and lack of long-term effect investigation.

Silverman and Crandell (2010) conducted a correlational study looking at the relationships between different teacher $(n=16)$ vocabulary instruction practices and student ( $n=244$ prekindergarten and kindergarten children) vocabulary learning during storybook reading and non-read-aloud time. Researchers presented findings from two studies (Silverman, 2007a, 2007b) on vocabulary practices (e.g., semantic analysis of words, word study, acting out and illustrating words). Teachers were observed three times throughout the course of the school year during their language arts block. Research 
Assistants (RAs) were trained to take field notes on explicit teaching of word meanings, various practices used to teach the words (e.g., Act/Illustrate, Analyze, Contextualize, Define, and Word Study), and frequency of practices used; reliability of observers was .82. Student vocabulary knowledge was assessed at the beginning and end of the year with the PPVT-III as well as a researcher-designed Target Vocabulary Assessment (TVA) modeled on the PPVT to assess knowledge of target words. Students scored higher on both measures from pretest to posttest. Overall, vocabulary instruction during both read-alouds and non-read-alouds was positively related to student learning. The most used practice was Contextualize, followed by Define. Acting out/Illustrating words was positively related to vocabulary growth of students with low initial knowledge, but not for students with high initial knowledge. Analyze was used least and showed no effects. Use of applying words in new contexts (Contextualize) was related to higher posttest scores of all children, but had greater effects with those who had high initial knowledge. Defining words explicitly during non-read-aloud times had a greater effect on children with initial high knowledge than those with initial low knowledge. Word Study of target words was positively correlated during both read-aloud and non-readaloud times with all students. Differences in outcomes depending on initial vocabulary knowledge suggest that children with different levels of vocabulary acquisition respond differently to instruction and more research is necessary to learn optimal ways to teach children at varying levels. The study is limited by nature because it is correlational and in addition investigated a small number of teachers with few observations. Observation notes and coding of RAs could have overlooked important practices. Furthermore, the TVA measure may not have adequately captured vocabulary learning, as the effects were 
small. Researchers conclude that certain practices are related to improved vocabulary learning, but that we need more information about what practices are best to support children with lower vocabulary knowledge.

\section{Vocabulary Interventions in Special Education}

Coyne and colleagues conducted an earlier study in 2004 to examine effects of explicit instruction within shared storybook reading with kindergarten students at-risk for reading disabilities. Data was collected from two groups: the experimental group who received storybook intervention $(n=34)$ and the control group who received a sounds and letters module of the commercial program Open Court (Adams et al., 2000). Students were individually assessed pre- and post intervention with a 20 -item researchercreated measure as well as with the PPVT. Students who received the storybook intervention made greater growth on taught words than the control group $(t(61)=2.07, \mathrm{p}$ $=.04)$. In fact, the storybook intervention was more efficacious for students with smaller vocabularies compared to the control group. Researchers concluded that the study adds to literature on how to teach vocabulary explicitly, but that empirical evidence to guide instruction still lacks.

Justice, Meier, and Walpole (2005) examined the learning of new vocabulary words with 57 at-risk kindergarten students who were in low socioeconomic schools experiencing difficulty with vocabulary and literacy. In addition to looking at storybook reading, the study investigated the effects of word elaboration and responses to treatment of children with low versus high vocabulary. The experimental pretest-posttest study randomly assigned students to treatment $(n=29)$ and comparison group $(n=28)$. The treatment group had 20 small group sessions of storybook reading in which they were 
exposed to 60 new words; half were randomly assigned to the word elaboration condition and the other half to non-elaborated. Pre and posttest measures were administered individually and consisted of an informal criterion-referenced test of 60 vocabulary word definitions. The treatment group (77\%) made significantly higher gains in elaborated words than the comparison group $\left(21 \% ; X^{2}(1, \mathrm{~N}=57)=12.97, \mathrm{p}<.001\right)$. With nonelaborated words, no influence of storybook reading was shown. Students with lowest vocabulary made greatest gains on elaborated words. Justice et al. recommend using a mix of vocabulary methods, having opportunities to foster deep processing, and spending more time on a vocabulary word with multiple exposures to that word, when working with at-risk children. A few limitations include (a) teachers were restricted to using certain behaviors (for procedural fidelity purposes) that may not generalize to a more naturalistic setting, (b) it is unclear which part of the word elaboration procedure contributed most to vocabulary growth (hearing the definition, hearing the word in context, or hearing the word several times), and (c) the assessment may have underestimated word learning by not assessing early stages of word knowledge.

Wasik, Bond, and Hindman, (2006) conducted an experimental design study to determine whether an intensive language and literacy intervention (altered from materials used by Wasik and Bond in 2001) resulted in language and vocabulary development of young disadvantaged children in two Head Start programs. Researchers trained teachers to use the intensive intervention and were curious if training resulted in teachers effectively discoursing with children to increase oral language opportunities. Exploratory analyses of links between teacher behavior and student outcomes were conducted. The two Head Start centers were randomly assigned to the intervention (teachers $n=10$; 
students $n=139$ ) and control (teachers $n=6$; students $n=68$ ) group. The intervention teachers were trained in three areas of book reading: (a) asking questions, (b) building vocabulary, and (c) making connections, based on a module of Whitehurst, Arnold, et al. (1994) and Wasik and Bond (2001). Children were individually pretested and post-tested with the PPVT-III (Dunn \& Dunn, 1997) and the EOWPVT-III (Brownell, 2000), as well as an alphabet knowledge test in which they were asked to identify the 26 letters of the alphabet. All teachers were observed reading a book twice- once at the beginning of data collection and again at the end. Additionally, a running record of teachers' talking and questioning strategies was recorded. Intervention teachers were observed twice engaging with students during activities outside of storybook reading. Six observations were conducted after each of the six areas of training (three for language development and three for book reading). Several positive results were noted. First, disadvantaged children can show significant increases in vocabulary learning if they are exposed to appropriate instruction including opportunities to express themselves and converse with trained teachers. Exploratory findings reveal that the way teachers talk to children during storybook reading and outside of reading can affect language acquisition. If teachers provide feedback to children's language, ask descriptive questions, and use active listening strategies, student outcomes may be higher. A finding that is particularly relevant to the current study and aligns with the current study's training intervention is that teachers can be trained to use strategies that have positive results with children's language and literacy development, if the teacher training involves (a) explanations as to why the intervention is beneficial to children, (b) opportunities to see implementation of strategies, and (c) chances to practice strategies with feedback. 


\section{Multiple Approaches}

Several vocabulary interventions have been suggested by recent empirical findings to be effective for students with learning disabilities (Beck \& McKoewn, 2007; Biemiller \& Boote, 2006; Bryant et al., 2003; Coyne et al., 2004; Coyne et al., 2007; Jitendra, Edwards, Sacks, \& Jacobson, 2004; NRP, 2000). A single best method of vocabulary instruction has not been identified (Baker et al., 1995), but rather, using a variety of techniques that involve multiple exposures to unknown word meanings yield best learning results (Beck \& McKeown, 1991). Recent studies suggested the following occur in classrooms to decrease the widening vocabulary gap that exists between typically-developing students and struggling readers: (a) explicitly teach word meanings (Coyne et al., 2004; Coyne et al., 2007), (b) effective rich vocabulary instruction (Coyne et al., 2007), (c) direct instruction of sophisticated words or those of mature language users (Beck \& McKoewn, 2007), and (d) repeated shared storybook readings with explanation of target words as they appear in text (Biemiller \& Boote, 2006). Explicit instruction of vocabulary through shared storybook reading has been heavily suggested by research (e.g., Coyne et al., 2004; Justice et al., 2005; NRP, 2000; Penno et al., 2002; Wasik \& Bond, 2001; Wasik, Bond, \& Hindman, 2006). When including corrective feedback and discussion of target words during repeated readings, students are found to have greater retention of word meanings (Brabham \& Lynch-Brown, 2002).

\section{Intensifying Vocabulary Intervention}

Clearly some research exists indicating effective vocabulary practices that should be occurring in schools, especially with students with reading difficulties. The current study addresses a promising method to encourage and teach use of effective vocabulary 
instruction so that future teachers leave their training equipped to improve vocabulary. Components of IVI have been supported by past research and research examining IVI itself. IVI has been shown to be an effective special education model of vocabulary instruction based on shared storybook reading. Research supports shared storybook reading as an effective vocabulary delivery method (Arnold, Lonigan, Whitehurst, \& Epstein, 1994; Coyne et al., 2004; Hargrave \& Senechal, 2000; Justice, Meier, \& Walpole, 2005; Pullen \& Justice, 2003; Wasik \& Bond, 2001; Whitehurst et al., 1994). The vocabulary found in children's books is richer than those encountered in conversation (Coyne, McCoach, \& Kapp, 2007).

The rich instruction embedded in IVI consists of several components to directly teach word meanings within the context of a story. Following storybook reading, students are provided with extended opportunities to gain a deeper understanding of the target words. IVI implementation during storybook reading has been described in detail by researchers (Maynard, Pullen, \& Coyne, 2010; Pullen, Tuckwiller, Ashworth, Lovelace, \& Cash, 2011): (a) before reading, teacher prompts students to pronounce target words, (b) students are told to listen for each "magic word" and raise their hand when they hear one in the story, (c) words are acknowledged in the story and sentences that contained each word are reread, (d) students are given a simple, student-friendly definition, (e) the teacher rereads the sentence with the definition instead of the target word, and last, (f) students are prompted to again pronounce the word. Following this 10-20 minute storybook reading session, students are engaged in after-reading opportunities to interact with words in other rich and varied ways (Beck et al., 2002). Students are first reintroduced to the target word(s) and reminded how they were used in 
the story. Examples of after-reading activities include, (a) recognizing examples and non-examples of words, (b) answering questions about words, (c) creating sentences with words using pictorial representations of word meanings, and (d) responding to sentences containing more than one target word. Teachers ask open-ended questions to encourage students to use target words in full sentences and to demonstrate understanding of word meanings. Corrective feedback is provided and constant restating of the word and definition are embedded throughout. This second session lasts about 10-15 minutes.

Recent studies (e.g., Loftus, Coyne, McCoach, Zipoli, \& Pullen, 2010; Maynard, Pullen, \& Coyne, 2010; Pullen et al., 2010) have examined effects of different student populations' vocabulary development when teachers use IVI in various ways (whole group and supplemental small-group settings). Findings support use of the practices embedded in IVI, therefore giving the current study ammunition to prioritize this particular evidence-based practice into teacher preparation.

Maynard, Pullen, and Coyne (2010). Maynard, Pullen, and Coyne (2010) compared rich instruction (i.e., lesson components of IVI discussed previously) and basic instruction of vocabulary to incidental exposure through storybook reading to determine the optimal method for whole-group vocabulary learning of first grade students $(n=224)$ from 12 general education classrooms. The experimental study included standardized (PPVT-III; Dunn \& Dunn, 1997) and researcher-made baseline, posttest, and delayed posttest assessments of student vocabulary knowledge. Rich instruction resulted in the most complete level of word knowledge; most students who received rich instruction produced at least partial knowledge of words on all measured variables. Students exposed to both rich and basic instruction significantly outperformed the incidental 
learning group. Researchers determined that an effective intervention for vocabulary learning includes (a) explicit, intense, and scaffolded instruction, (b) multiple opportunities for practice with quality feedback, (c) multiple exposures to words in various contexts, and (d) repeated readings with target words embedded in context. In conclusion, basic instruction may be necessary to introduce new word meanings, but in order to foster a complete word knowledge base in which students can use words expressively and contextually, rich instruction is needed.

Loftus, Coyne, McCoach, Zipoli, and Pullen (2010). Loftus and colleagues (2010) conducted an experimental, within-subjects design study to examine the same vocabulary intervention, but with small groups of kindergarten students at-risk for language and learning disabilities $(\mathrm{n}=43)$. Researchers were interested in learning whether at-risk students with the lowest initial vocabulary knowledge $(n=20)$ learned vocabulary better through classroom instruction and supplemental instruction than classroom instruction alone and whether supplemental vocabulary intervention was enough to accelerate word learning of at-risk children compared to not at-risk peers who responded to classroom instruction. Teachers were observed by researchers to ensure fidelity of instruction twice during classroom instruction and three times during small group instruction. Initial student vocabulary knowledge was measured through the PPVT-III (Dunn \& Dunn, 1997) and four researcher-created measures assessed target word knowledge post treatment. Students who received additional instruction on words than those who solely received classroom instruction performed higher on three of four vocabulary measures. Potential problems with the research-created measure could be a reason for lack of positive effects on the Picture Vocabulary Measure. Overall, 
elementary teachers can support vocabulary learning of at-risk students with direct vocabulary instruction and reinforcement of taught vocabulary with supplemental smallgroup instruction (i.e., Tier 2 instruction).

Pullen, Tuckwiller, Konald, Maynard, \& Coyne (2010). Pullen et al. (2010) conducted a related quasi-experimental posttest-only study that examined the same vocabulary intervention model, but within a context of tiered instruction with first-grade students $(n=224)$, some of which were at risk for reading disability $(n=98)$. To provide a sensitive measure that would detect change from a short-term intervention, a researcherdeveloped measure assessed student acquisition of vocabulary at the receptive, contextual, and expressive levels. Students at-risk for reading disability who received supplemental Tier 2 instruction in addition to Tier 1 achieved significantly higher posttest scores on receptive and contextual levels of word knowledge compared to peers who only received Tier 1 . Therefore, more instructional time is necessary to improve outcomes for students with vocabulary deficits. However, benefits were not maintained four weeks post intervention; perhaps indicating the intervention duration needed to be lengthened to maintain high levels of word knowledge. Regardless, this study mirrors previously mentioned (Loftus et al., 2010) findings that supplemental vocabulary instruction results in significant more vocabulary knowledge of students at-risk for reading disabilities.

\section{Implications}

There is a clear need to encourage and prepare future teachers to use vocabulary practices supported by research to be effective with young children, especially those with or at-risk for reading struggles. I chose Intensifying Vocabulary Intervention (IVI) as the focus intervention for this research based on previous empirical support for IVI, and the 
vocabulary-instruction components embedded in IVI. Considering the need to create teacher preparation methods that generate knowledge and ability to teach vocabulary effectively, I turned to a teacher education method that has ample research support: multimedia instruction. Successful findings from research on multimedia instruction in teacher preparation are discussed in the following section, and yield promise for the video plus CAP tool.

\section{Technology Use in Teacher Education}

Use of innovative technology may help meet the demand for quality teachers who use evidence-based practices in reading instruction with all students, including those with disabilities (Kennedy, Deshler, \& Lloyd, 2013). Researchers are examining how new technologies affect teacher preparation and classroom instruction (Mitchem et al., 2009; Resta \& Carroll, 2011; Robinson \& Kelley, 2007; Spooner, Knight, Lo, \& Wood, 2007). Technology can address the challenge of delivering an in-depth knowledge and skill base in teacher education, by providing a practice-centered training (Gomez, Sherin, Griesdorn, \& Finn, 2008). Developments in educational technology, such as video, podcasting, video-conferencing, use of wikis and blogs, have emerged to be beneficial in preparing educators (O’Brien, Aguinaga, Hines, \& Hartshorne, 2011). By allowing learners to revisit material as often as necessary (Pryor \& Bitter, 2008), technology may supplement the university classroom to foster a necessary in-depth knowledge of teacher practice (Zeichner, 2006) and thereby increase teacher education productivity (Lessen \& Sorensen, 2006). Students in teacher education programs have expressed that the use of multiple technologies in classrooms increased performance, opportunities, and attitudes (Cradler, Freeman, Cradler, \& McNabb, 2002). 
Despite an array of perceived benefits, several technology-based strategies used in higher education have little effectiveness (Clark, 2009; Kirschner et al., 2006; Mayer, 2004; Merrill, 2002, 2006; Sweller et al., 2007). To ensure usefulness of technology and that limited academic time is well spent, teacher educators should utilize multimedia tools that have empirical backing to support learning. Video and podcasting are two multimedia methods supported by researchers to aid teacher preparation.

\section{Video in Teacher Education}

There is emerging, but limited literature on the effectiveness of videos to teach preservice teachers about teaching (Santagata \& Angelici, 2010), and in particular, video to teach evidence-based reading practices is lacking. Widely used for teacher preparation, videos provide instant virtual access to a diverse array of classrooms (Sherin, 2004) that preservice teachers might not otherwise be exposed to due to location constraints (e.g., classrooms in rural or urban areas). Classroom video is suggested as a powerful tool in encouraging preservice teachers to not just learn about the theory and practice of teaching, but to actually develop practices and theories based on evidence (Gomez, Sherin, Griesdorn, \& Finn, 2008).

Video for reflection. Reflection is a long-valued practice in the field of education in order to shape, change, or enhance one's teaching. Videos of teaching can promote and encourage analysis of practice (Gomez, Sherin, Griesdorn, \& Finn, 2008; Santagata, Zannoni, \& Stigler, 2007), whether it is a video of your own teaching or someone else's. To illustrate, an experimental pretest-posttest design study (Santagata \& Angelici, 2010), interested in learning how to effectively teach reflection, investigated the effects of two observation frameworks on 34 preservice teachers' abilities to engage and 
reflect on videos of teaching. Though results were nonsignificant, researchers found that participants who used the Lesson Analysis Framework (i.e., a researched framework characterized by analyzing the effect of teacher decisions on student learning) improved their reflection of lessons. Unless specific lenses (i.e., guidelines) are provided to preservice teachers to guide reflections, use of video for reflection can be unproductive (Santagata et al., 2007; Santagata \& Angelici, 2010).

In a similar study, researchers interviewed four middle school teachers and seven elementary teachers across one year to determine whether video club participation (i.e., watching and discussing video excerpts from each others' classrooms) changed or augmented reflection over time. Although results indicated that video clubs helped develop professional vision and ability to attend to student thinking, several questions about best ways to use video clubs remain (Sherin \& van Es, 2009).

Using a within-subjects design, Rosaen et al. (2008) investigated use of video to aid three interns with reflection compared to memory-based written reflections. Findings indicated that video helped the three novice teachers analyze their practice and focus on their instruction more than when they relied on memory alone. Helpful for analysis, video technology is capable of slowing down what is viewed with its ability to pause and rewind teaching moments.

Friel and Carboni (2000) found that use of a video in a teacher education program facilitated teacher learners to broaden their reflection to consideration of student learning rather than just instruction. Interview and written data from three case studies of three preservice teachers revealed that video may serve as an exemplar of authentic teaching 
situations, and therefore a way for preservice teachers to problem solve, reflect, and feel more prepared for the realities of teaching.

Another research team (Kersting, Givvin, Sotelo, \& Stigler, 2010) was interested in studying whether teacher knowledge, as measured through video reflections, predicted student learning when instructed by that same teacher. A subset of 19 teachers collected pre and posttest data from their students $(\mathrm{N}=317)$ prior and after teaching a mathematics lesson, in addition to 327 teachers completing a classroom video analysis measure, and 223 teachers completing a Mathematics Knowledge for Teaching (MKT) scale that assessed fraction knowledge. Teacher knowledge, as indicated by video analysis, did not have a direct effect on student learning. The conclusion that "teachers might know things in a theoretical context but be unable to activate and apply that knowledge in a real teaching situation" (p. 178), supports the need to conduct this particular study, which examines video modeling as a method to teach inservice teachers to effectively use such lessons in a real classroom setting.

To cultivate knowledge that preservice teachers may actually be able to put into educational practice, what they learn should be situated in practice (Gomez, Sherin, Griesdorn, \& Finn, 2008). Videos can provide a model of teaching, which may help teacher candidates develop an understanding of how to translate knowledge into practice. There is important research on video to foster reflection of practice, yet none of the previously mentioned studies examine use of video to directly teach effective practices.

Video to model instructional practices. Though research on the use of video in teacher education is limited, findings thus far support video use to teach effective practices. For example, Dymond and Bentz (2006) created a digital video library 
consisting of a series of videos demonstrating exemplary practices with students with disabilities to use with elementary education teacher candidates. Deliberate steps were taken to create the videos and after video viewing, participants completed a 12 -item survey to evaluate each videos quality. Participant feedback indicated that videos helped them feel more comfortable about teaching children with disabilities and encouraged discussion regarding instructional issues. This research serves as a solid framework for creating videos to show educational practices; our current study takes this a step further by looking at whether video can actually teach participants how to implement specific instructional strategies.

Dieker et al. (2009) created and field-tested three videos to model effective reading, mathematics, and science lessons to preservice and inservice teachers. The reading instruction video focused on a difficult research-based strategy to implement, Text Talk (Beck \& McKeown, 2001). Preservice teachers $(n=23)$ were asked to write a description of the Text Talk strategy before instruction on the strategy, to evaluate incoming knowledge. After traditional lecture-style instruction on Text Talk, preservice teachers were randomly assigned to one of two groups (video group who watched Text Talk being modeled and no-video group who read about the same lesson). One week later, preservice teachers wrote another description of the strategy and summaries were scored based on inclusion and accuracy of lesson elements. Both groups improved understanding, but the video group demonstrated more detail and a better understanding of essential lesson components than the no-video group. To examine effects of video modeling with inservice teachers, teachers underwent a professional development on evidence-based vocabulary practices and review of the book, Bringing Words to Life 
(Beck et al., 2002). After the PD, more explicit training occurred with PowerPoint presentations and modeling. Following this, lesson plans of 11 elementary teachers were examined using same criteria as in the examination of preservice teacher descriptions. Two kindergarten teachers were observed prior and after viewing the video model of Text Talk. Both teachers included each strategy element, and also implemented more engaging activities. Teachers reported the video helped them to more clearly understand the practice and gave them more confidence in their lesson. Results from this study leave important implications for the current research and for future related research. The relatively small sample size, especially of inservice teachers, may affect the ability to generalize findings. Future research is necessary.

Also interested in video for teacher preparation, Schrader, Leu, and Kinzer (2003) compared traditional instruction, commercially produced instructional video, and casebased video. Though there were no significant differences between treatment conditions on student reports of their understanding of reading instruction, teacher learners reported feeling more confident to use research-based literacy practices when they were able to watch the video after receiving traditional instruction.

Kent and Simpson (2010) investigated the extent to which interactive videoconferencing (IVC) was considered helpful in bridging theory to practice for teacher learners. The study took place over the course of three semesters. During year 1, the spring of 2006, 48 undergraduates participated; during year 2, the fall of 2006, there were 63 participants, and later in year 2, the spring of 2007, there were 102 participants. Teacher candidates received instruction on research-based practices in reading, followed by the use of IVC as they watched modeled lessons of effective practices. Based on 
researcher-created surveys (i.e., Listening/Viewing Guides) of the video process as well as group discussions, interactive videoconferencing was suggested to build confidence and ability to deliver improved reading instruction. Most participants reported feeling that IVC helped increase their knowledge and ability to teach reading $(91 \%$ in year 1 , and $90 \%$ in year 2). Those who did not report IVC to be helpful noted that they saw the same practices in their field experiences and didn't feel they needed additional observations through IVC. About $80-85 \%$ of participants found the listening/viewing guide to be helpful and more than $90 \%$ found debriefing with the classroom teacher to be beneficial. To further support this study's effects of IVC technology, future studies could continue to learn about optimal uses of this instructional tool to prepare teachers.

Mitchem et al. (2009) conducted a mixed-methods study investigating how and what preservice and inservice teachers $(n=251)$ learn from multimedia case-based instruction. Multimedia cases in the Teacher Problem Solving Skills (TPSS) series (Fitzgerald \& Semrau, 1993-1997, 1998-2000) were used in this study, which involve interactive materials embedded with authentic casework activities and electronic support tools to provide information and skill development. Multimedia cases were implemented in 20 different higher education courses at one mid-west university. At the beginning and end of the course, participants created concept maps to show how they conceptualized approaches for students with emotional and behavioral disorders (EBD). A scoring rubric that had been developed from an expert map was used to score concept maps. Interrater reliability was conducted four times with the following agreements between two raters: $86 \%, 81 \%, 87 \%$, and $81 \%$. Qualitative data was also collected in the form of semi-structured interviews and student narratives of growth. Participants who worked 
more extensively with the cases showed greater understanding with how to work with students who had EBD. Researchers concluded that teacher educators could enhance learning with cases like these that reflect authentic practice problems. However, a few limitations exist (e.g., the influences of undergraduate versus graduate students and general education versus special education major, as well as lack of control for variations in instructor effectiveness- some may have been less effective facilitating multimedia case based instruction during the study).

The Cognition and Technology Group at Vanderbilt (1990) University includes researchers (e.g., Glaser, Rieth, Kinzer, Colburn, \& Peter, 1999; Rieth et al., 2003) who, in their pursuits of learning about uses of instructional technology in special education teacher preparation, have found similar results to previously mentioned studies that video can be a powerful tool which could go beyond traditional or text-based instruction. Future researchers should continue to evaluate the effects of video modeling on teacher knowledge, ability to teach, and student learning. In addition, our field needs to learn about optimal ways to create and disseminate videos in teacher education.

Recent research findings on video in teacher preparation show the technological tool to be preferred over traditional teaching methods (Dieker et al., 2009), to boost confidence to teach (Dymond \& Bentz, 2006; Friel \& Carboni, 2000; Kent \& Simpson, 2010), and to improve knowledge of teaching (Dieker et al., 2009). Just one study (Dieker et al., 2009) was found to examine the effect of videos modeling strategies on actual teaching ability. The current study adds to this line of research by not only measuring whether preservice teacher knowledge increases from a video modeling an 
effective reading strategy, but also whether preservice teachers are able to translate acquired knowledge into practice to demonstrate effective teaching.

\section{Podcast Use to Prepare Teachers}

Empirical evidence on podcasts and enhanced podcasts has evolved within recent years (Kennedy, Driver, Pullen, Ely, \& Cole, 2013; Kennedy, Ely et al., 2012; Kennedy, Hart, \& Kellems, 2011; Kennedy, Newton et al., 2012; Kennedy \& Thomas, 2012), though there is still much to learn with regard to use of podcasts to effectively teach new practices to preservice and inservice teachers. Traditional audio-only podcasts are widely used in education (Saeed, Yang, \& Sinnappan, 2009), yet scant empirical evidence exists to support the use of audio-only podcasts to promote measurable learning outcomes during higher education or PD activities (Heilesen, 2010). CAPs differ from traditional audio-only podcasts in that they promote understanding of various topics because they are created in alignment with valid principles of multimedia learning theory (Mayer's CTML, 2009) to maximize retention of information. To date, there are five studies that support the use of CAPs to improve teacher candidates' knowledge of content needed to teach students with exceptionalities (Kennedy et al., 2011; Kennedy et al., 2013; Kennedy, Ely et al., 2012; Kennedy, Newton et al., 2012; Kennedy \& Thomas, 2012).

Kennedy, Hart, and Kellems (2011) created Content Acquisition Podcasts following Mayer's CTML to deliver content to 79 undergraduate teacher education candidates. In this experimental, quantitative, two-group posttest design, participants were randomly assigned to one of two groups to interact with either audio podcasts or enhanced podcasts (CAPs) across two experiments. Two podcasts were created to teach

(a) No Child Left Behind (NCLB) and (b) Traumatic Brain Injury (TBI). Prior to 
viewing each podcast, a pretest was given to all students, which consisted of one question apiece. After the pretest, students were exposed to their version of the podcast on the same content. After intervention occurred, students took an untimed posttest that was created following procedures of Mayer and Johnson (2008) to test students' recall of content. Each test had an open-ended recall item (same as pretest) and open-ended transfer items that were scored depending on points per question. Regarding data from the NCLB experiment, the enhanced podcast (CAP) group significantly outperformed the audio-only group on the test of recall $(\mathrm{p}<.01)$ and though the enhanced (CAP) group also outperformed the audio-only group on the transfer items, differences were not significant $(\mathrm{p}=.15)$. There was a large effect for learning about NCLB (i.e., Cohen's $d=$ .82). TBI experiment results were similar: The enhanced podcast (CAP) students scored significantly higher than the audio-only group on both recall measures $(\mathrm{p}<.01)$ and transfer items $(\mathrm{p}<.01)$, with a moderate effect for learning about TBI (i.e., Cohen's $d=$ .64). A few limitations are worth noting: (a) participants were selected out of convenience and came from one institution, (b) there was no true control group, and (c) the measures were brief and created by the researchers; it is possible the items measured unintended constructs. The study provided reason for future research on CAPs with varied content and more diverse participants to further reveal effects of the tool in teacher preparation. Regardless, this study supports the use of CAPs, enhanced podcasts, when designed with Mayer's CTML and accompanying design features to enhance recall of information.

Kennedy and Thomas (2012) conducted a follow-up experimental two group pretest-posttest-maintenance study evaluating the extent to which preservice teachers 
could learn information related to schoolwide positive behavioral interventions and supports (SW-PBIS) through content acquisition podcasts (CAPs) versus traditional reading and note taking methods. Participants included 164 teacher candidates in general education programs from two universities in the midwest. The pretest of SW-PBIS knowledge contained 16 multiple-choice items based on information in the Lewis et al. (2006) chapter that was used with the comparison, text-only group. The CAP group had individual computers and headphones to listen to the CAP once without taking notes. The text-only group was given a graphic organizer, outline of the chapter, and a chapter on SW-PBIS (Lewis et al., 2006), with encouragement to take notes and reread as much as they wanted. Maintenance probes occurred at different times for both universities (i.e., two weeks after experiment and 16 weeks after experiment). The CAP group scored significantly higher on the posttest than the text-only group, with a large effect (i.e., Cohen's $d$ ) preferring CAP viewing at posttest (.98) and maintenance (.97). Limitations included (a) researcher-created measures that may never be perfectly reliable or valid, (b) participants were a convenient sample, (c) though there was a comparison group, there was no control group, and (d) only one topic was tested.

Kennedy, Ely et al. (2012) looked further at the use of CAPs in teacher education to promote increased preservice teacher knowledge of characteristics of students with learning disabilities (LD) and high-functioning autism (HFA). Additionally, Kennedy et al. looked at the use of CAPs paired with textbook reading of the same content to determine if CAPs are more effective with supplemental materials compared with students who only read (and have access to a graphic organizer and chapter outline). Participants included 168 undergraduates enrolled in introductory special education 
courses from two universities; 37 students came from the midwest university and 138 came from the eastern university. The experimental, three-group pretest-posttest design involved identical procedures for two studies, on LD and HFA. Participants were randomly assigned to one of three conditions in which students either (a) watched a CAP before chapter reading (Pre-CAP), (b) watched a CAP after chapter reading (Re-CAP), and (c) only read the textbook chapter with access to a graphic organizer and outline (Text-Only). Experts in the field created the multiple-choice instruments for both experiments, which consisted of 25 items (LD) and 20 items (HFA). Results were similar for both experiments. Students in the Pre-CAP and Re-CAP groups significantly outperformed students in the Text-Only group. The effect size (i.e., Cohen's d) for the Pre-CAP group compared to the Text-Only group was large for the LD experiment (1.24) and moderate for HFA (.63). Comparing the Re-CAP group with the Text-Only group showed a large effect size for both experiments $(\mathrm{LD}=.94$, and HFA $=.94)$. There were no significant differences on posttest between the two CAP groups (Pre-CAP and ReCAP). Therefore, students can gain knowledge of LD and HFA regardless of when CAPs are viewed when coupled with chapter reading, and learn much more watching CAPs than those who read a textbook chapter with organizer and outline.

Kennedy, Newton et al. (2012) continued CAP research by studying multimedia instruction of CAPs and case studies with feedback, to promote teacher candidate learning of evidence-based practices for students with learning disabilities. The research design of this study was different than previous studies, being a design research methodology to continuously test and shape CAPs and case studies during a semester. Participants included the first three authors of the study, who were instructors for a 
course on exceptional children in the general education class, and 11 enrolled students. Data came from teacher candidate reflections, semi-structured interviews, and performance on a final case project. The final case assignment required students describe how they would modify teaching to accommodate students with evidence-based practices and principles of universal design for learning. Data analysis revealed that most students reported satisfaction with the CAP intervention and case studies. This study mirrors previous experimental studies (Kennedy, Ely et al., 2012; Kennedy \& Thomas, 2012; Kennedy et al., 2011) with recommendation to use CAPs in teacher preparation. Most final case assignments revealed strong knowledge gained from case studies. Providing feedback to students also seemed beneficial according to interview and case reports. The study had a small number of participants over a brief time period, yet researchers confidently recommend effective uses of CAPs, case studies, and feedback in teacher preparation based on their findings.

Kennedy et al. (2013) conducted a recent study examining a CAP designed to teach about phonological awareness (PA) as well as present instructional methods to develop PA. Researchers employed an experimental two-group pretest-posttestmaintenance design study and randomly assigned 148 undergraduates (preservice teachers and other voluntary undergraduates) to watch a CAP or read a practitioner friendly article on PA. A 26-item survey of reading constructs measured participant knowledge; the survey included knowledge-based items as well as performance-based items. Specifically, survey items were pulled from the Survey of Language Constructs Related to Literacy Acquisition (Joshi et al., 2009) and the Teacher Knowledge Survey Form \#1-3 (Moats \& Foorman, 2003). Results from an omnibus ANOVA and 
Bonferonni correction revealed significant treatment effects (i.e., cohen's d). To illustrate, there were significant group differences on the posttest (.86) and maintenance probe two weeks later (.97). Following intervention, the CAP group $\left(\mathrm{M}_{\text {Post }}=26.27\right.$; $\left.\mathrm{M}_{\text {Main }}=25.94\right)$ scored significantly higher than the group who read the text $\left(\mathrm{M}_{\text {Post }}=\right.$ 22.65; $\left.\mathrm{M}_{\text {Main }}=21.56\right)$. CAPs serve as an effective method, with attention to theory, to help undergraduates improve their knowledge of PA. Researchers suggest further research to evaluate the affect of CAPs on learner motivation and actual teacher practice.

\section{Summary}

Implications and limitations of the studies mentioned above were similar for each and leave room for further research on CAPs. Measures were relatively brief and researcher-created, causing possibility that unintended constructs were measured. Only six topics have been tested (e.g., SW-PBIS, NCLB, TBI, LD, HFA, and PA) and research that uses CAPs to teach other topics may have varying results. Additionally, it would be beneficial to test CAPs with diverse participant groups. Continued investigation from researchers who did not create CAPs themselves may reveal generalizability and important implications. No studies to date examine a combination of CAPs paired with video to teach future teachers.

Considering the limited literature on the use of videos and CAPs as tools to promote use of evidence-based practices with fidelity (Dieker et al., 2009), much more research is needed on the efficacy of enhanced videos to guide and change teacher practice; a review of the literature revealed no existing studies that empirically explore the impact of videos paired with CAPs on teacher use of evidence-based practices in reading. The current research study is intended to provide preliminary support for the use 
of enhanced videos, which model evidence-based practices and are paired with CAPs to discuss the practices, as an intervention to encourage and teach evidence-based practices to current teachers. Due to the positive outcomes from studies that used videos and CAPs, we hypothesized that the combination of these technologies would be an effective tool in teaching evidence-based practices.

Empirical findings show technology to be a beneficial tool in some cases and less effective in producing teacher learning in others. Many popular multimedia programs appear to be counterproductive, perhaps when they include entertainment elements that hinder learning by distracting and mentally overloading students with irrelevant information (Clark, 2009b; Mayer, 2004). Teacher educators often use multimedia approaches on the basis that they are available and easy to use (Kennedy et al., 2013). However, many multimedia tools have not undergone experimental testing to confirm their function in helping teachers and students learn (Clark, 2009; Clark \& Estes, 2008). Critics of technology tools encourage the use of multimedia that is shaped by solid theory (Clark, 2009).

\section{Theoretical Framework}

In order to create multimedia tools that effectively deliver information on teacher practice and thereby improve teacher practice, such tools must be carefully designed to address cognitive learning needs of viewers. The video plus CAP method examined in the current study was developed based on theories of learning. Specifically, both parts of the tool- the CAP and video- are grounded in the cognitive load theory (Sweller, 1988). The decision to include a video-modeling piece is based on Bandura's (1977) social behavioral theory. 


\section{Cognitive Load Theory}

Approaches to teacher education often do not consider cognitive load and automaticity of effective pedagogical skills (Feldon, 2007). Cognitive load refers to the mental effort from non-automatic (i.e., conscious) processing in working memory that is necessary to solve a problem (Salomon, 1984). It is important for teacher educators (and others who design instruction) to understand cognitive load theory because it offers a clear path to recognizing the limitations of human cognition, which is easily overwhelmed by excessive and/or irrelevant environmental stimuli, thereby hindering ability to learn (Chandler \& Sweller, 1991; Feldon, 2007; Kirschner, Sweller, \& Clark, 2006; Sweller, 1999, 2004).

Instructional materials can be carefully designed to reduce cognitive load and facilitate automaticity (e.g., when one can process information quickly with little to no conscious effort). In doing so, teacher candidates can put limited mental capacities to work in ways that are proven to maximize and ensure learning (Feldon, 2007). Studies (Mayer, 2001; Sweller, 1988, 1999) validate the cognitive load theory, and have supported guided instruction as a means to produce recall of facts and long term transfer of knowledge and skills, rather than free and unguided environments.

Recognizing the ill prepared state of reading teachers and the room for improvement in teacher preparation, we created the CAP used in this study following design features that are supported to reduce cognitive load and therefore ensure learning: Mayer's (2009) CTML and accompanying design features (Mayer, 2008). The video was edited in alignment with Brunvand's (2010) video design guidelines (see Figure 2) in an effort to support cognitive processing of preservice teachers. These design guidelines 
provide reassurance that preservice teacher cognitive demands are low, and active learning is bolstered.

\begin{tabular}{|l|l|}
\hline Design Strategy & Description of Design Strategies \\
\hline Elicit Prompts & $\begin{array}{l}\text { Point out important aspects of practice that the viewer should } \\
\text { attend to with onscreen text or title overlay of relevant key } \\
\text { information. }\end{array}$ \\
\hline $\begin{array}{l}\text { Teacher } \\
\text { Commentary }\end{array}$ & $\begin{array}{l}\text { Include commentary because it provides insight into teacher } \\
\text { thought processes and enhances the viewer's ability to notice } \\
\text { relevant content. Commentary can be provided at different times } \\
\text { during the video. }\end{array}$ \\
\hline $\begin{array}{l}\text { Establishing } \\
\text { Tasks }\end{array}$ & $\begin{array}{l}\text { Include a clear set of objectives so that viewers understand what } \\
\text { they should be able to do or understand after watching specific } \\
\text { video segments; objectives will ensure attention to specific aspects. }\end{array}$ \\
\hline $\begin{array}{l}\text { Process } \\
\text { Management }\end{array}$ & $\begin{array}{l}\text { Include scaffolds or support for process management to help } \\
\text { learners progress through a set of tasks in an orderly fashion by (a) } \\
\text { arranging a video sequentially to depict lessons in chronological } \\
\text { order (beginning, middle, and end of the lesson) and/or (b) using } \\
\text { hyperlinks that connect to supplementary resources. }\end{array}$ \\
\hline $\begin{array}{l}\text { Provide Alternate } \\
\text { Perspectives }\end{array}$ & $\begin{array}{l}\text { Provide exposure to examples of classroom practice from multiple } \\
\text { perspectives and viewpoints to help novice teachers make } \\
\text { connections between authentic situations of teaching and their } \\
\text { existing knowledge. }\end{array}$ \\
\hline Reflection Tools & $\begin{array}{l}\text { Include tools to foster reflection to provide the learner } \\
\text { opportunities to analyze new information deeply and make sense of } \\
\text { the video, ultimately to hold information in memory. Such tools } \\
\text { could include prompts and questions to consider and respond to. }\end{array}$ \\
\hline $\begin{array}{l}\text { Use contextual cues to guide viewer attention to certain aspects of } \\
\text { video such as, camera movement, visual effects, onscreen titles, } \\
\text { blurred irrelevant portions, slow motion or freeze frame, arrows, } \\
\text { and highlighting tools. A cueing system will alleviate the cognitive } \\
\text { load that occurs with simultaneous visual and verbal information. }\end{array}$ \\
\hline
\end{tabular}

Figure 2. Brunvand's Video Production Strategies. These guidelines were followed to create the video modeling piece of Video plus CAP. Adapted from "Best practices for producing video content for teacher education," by S. Brunvand, 2010, Journal of Contemporary Issues in Technology and Teacher Education, 10, 247-256.

\section{Social Cognitive Theory}

When formulating a teacher education tool that might address the need to better prepare teachers to teach evidence-based vocabulary instruction, I saw video modeling as a valuable piece considering Bandura's (1977) social cognitive theory. This theory 
recognizes that there are not only cognitive processes, but also behavioral and environmental factors that affect learning (Bandura, 1989). According to the social cognitive theory, individuals learn from observation of others' behaviors, seeing models, and practice opportunities to imitate models. In fact, "most human behavior is learned observationally through modeling: from observing others, one forms an idea of how new behaviors are performed, and on later occasions this coded information serves as a guide for action" (Bandura, 1977, p. 22). Learning by observation can occur if learners are motivated, have focused attention on the behavior, and are capable of retaining information in memory (Bandura, 1977).

Video modeling may provide an opportunity for preservice teachers to situate their knowledge of vocabulary instruction in actual teaching, and may be an effective piece in developing engaged knowledge, which Brownell (2009) encourages teacher educators to foster. The video shows preservice teachers a model of effective vocabulary instruction; following video viewing, preservice teachers are given a chance to imitate the observed behaviors. In addition to providing an authentic teaching context to help situate learning, video serves as another representation for preservice teachers to construct meaning of effective vocabulary instruction, and research indicates that meaningful learning occurs when learners gather meaning from multiple representations (Mayer, Moreno, Boire, \& Vagge, 1999).

\section{Summary}

Given the need for effective teacher preparation methods that result in teacher candidates who are confident and able to meet the needs of diverse learners, video plus CAP was created to address the cognitive load theory. Specifically, the video modeling 
piece was constructed following Brunvand's video production guidelines and the CAP was created based on Mayer's CTML to reduce cognitive load and support learning. Bandura's social cognitive theory that humans learn from observing others supports the decision to incorporate video modeling in teacher education. Attention to theories of learning is critical in creating effective multimedia teacher education methods. In reality, many uses of multimedia are distracting, confusing, and ineffective if not created with consideration of cognitive learning needs (Mayer, 2009; Mayer \& Johnson, 2008). Thus, Mayer's CTML and Brunvand's video production guidelines, which adhere to theoretical principles of multimedia and cognitive learning, may be effective pathways to deliver knowledge and skills related to evidence-based vocabulary instruction to future teachers.

\section{Gaps in the Literature}

Across all major components discussed in the literature review are unanswered questions and gaps that require further research. Though some empirical evidence exists to suggest vocabulary practices that may be effective for students with disabilities, it is evident in reading pedagogy research that teacher preparation has lacked emphasis on the area of vocabulary instruction. Teacher educators must find effective ways to prepare teacher candidates to use evidence-based vocabulary practices. Few quality studies have been conducted on multimedia tools, particularly video, to teach evidence-based practices to preservice teachers. Just one study was found (Dieker et al., 2009) to examine effects of video instruction on teaching ability; the use of video to translate research knowledge into practice requires further investigation. Furthermore, there is a huge gap in research that welcomes the need to create and experimentally test multimedia methods based on theories of learning. Given the need for teacher educators to deliver effective vocabulary 
practices to future teachers, as well as the promising research on (a) video-modeling and CAPs in teacher education, and (b) multimedia tools based on theories of cognitive learning, it is logical to combine these concepts in an attempt to better prepare future teachers.

\section{Research Questions}

The research questions of this study were created based on the aforementioned review of (a) reading teacher preparation, (b) evidence-based vocabulary practices for students with learning disabilities, (c) multimedia tools in teacher preparation, as well as (d) theories of cognitive and multimedia learning. Many children enter school with limited oral language experiences and if not immediately addressed, these struggles are increasingly difficult to remediate causing severe reading deficits. Additionally, students at-risk for or with reading disabilities are likely to struggle with vocabulary acquisition, affecting ability to comprehend and academic success across content. Video plus CAP, created following Mayer's CTML and Brunvand's video production guidelines, may serve as a pathway to effective vocabulary instruction in classrooms and ultimately prevent vocabulary deficits among children.

1. To what extent can video plus CAP improve preservice teacher knowledge of an evidence-based vocabulary intervention?

2. Does overall preservice teacher knowledge about effective vocabulary instruction increase after watching the video plus CAP on IVI as demonstrated from differences on a pre-test and posttest? If so, is preservice teacher knowledge maintained three weeks after viewing video plus CAP as demonstrated on a maintenance test? 
3. To what extent can video plus CAP improve preservice teachers' ability to demonstrate behaviors associated with IVI with fidelity with struggling elementary students (i.e., low-performing students at risk for or with learning disabilities and/or English Language Learners)? 


\section{CHAPTER III}

\section{METHODOLOGY}

Two separate but related studies were conducted to answer the research questions.

Study 1 was an experimental pretest-posttest-maintenance design; outcome measures consisted of a pretest, posttest, and maintenance test of vocabulary instruction knowledge. Study 2 had an experimental post-only design; outcome measures consisted of a posttest of vocabulary instruction knowledge and observations of actual vocabulary instruction. Study 1 answered research question 1 and 2, examining the knowledge of preservice teachers before and after the intervention. Study 2 answered research question 3 , as it looked at preservice teacher ability to use practices with students after the intervention. Both studies consisted of different preservice teacher participants from the same institution. Participant selection was based on students who volunteered to receive two research credits.

\section{Study 1 Participants and Setting}

Participants of Study 1 included 101 undergraduate and graduate students enrolled in teacher education coursework at a public university in the mid-Atlantic. This institution is comparable to other American leading universities with respect to overall student characteristics and the structure of teacher education programs. Caucasian students represent the largest ethnic group (62.2\%); Asians are the next largest group at 21.1\%, and African American students constitute 7.4\%. 
Table 1 displays the demographic information collected for Study 1. Participants for both studies were primarily white females of middle to upper socioeconomic status. Most participants in Study 1 ranged in age from 21-24 years old, had attended the university for three to four years, and planed to teach after graduation (92\%). On a scale of 1 to 6 with 6 being the most comfortable, on average, participants indicated feeling fairly comfortable teaching vocabulary prior to intervention with a mean score of 3.9. Additionally, participants indicated feeling less comfortable teaching the specific practices known as Intensifying Vocabulary Intervention (IVI), with an average score of 1.5 prior to the intervention. This low score indicates that most participants likely had not heard of IVI prior to this study.

Table 1. Demographic Information for Study 1

\begin{tabular}{|c|c|c|c|c|c|c|c|c|c|}
\hline & \multirow[t]{2}{*}{$N$} & \multicolumn{3}{|l|}{ Major } & \multicolumn{3}{|c|}{ \#Years at University } & \multicolumn{2}{|l|}{ Level } \\
\hline & & Elem & Sped & Other & $1-2$ & $3-4$ & $5+$ & $\mathrm{U}$ & G \\
\hline Total Participants & 101 & 26 & 20 & 55 & 24 & 55 & 22 & 55 & 46 \\
\hline Reading Group & 51 & 15 & 8 & 28 & 12 & 31 & 8 & 30 & 21 \\
\hline \multirow[t]{3}{*}{ Video Group } & 50 & 11 & 12 & 27 & 12 & 24 & 14 & 25 & 25 \\
\hline & $N$ & \multicolumn{2}{|c|}{ Read-Course } & \multicolumn{3}{|c|}{ Comfort Vocab } & \multicolumn{3}{|c|}{ Comfort IVI } \\
\hline & & $\mathrm{N}$ & $\mathrm{Y}$ & Least & Fairly & Very & Least & Fairly & Very \\
\hline Total Participants & 101 & 33 & 68 & 8 & 74 & 19 & 89 & 11 & 1 \\
\hline Reading Group & 51 & 16 & 35 & 5 & 37 & 9 & 44 & 6 & 1 \\
\hline Video Group & 50 & 17 & 33 & 3 & 37 & 10 & 45 & 5 & 0 \\
\hline
\end{tabular}


Note. Frequencies are presented. Elem $=$ Elementary Education; Sped $=$ Special Education; $U=$ Undergraduate; Read-Course $=$ Previously taken reading-related courses; $G=$ Graduate; $Y=$ Yes; $N=$ No.

\section{Study 1 Instructional Materials}

\section{Video Plus CAP}

Video. A white female researcher and former kindergarten teacher was videotaped teaching the research-based strategy called Intensifying Vocabulary Intervention (IVI) with three kindergarten students. The researcher taught kindergarten for three years and was a reading coach before entering a doctoral program in special education. During videotaping, the researcher followed a script (see Appendix F) to ensure fidelity of the intervention.

To address the cognitive load theory (Sweller, 2004) and limit extraneous information presented, the video was edited following Brunvand's (2010) video production guidelines (see Figure 2). Brunvand's guidelines, based on research of video in teacher education, suggest ways to create videos that will draw viewer attention to relevant information, reduce cognitive load of viewers, and eliminate elements that may be distracting, overwhelming, and hinder learning (Salomon, 1994). Drawing attention to salient content and helping preservice teachers focus on pertinent aspects of teaching practices can enhance the instructional value of video materials (Brunvand, 2010). For example, I removed unnecessary prolonged pauses and added captions to emphasize pertinent lesson characteristics. The purpose of this is to alert the viewer to aspects he/she should pay attention to while using the strategy. Figure 3 provides the specific steps that were taken to ensure the intervention video followed Brunvand's design strategies for video. 


\begin{tabular}{|l|l|}
\hline $\begin{array}{l}\text { Design Strategy } \\
\text { (Brunvand, 2010) }\end{array}$ & $\begin{array}{l}\text { Current Study's Video Production Steps Relevant to Brunvand's } \\
\text { Design Strategies }\end{array}$ \\
\hline Elicit Prompts & $\begin{array}{l}\text { Onscreen text captions were added to the bottom of the screen to } \\
\text { point out effective vocabulary instruction characteristics as the } \\
\text { teacher demonstrates each and prior to each lesson section (pre- } \\
\text { reading, during reading, and after-reading) headings and terms } \\
\text { were displayed to prepare the viewer for pertinent lesson } \\
\text { characteristics. }\end{array}$ \\
\hline Teacher Commentary & $\begin{array}{l}\text { Commentary was provided at the beginning of the video (in the } \\
\text { form of a CAP) to introduce the lesson to be shown. }\end{array}$ \\
\hline $\begin{array}{l}\text { Establishing } \\
\text { Perspective and Tasks }\end{array}$ & $\begin{array}{l}\text { In the pre-CAP (before the modeled lesson) video objectives were } \\
\text { stated and shown with onscreen texts. }\end{array}$ \\
\hline Process Management & $\begin{array}{l}\text { The IVI lesson demonstrated was included in a chronological } \\
\text { order including pre-reading activities, during reading activities, } \\
\text { and after-reading activities. }\end{array}$ \\
\hline $\begin{array}{l}\text { Provide Alternate } \\
\text { Perspectives }\end{array}$ & $\begin{array}{l}\text { Viewers are able to see an example of a teacher using IVI with a } \\
\text { small group in an authentic setting as well as hear and read IVI } \\
\text { lesson steps. Examples of IVI used with other grades, students, } \\
\text { and teachers would be beneficial in the future, but were not } \\
\text { included to reduce video length. }\end{array}$ \\
\hline Cueing Systems & $\begin{array}{l}\text { Periodically after each lesson section, viewers are asked questions } \\
\text { in order to help them assess their learning. The post-CAP after the } \\
\text { entire lesson is modeled also reviews what was shown in the IVI } \\
\text { lesson. }\end{array}$ \\
\hline $\begin{array}{l}\text { Onscreen titles were provided each time the teacher in the video } \\
\text { exhibited a pertinent effective vocabulary practice and parts of the } \\
\text { lesson were deleted as to not detract from important } \\
\text { characteristics. }\end{array}$ \\
\hline
\end{tabular}

Figure 3. Video Production Steps that Followed Brunvand's (2010) Strategies

CAP. A CAP was created and added to the video prior to IVI being modeled.

CAPs are multimedia-based instructional materials that can be used in teaching and

learning. Essentially, CAPs are audio recordings synced in time with visuals (e.g.,

pictures and on-screen text; Kennedy, Hart, \& Kellems, 2010). CAPs can be thought of

as enhanced podcasts that follow instructional design principles (Mayer, 2009) based on

cognitive learning. The CAP set the stage for what the viewer was about to see, and what

the viewer should prioritize attention-wise when watching the video. The decision to 
include an introduction to the videotaped modeled lesson is supported by Dieker et al. (2009) who found that novice teachers who watched a video without an introduction on exemplary practices expressed uncertainty about what they were supposed to obtain from the videos. The script for the CAP originated from the reading used with the comparison group.

The CAP was created based on methods described in former studies on CAPs (Kennedy \& Thomas, 2012). First, I constructed Microsoft PowerPoint slides in adherence to Mayer's CTML (2009) and accompanying design features (Mayer, 2008). Mayer (2009) describes five cognitive processes that must occur with the learner to obtain meaningful learning from multimedia instruction: (a) select relevant key words, (b) select relevant key pictures, (c) organize key words into a verbal mental model and (d) organize relevant pictures into a visual mental model, so that connections are made into working memory, (e) make connections between words and images, while integrating prior knowledge. Furthermore, Mayer established 12 principles to consider when designing multimedia instruction (Figure 4), which have been tested in experimental comparisons. Design principles serve as a means to (a) reduce extraneous processing, (b) manage essential germane processing, and (c) foster generative processing.

\begin{tabular}{|l|l|l|}
\hline $\begin{array}{l}\text { Triarchic Model } \\
\text { of Cognitive } \\
\text { Load (DeLeeuw } \\
\text { \& Mayer, 2008) }\end{array}$ & $\begin{array}{l}\text { Research-Based } \\
\text { Instructional Design } \\
\text { Principles (Mayer, } \\
\text { 2009) }\end{array}$ & $\begin{array}{l}\text { Brief Description of Mayer's Instructional } \\
\text { Design Principles (Mayer, 2009) }\end{array}$ \\
\hline $\begin{array}{l}\text { Limit } \\
\text { Extraneous }\end{array}$ & Coherence Principle & $\begin{array}{l}\text { Learning is enhanced when irrelevant or } \\
\text { extraneous information is excluded }\end{array}$ \\
\hline
\end{tabular}




\begin{tabular}{|c|c|c|}
\hline \multirow[t]{4}{*}{ Processing } & Signaling Principle & $\begin{array}{l}\text { Learning is enhanced when explicit cues are } \\
\text { provided that signal the beginning of major } \\
\text { headings or elements of the material being } \\
\text { covered }\end{array}$ \\
\hline & $\begin{array}{l}\text { Redundancy } \\
\text { Principle }\end{array}$ & $\begin{array}{l}\text { Learning is enhanced when extensive text } \\
\text { (transcription) on screen along with spoken } \\
\text { words and pictures is not used. Carefully } \\
\text { selected words or short phrases, however, } \\
\text { augment retention (Mayer \& Johnson, 2008) }\end{array}$ \\
\hline & $\begin{array}{l}\text { Spatial Contiguity } \\
\text { Principle }\end{array}$ & $\begin{array}{l}\text { Learning is enhanced when on-screen text and } \\
\text { pictures are presented in close proximity to one } \\
\text { another to limit eye shifting during instructional } \\
\text { presentations }\end{array}$ \\
\hline & $\begin{array}{l}\text { Temporal } \\
\text { Contiguity Principle }\end{array}$ & $\begin{array}{l}\text { Learning is enhanced when pictures and text } \\
\text { correspond to the audio presentation }\end{array}$ \\
\hline \multirow{3}{*}{$\begin{array}{l}\text { Manage } \\
\text { Essential } \\
\text { Processing }\end{array}$} & Modality Principle & $\begin{array}{l}\text { Learning is enhanced when spoken words and } \\
\text { pictures are used as part of instruction }\end{array}$ \\
\hline & $\begin{array}{l}\text { Segmenting } \\
\text { Principle }\end{array}$ & $\begin{array}{l}\text { Learning is enhanced when multimedia } \\
\text { presentations are divided into short bursts (5-7 } \\
\text { minutes) as opposed to longer modules }\end{array}$ \\
\hline & $\begin{array}{l}\text { Pretraining } \\
\text { Principle }\end{array}$ & $\begin{array}{l}\text { Learning is enhanced when instructional } \\
\text { messages contain an orienting message to } \\
\text { introduce the forthcoming content }\end{array}$ \\
\hline \multirow{2}{*}{$\begin{array}{l}\text { Foster } \\
\text { Generative } \\
\text { Processing }\end{array}$} & $\begin{array}{l}\text { Multimedia } \\
\text { Principle }\end{array}$ & $\begin{array}{l}\text { Learning is enhanced when pictures and spoken } \\
\text { words are used instead of words alone }\end{array}$ \\
\hline & $\begin{array}{l}\text { Personalization, } \\
\text { Voice, and Image } \\
\text { Principles }\end{array}$ & $\begin{array}{l}\text { Learning is enhanced when narration is } \\
\text { presented in a conversational style instead of } \\
\text { more formal audio presentations }\end{array}$ \\
\hline
\end{tabular}

Figure 4. Mayer's design principles (Kennedy et al., 2010)

To view CAP production steps, (a) watch a CAP on how to make a CAP at https://vimeo.com/24179998 (part 1) and https://vimeo.com/241827724 (part 2) or (b) read written procedures at http://people.virginia.edu/ mjk3p/docs/CAP_Production_Steps_MK.pdf. Specific steps 
for this study's CAP creation can be viewed in Figure 5; the CAP was carefully constructed to abide by each instructional design principle. The video plus CAP can be viewed at: https://vimeo.com/52186714.

\begin{tabular}{|c|c|c|}
\hline $\begin{array}{l}\text { Triarchic } \\
\text { Model of } \\
\text { Cognitive Load } \\
\text { (DeLeeuw \& } \\
\text { Mayer, 2008) }\end{array}$ & $\begin{array}{l}\text { Research-Based } \\
\text { Instructional Design } \\
\text { Principles and effect } \\
\text { sizes* } \\
\text { (Mayer, 2009) }\end{array}$ & $\begin{array}{l}\text { Brief Description of Mayer's Instructional } \\
\text { Design Principles (Mayer, 2009) }\end{array}$ \\
\hline \multirow{5}{*}{$\begin{array}{l}\text { Limit } \\
\text { Extraneous } \\
\text { Processing }\end{array}$} & $\begin{array}{l}\text { Coherence Principle } \\
E S=.97,14 \text { Studies }\end{array}$ & $\begin{array}{l}\text { Each CAP only contains information relevant to } \\
\text { the history term/concept being presented }\end{array}$ \\
\hline & $\begin{array}{l}\text { Signaling Principle } \\
E S=.52,6 \text { Studies }\end{array}$ & $\begin{array}{l}\text { Each CAP contains recurring explicit cues to } \\
\text { signal the beginning of a new section }\end{array}$ \\
\hline & $\begin{array}{l}\text { Redundancy } \\
\text { Principle } \\
E S=.72,5 \text { Studies }\end{array}$ & $\begin{array}{l}\text { Each CAP only contains carefully selected key } \\
\text { text }\end{array}$ \\
\hline & $\begin{array}{l}\text { Spatial Contiguity } \\
\text { Principle } \\
E S=1.12,5 \text { Studies }\end{array}$ & $\begin{array}{l}\text { The on-screen text and pictures in each CAP are } \\
\text { presented in close proximity to one another }\end{array}$ \\
\hline & $\begin{array}{l}\text { Temporal } \\
\text { Contiguity Principle } \\
E S=1.31,8 \text { Studies }\end{array}$ & $\begin{array}{l}\text { Pictures and text within each CAP correspond to } \\
\text { the audio presentation }\end{array}$ \\
\hline \multirow[t]{3}{*}{$\begin{array}{l}\text { Manage } \\
\text { Essential } \\
\text { Processing }\end{array}$} & $\begin{array}{l}\text { Modality Principle } \\
E S=1.02,17 \\
\text { Studies }\end{array}$ & $\begin{array}{l}\text { CAPs are multimedia; therefore this principle is } \\
\text { addressed }\end{array}$ \\
\hline & $\begin{array}{l}\text { Segmenting } \\
\text { Principle } \\
E S=.98,3 \text { Studies }\end{array}$ & $\begin{array}{l}\text { Each CAP is broken either into segments as } \\
\text { noted by instructions to pause the video, or main } \\
\text { ideas are separated into separate CAPs }\end{array}$ \\
\hline & $\begin{array}{l}\text { Pretraining Principle } \\
E S=.85,5 \text { Studies }\end{array}$ & $\begin{array}{l}\text { Each CAP begins with an explicit statement of } \\
\text { purpose and an advance organizer for the term }\end{array}$ \\
\hline \multirow[t]{2}{*}{$\begin{array}{l}\text { Foster } \\
\text { Generative } \\
\text { Processing }\end{array}$} & $\begin{array}{l}\text { Multimedia } \\
\text { Principle } \\
\text { ES }=1.39,11 \\
\text { Studies }\end{array}$ & $\begin{array}{l}\text { The CAPs are multimedia; therefore this } \\
\text { principle is addressed }\end{array}$ \\
\hline & $\begin{array}{l}\text { Personalization, } \\
\text { Voice, and Image } \\
\text { Principles } \\
\text { ES }=1.11,11 \\
\text { Studies }\end{array}$ & $\begin{array}{l}\text { The narration in each CAP is presented in a } \\
\text { conversational style and by a human voice. The } \\
\text { speaker's image is not on the screen. Images are } \\
\text { non-abstract and easily recognizable by viewers }\end{array}$ \\
\hline
\end{tabular}

Figure 5. CAP Production Steps that Follow Mayer's CTML and Instructional Design Principles (Kennedy et al., 2011).

Note: Effect sizes are summaries of empirical research conducted by Mayer and his colleagues and are reported in Mayer (2008) 


\section{Reading}

The control group was provided with a practitioner-friendly reading (see Appendix D) that covered the same content disseminated in the video plus CAP. The reading, created to model 'HotSheets' by the Division for Learning Disabilities (DLD) of Council for Exceptional Children (CEC) (see www.TeachingLD.org), was 6.5 pages in length. HotSheets are brief documents developed for teacher use that focus on one instructional topic and include research-based information pertaining to the topic. The reading contained scripts used in the video to provide readers with specific vocabulary lesson steps and examples of what teachers should say during each step. The reading was created with the assistance of an Associate Professor of special education who created and validated the vocabulary intervention disseminated- IVI. In addition, she has over 13 years of college-level teaching experience on courses related to reading development and special education and providing professional development training on early literacy development and reading interventions for students with learning disabilities. An independent researcher reviewed the reading and video plus CAP to ensure a match in content.

\section{Study 1 Measurement Instruments}

To measure preservice teacher knowledge of vocabulary instruction in Study 1, I created a 30-item multiple-choice instrument (see Appendix B) based on IVI fidelity checklists and characteristics of IVI that were disseminated through instructional materials. This assessment was disseminated (a) as a pretest one week prior to intervention, (b) a posttest immediately after intervention, and (c) a maintenance test 
three weeks post intervention. The posttest and maintenance tests consisted of the same test items and answers as the pretest, but were presented in a different order.

The construction of this instrument reflects best practices for multiple-choice item construction indicated by Haladyna, Downing, and Rodriguez (2002). Two professors and one doctoral student with extensive knowledge of vocabulary instruction reviewed the test items for difficulty, clarity, and errors in content or grammar. The instrument was revised accordingly several times. Items were formulated based on the IVI fidelity checklist and intervention steps. The researcher who created and validated IVI reviewed instrument items and made suggestions for improvement. The test was piloted with 14 teacher candidates from a small university in South Carolina. Changes or omissions occurred on items that all teacher candidates scored $90 \%$ correctly or incorrectly. The same researcher who created IVI edited the instrument with pilot results. A review of the final instrument confirmed that reviewer concerns were addressed.

\section{Study 1 Procedures}

\section{Selection of Vocabulary Strategy}

Vocabulary knowledge is a strong predictor of reading comprehension (Bos \& Anders, 1990; NRP, 2000), the ultimate goal of reading instruction. Because of the vital role vocabulary plays in reading achievement, teachers must be equipped with evidencebased techniques to teach vocabulary. The video plus CAP used in this study models a vocabulary technique known as Intensifying Vocabulary Intervention (IVI). This particular strategy was chosen because it is validated by research to improve vocabulary learning of students who are at-risk for reading difficulties (Maynard, Pullen, \& Coyne, 2010; Pullen, Tuckwiller, Konold, Maynard, \& Coyne, 2010). The UVA IRB-SBS 
approved IVI as standard educational practice based on previous studies (Maynard et al., 2010) and IVI lesson formats used to create the video are currently used in some elementary schools. Considering the importance of effective vocabulary instruction and the lack of research and teacher preparation addressing effective vocabulary instruction, this study's focus on IVI is needed.

\section{Recruitment of Participants}

Permission to conduct research was secured from the University of Virginia (UVA) Institutional Review Board for the Social and Behavioral Sciences (IRB-SBS). For Study 1, undergraduate students enrolled in an education program at university on the East coast were approached via email with an opportunity to participate for two research credits.

\section{Study Procedures}

Following consent, participants were added to a course management site through the university, where procedures, directions, and tests for the study were disseminated. The pretest was shared with participants in Study 1 during one week of time on Collab (i.e., the University's course management website). Participants were asked to complete the pretest in one sitting with no aid or distractions; one of the questions required they indicate that they followed the universities honor code. Specifically, I sent the following message to participants prior to taking the pretest:

The pretest contains 30 multiple-choice items that ask about vocabulary instruction. You are not expected to know the answers to these items; however, please do the best that you can. Do not study for this test. There is no penalty for incorrect answers, and results of the instruments used in this study will not affect 
your grades in courses. Take the pretest in one sitting with no distractions; this test has a 1.5 -hour time limit. Last, do not receive or give any aid on the test. The test was timed to ensure they completed it in one sitting. Baseline data was gathered during the pretest including: Level (undergraduate or graduate), the number of years attending the university, the number of reading-related courses previously taken, future teaching plans, age, major, and comfort teaching vocabulary and the specific practice of IVI.

Using a table of random numbers, participants were randomly assigned to one of two conditions. The group assigned to the experimental (i.e., treatment) condition viewed a video plus CAP on an evidence-based vocabulary strategy, whereas the group assigned to the control condition read an informational packet including vocabulary lesson scripts that covered the same content embedded in the video plus CAP. I emailed participants to inform them of their assigned instruction.

One week after the pretest was given to Study 1 participants, the intervention was disseminated through email. I provided clear directions and due dates for intervention tasks to each treatment group. Appendix E displays the emails that were sent to participants in the experimental group and control group. The control group was sent the reading as a PDF.

Following the intervention, study 1 participants immediately took a posttest on vocabulary instruction knowledge. Three weeks after, participants completed a maintenance probe via collab. The maintenance probe consisted of the same posttest items to determine whether their knowledge was sustained over time. 
Study 1 included a total of four online tasks: pretest, vocabulary intervention, posttest, and maintenance probe. The pretest, posttest, and maintenance probe were scored automatically through online testing in the course management website. The course management site transfers scores into an excel sheet. To ensure data were entered accurately, I checked $10 \%$ of each outcome measure. No data entry errors were found.

\section{Study 1 Research Design and Data Analysis}

In Study 1, an experimental, two-group pretest-posttest-maintenance design was used to determine the utility of video plus CAP to improve preservice teacher knowledge of evidence-based vocabulary instruction. The content and information provided to both the treatment group (video plus CAP) and the control group (reading) was the same. All participating preservice teachers completed the same pretest, posttest, and maintenance

assessment. Additionally, participants completed a scale of comfort teaching vocabulary and comfort teaching IVI prior to and after the intervention.

Using simple regression procedures, I began by looking for variation among groups to ensure groups were similar prior to the intervention. I looked for variation of Study 1 groups regarding incoming knowledge as demonstrated on the pretest, as well as academic level, the number of years attending the university, age, the number of readingrelated courses taken, major, future teaching goals, and comfort teaching vocabulary and IVI:

Group $_{\mathrm{i}}=\beta_{0}+\beta_{1}$ Pretest $+\beta_{2}$ Level $+\beta_{3}$ Years $+\beta_{4}$ ReadCourses $+\beta_{5}$ PlanTeach $+\beta_{6}$ Age $3+$ $\beta_{7}$ Age $1+\beta_{8}$ Major $1+\beta_{9}$ Major $2+\beta_{10}$ ComfortVocab $+\beta_{11}$ ComfortIVI $+\varepsilon_{i}$. 
Table 2 presents descriptive statistics of baseline covariates. An Omnibus F-test was conducted in an attempt to confirm no significant differences between groups and to indicate that the randomization process was successful.

Table 2. Study 1 Descriptive Statistics

\begin{tabular}{llllll}
\hline Baseline Covariates & Video $M$ & $S D$ & Read $M$ & $S D$ & $p$ \\
& & & & & \\
\hline & & & & & \\
Pretest & 19.76 & 4.59 & 18.98 & 3.50 & 0.503 \\
Level (U/G) & 0.50 & 0.51 & 0.41 & 0.49 & 0.341 \\
\#Years & 3.34 & 1.45 & 3.29 & 1.23 & 0.641 \\
\#Read Courses & 0.66 & 0.47 & 0.68 & 0.46 & 0.268 \\
Plan to Teach & 0.94 & 0.24 & 0.90 & 0.30 & 0.259 \\
Age 3 (25+) & 0.16 & 0.37 & 0.12 & 0.33 & 0.459 \\
Age 1 (18-20) & 0.18 & 0.39 & 0.19 & 0.40 & 0.485 \\
Major 1 (Elem) & 0.22 & 0.42 & 0.29 & 0.46 & 0.520 \\
Major 2 (Sped) & 0.24 & 0.43 & 0.16 & 0.37 & 0.712 \\
Comfort Vocab & 3.90 & 0.97 & 3.88 & 0.95 & 0.712 \\
Comfort IVI & 1.46 & 0.79 & 1.55 & 0.90 & 0.845 \\
R $=.056$ & & & & & \\
F $=.437$ & & & & & \\
$p=.944$ & & & & &
\end{tabular}

Note. $N=101$. The joint test of significance (Omnibus F-test) showed no significant differences between treatment groups (video and reading) in all baseline covariates $(F=$ .437, $p=.944)$.

I used regression procedures to investigate treatment effects on the posttest, maintenance test, and comfort teaching vocabulary and IVI. I used the same regression procedures for the four outcome measures. First, I used a simple regression procedure with test scores as the dependent variable and held treatment conditions (group) constant. I analyzed the following regression equation:

$\mathrm{Y}_{\mathrm{i}}=\beta_{0}+\beta_{1}$ Group $_{\mathrm{i}}+\varepsilon_{\mathrm{i}}$ 
where $\mathrm{Y}$ is the dependent variable, or outcome (e.g., posttest) score. $\beta_{0}$ and $\beta_{1}$ are the estimates; specifically, $\beta_{0}$ is the estimate for constant when all independent variables are equal to 0 and $\beta_{1}$ is the estimate of treatment effects. Group indicates the treatment group, where 1 is the treatment group (i.e., video plus CAP) and 0 is the control condition (i.e., reading). $\varepsilon$ is the error term, which is assumed to be independent and identically distributed (IID). Following the simple equation, I adjusted the regression equation to include an added predictor, pretest score, as an additional control covariate to improve precision of treatment effect estimates and adjust for any residual differences between groups on pretest. The adjusted multiple regression equation is:

$\mathrm{Y}_{\mathrm{i}}=\beta_{0}+\beta_{1}$ Group $_{\mathrm{i}}+\beta_{2}$ Pretest $_{\mathrm{i}}+\varepsilon_{\mathrm{i}}$

where $\mathrm{Y}, \beta_{1}, \varepsilon$, and Group are defined the same as above, and Pretest indicates individual i's pretest score before the intervention. A standard multiple regression was performed between test scores as the dependent variable with group and pretest as independent variables. Normal regression models assume all observations are independent and identically distributed, but because I had baseline observations that are not independent from each other, standard errors would not be accurate. Therefore, I inflated the standard errors using Robust Standard Errors to account for the correlation between pretest and posttest observations. A third regression model included all baseline covariates as predictors; the multiple regression equation is:

$\mathrm{Y}_{\mathrm{i}}=\beta_{0}+\beta_{1}$ Group $_{\mathrm{i}}+\beta_{2}$ Pretest $_{\mathrm{i}}+\beta_{3}$ Level $_{\mathrm{i}}+\beta_{4}$ Years $_{\mathrm{i}}+\beta_{5}$ ReadCourses $_{\mathrm{i}}+\beta_{6}$ Age $_{\mathrm{i}}+$

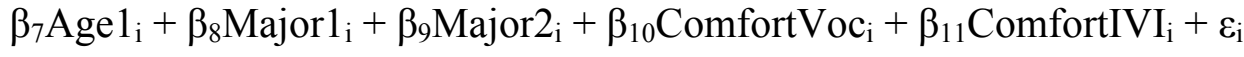

where $\mathrm{Y}, \beta_{1}, \varepsilon$, Group, and Pretest are defined the same as above, and Level is the academic level ( 0 if undergraduate; 1 if graduate), Years is the number of years attending 
the university, ReadCourses is the number of reading-related courses taken prior to the study, Age 3 is a dummy variable for age 3 (i.e., 25 years old or older), Age1 is a dummy variable for age 1 (between 18 and 20 years old), Major 1 is a dummy variable for major 1 (elementary education), Major2 is a dummy variable for major 2 (special education), ComfortVoc is the comfort teaching vocabulary score, and ComfortIVI is the comfort teaching IVI score.

I compared group means on the posttest, maintenance test, and score of comfort teaching vocabulary and comfort teaching IVI using a simple t-test. Mean comparisons indicate which group, if any, significantly outperformed the other.

\section{Study 2 Participants and Setting}

Study 2 participants included 49 different undergraduate and graduate students enrolled in a teacher education course titled "Fieldwork Experience with Elementary English Language Learners" from the same university. Participants were early in the education program and were exposed to fieldwork in schools for the first time.

During data collection, researchers observed and videotaped participants in three public elementary schools near the university. Demographics vary for each public school with enrollment ranging from as low as 329 to 554. The school where the majority of tutoring occurred was made up of 50\% Caucasian students, 33\% African American students, $10 \%$ Hispanic, and 7\% Asian students. Participants were assigned to these public elementary schools as a practicum experience; they taught a small group of three to four students who were at-risk for or with academic struggle and or language barriers. Participants taught lessons in empty spaces including hallways, offices, or other unoccupied classrooms. 
Table 3 shows baseline information for participants in Study 2. Most participants (i.e., 69\%) attended the university for three years and were enrolled in an elementary education major (71\%). Like Study 1, the majority in Study 2 were white females of middle to upper socioeconomic status.

Table 3. Demographic Information for Study 2

\begin{tabular}{llllllll}
\hline & $N$ & \multicolumn{2}{c}{ Major } & & \multicolumn{3}{c}{ \#Years at University } \\
& & Elem & Sped & Other & $1-2$ & $3-4$ & $5+$ \\
\hline Total Participants & 49 & 34 & 13 & 1 & 11 & 33 & 4 \\
Reading Group & 25 & 17 & 7 & 0 & 5 & 16 & 3 \\
Video Group & 24 & 17 & 6 & 1 & 6 & 17 & 1 \\
\hline
\end{tabular}

Note. Frequencies are presented. Elem $=$ Elementary Education; Sped $=$ Special Education; $U=$ Undergraduate; $G=$ Graduate; $Y=$ Yes; $N=$ No.

\section{Study 2 Instructional Materials}

The intervention materials used in Study 2 were identical to materials used in Study 1. Specifically, participants viewed the same video plus CAP or reading as described in Study 1.

\section{Study 2 Measurement Instruments}

Study 2 participants received the same multiple-choice test used in Study 1. With a posttest-only design, participants were administered the test once immediately after the intervention.

I used an IVI fidelity checklist, validated by past research, to observe actual teaching (see Appendix C; Maynard, Pullen, \& Coyne, 2010). I used the IVI fidelity checklist to assess the number of IVI-related practices used by each participant one-week 
post intervention. I marked yes or no to indicate whether or not participants demonstrated certain lesson characteristics. Specifically, I coded 18 instructional practices that IVI incorporates during storybook reading, and 12 characteristics during after-reading activities. The total number of checklist items varied depending on how many vocabulary words the preservice teacher incorporated into the lesson (with a maximum of 79 items).

\section{Inter-Observer Agreement}

Inter-observer agreement (IOA) was obtained for Study 2 to indicate reliable analysis of teacher observations (Egel \& Barthold, 2010). All participants $(N=49)$ were videotaped once teaching vocabulary to elementary student(s). I randomly selected $20 \%$ of participant videos (i.e., 10 videos) to have independently scored by a second observer. Two independent observers scored each video at separate times; observers included (a) the first author, and (b) a doctoral student who had been trained on IVI lessons and IVI fidelity checklists. First, we calculated percent agreement, as this is a popular way for describing IOA (McDermott, 1988). The average percent agreement of all double-coded videos for the total IVI fidelity checklist items was high, 0.85. Second, we calculated Kappa (Cohen, 1960) for each video, which examines the difference between observed agreement and agreement expected by chance. In other words, Kappa is the proportion of the total amount of agreement between observers that is not explained by chance. Interpretations are based on guidelines provided by Fleiss (1981) and Cicchetti (1994). One observation had a Kappa of 0.79 , an excellent and almost perfect agreement. Three observations were considered good agreement with Kappas of 0.71, 0.67, and 0.68. Three observations were considered fair agreement with Kappas of .56, .56, and .49. The 
last three observations had less than ideal agreement with a poor agreement of .07, no correlation between observers with .00 , and a negative agreement of -0.038 indicating more consistent disagreement. Overall, $70 \%$ of observations that were double coded had fair to excellent agreement.

\section{Study 2 Procedures}

\section{Recruitment of Participants}

Preservice teachers who were taking a course related to Field Experience with English Language Learners (ELL) were given an opportunity to participate for two research credits. Most individuals enrolled in this class opted to participate as the study was presented as a good learning opportunity; few declined based on concern for being videotaped. Participants were given consent forms for their field placement clinical teachers to sign with requirements of the study. Additionally, I emailed the teachers to learn about media release policies and answer questions. The teachers identified two to four students in their class who needed remediation due to low performance and/or language barriers. Informed consent forms were sent home for parents to sign, along with information regarding the purpose of the study and reassurance that confidentiality would be maintained.

\section{Study Procedures}

After random assignment to groups (i.e., video plus CAP or reading), participants in Study 2 were given the intervention with the same procedures as Study 1. Immediately after, participants took the multiple-choice posttest online. Different than Study 1, participants in Study 2 taught a vocabulary lesson to a small group of students identified by their teacher as low performing and/or with language barriers. Specifically, 
participants were asked to demonstrate vocabulary instruction skills learned from the intervention (video plus CAP or the reading) with two, three, or four low performing or language learning elementary students from their assigned fieldwork placement schools. Though students' academic performance and abilities varied, such variations should not affect the study's outcomes because outcomes focus on teaching ability rather than student performance. The placement teachers assigned to each field placement ensured that students who were videotaped had completed media release forms. Permission to work with students on an individual basis was approved by the principal, teacher, parents, and students themselves.

I provided children's books to each participant to use during their vocabulary lesson one week later. Participants were encouraged to write down lesson steps based on the intervention that could be used during teaching. They were allowed to plan for as little or as long as they wanted prior to tutoring. Tips on working with students were shared, such as how to briefly establish rapport with the child before beginning instruction. Last, participants were reminded that this is a learning process and they are not expected to perfectly demonstrate the strategy, but simply to do the best they can. They were told that they were being videotaped for the purposes of the study to learn about the effectiveness of their mode of instruction.

The week after the experiment occurred, participants reported to their designated elementary schools at their scheduled time slot with the provided children's book and any notes they wanted to bring. In a quiet setting, preservice teachers attempted IVI with one or a few struggling or ELL elementary student(s) for 15-30 minutes as I observed. I used the IVI fidelity checklist to record the number of IVI practices participants used at three 
different points during the lesson: During storybook reading, after-reading, and throughout the lesson (total). I was encouraging throughout the experience, but did not provide tips or suggestions on what the preservice teacher should or should not be doing in an attempt to evaluate effects of the conditions on ability to teach.

In summary, Study 2 included two online tasks: vocabulary intervention and posttest. Additionally, study 2 included an in-person observation post intervention.

\section{Study 2 Research Design and Data Analysis}

In Study 2, an experimental, two-group posttest-only design was used to determine the utility of video plus CAP to teach preservice teachers to use evidencebased vocabulary practices. The treatment group watched a video plus CAP on IVI and the control group read an informational packet on the same content. After the intervention, participants completed a posttest that was the same as the posttest in Study 1 , as well as a scale indicating comfort teaching vocabulary and comfort teaching IVI. In addition, participants were videotaped and observed teaching vocabulary to student(s) at an elementary school. Observations were examined using IVI fidelity checklists. I prepared the fidelity checklists for analysis by adding up the number of effective characteristics demonstrated for each lesson part: during reading, after reading, and the total lesson. Then I turned the numbers into percentages of IVI-related practices used for each lesson part.

I looked for group differences on baseline covariates of the number of years attending the university and major (see Table 4):

Group $_{\mathrm{i}}=\beta_{0}+\beta_{1}$ Years $+\beta_{2}$ Major $1+\beta_{3}$ Major $2+\varepsilon_{\mathrm{i}}$. 
A joint test of significance (Omnibus F-test) was conducted to further examine differences between groups.

Table 4. Study 2 Descriptive Statistics

\begin{tabular}{|c|c|c|c|c|c|}
\hline Baseline Covariates & Video $M$ & $S D$ & $\operatorname{Read} M$ & $S D$ & $p$ \\
\hline \#Years & 2.70 & 0.95 & 3.04 & 1.04 & .254 \\
\hline Major 1 (Elem) & 0.70 & 0.46 & 0.68 & 0.47 & .326 \\
\hline Major 2 (Sped) & 0.25 & 0.44 & 0.28 & 0.45 & .308 \\
\hline $\begin{array}{l}\mathrm{R}^{2}=.051 \\
\mathrm{~F}=.792 \\
p=.505\end{array}$ & & & & & \\
\hline
\end{tabular}

Note: $N=48$. The joint test of significance (Omnibus F-test) showed no significant differences between treatment groups (video and reading) in all baseline covariates ( $F=$ $.792, p=.505)$.

Simple regression procedures examined differences between groups on five outcome measures- three measures during the vocabulary lessons and two measures of comfort teaching vocabulary. Outcome measures included: (a) percentage of IVI practices used during a reading activity, (b) percentage of IVI practices used during afterreading activities, (c) the total percentage of IVI practices used during the entire lesson, (d) comfort teaching vocabulary, and (e) comfort teaching IVI. Below is an example of a simple regression equation used to look at group differences on each outcome measure: $\mathrm{Y}_{\mathrm{i}}=\beta_{0}+\beta_{1}$ Group $_{\mathrm{i}}+\varepsilon_{\mathrm{i}}$ where $\mathrm{Y}$, for example, is the percentage of IVI practices used during reading, and $\beta_{1}$ is the treatment group ( 0 if reading; 1 if video plus CAP). The same regression equation was used for each outcome, where Y is a different outcome (i.e., percentage of IVI practices after reading, percentage of IVI practices total, comfort teaching vocabulary, 
and comfort teaching IVI). I used Robust Standard Errors to account for correlation in error terms between the pretest and post-tests.

I prepared the fidelity checklists for analysis by adding up the number of effective characteristics demonstrated for each lesson part: during reading, after reading, and the total lesson. Then I turned the numbers into percentages of evidence-based practices used for each lesson part. 


\section{CHAPTER IV}

\section{RESULTS}

\section{Results for Study 1: Teacher Knowledge}

One hundred and one preservice teachers were randomly assigned to one of two experimental conditions. Students in the treatment group watched a video plus CAP explaining and modeling an evidence-based vocabulary intervention for students with learning disabilities. Students in the control group read a teacher practitioner reading containing teaching scripts. The content provided to each group was the same; the instructional format for each group was different. Baseline covariates included: (a) academic level (undergraduate or graduate), (b) the number of years attending the university, (c) age, (d) the number of reading-related courses previously taken, (e) major (elementary, special education, or other including non-education), (f) whether participants plan to teach in the future, $(\mathrm{g})$ scores on a pretest assessing incoming knowledge of vocabulary instruction, and (h) scores on a presurvey assessing comfort teaching vocabulary and (i) comfort teaching the specific vocabulary practices (i.e., IVI) prior to the intervention. Table 3 provides descriptive statistics of baseline covariates to examine group differences prior to intervention. It shows that the baseline covariate means were relatively the same for each group- video plus CAP and reading. Furthermore, the $p$ values of each baseline covariate well exceeded .05 , indicating no significant differences between treatment and control means. These results were expected with random assignment of preservice teachers to treatment groups. The 
Omnibus F-test confirmed that the randomization procedure was successful in creating two relatively-equivalent treatment groups, and there were no significant differences in covariates between groups prior to the intervention $(f(100)=.437, p=.944)$.

Regression procedures were used to investigate treatment and control group differences on the posttest and maintenance test. The 30 question multiple-choice posttest was provided immediately after the intervention. Three weeks later, a maintenance test made up of the same questions was provided to measure retention of knowledge.

\section{Vocabulary Posttest}

Table 5 presents vocabulary posttest results from three regression models and reports the coefficient and standard error on treatment effects among groups, as well as $p$ values from a t-test of coefficients to confirm results. First, a simple regression procedure was used to look for group differences on the vocabulary posttest that was taken immediately after intervention. Model 1 refers to the first stage in which I conducted a simple regression using posttest scores as the dependent variable and holding treatment conditions (group) constant. Model 2 includes one added predictor, pretest scores, as a control covariate to improve precision of treatment effect estimates and adjust for any residual differences between groups on the pretest. A standard multiple regression was performed between posttest scores as the dependent variable with group assignment and pretest scores as the independent variables. Model 3 includes all baseline covariates as predictors. The standard errors in Table 5 decrease slightly or stay relatively the same from Model 1 to Model 2 to Model 3. In other words, as I added control covariates to each model, the treatment effect estimates become more precise. 
Including control covariates results in more statistical precision, evident in the slightly decreasing standard errors when covariates are added. Additionally, including control covariates adjusts for the potential problem of imbalance between groups that could have occurred during random assignment. Because adding control covariates does not change the coefficients or standard errors much, we can assume that the control covariates do not contribute greatly to the treatment effects. In Model 2, the coefficient for Group went from a positive to a negative number, indicating that there may be some baseline differences between treatment groups on the pretest. However, including the pretest in Model 2 reduced the standard error from .66 to .57 , making the treatment effect estimate more precise. To take into account possible violation of the independence assumption in regression, I reran Model 2 (and Model 3) to reflect Huber-White robust standard errors. Potential violations of the independence assumption could be due to (a) nested data structure of participants resulting in data that is correlated with each other, and/or (b) the presence of a pretest that could result in correlations with outcomes across time. All outcome measures for Model 2 and Model 3 of Study 1 reflect Huber-White adjusted standard errors and significance values. By adding all covariates to Model 3, coefficient estimates for Group hardly changed indicating no other differences in covariates between treatment groups. Because including the additional covariates in Model 3 did not help or change coefficients much, the most parsimonious and therefore optimal model for treatment effects is Model 2. Additionally, the adjusted $\mathrm{R}^{2}$ was highest in Model 2 for some of my tables. Model 2 balances precision and residual imbalances that might have occurred during randomization, in this case by controlling for the covariate Pretest that indicated potential imbalance. 
Table 5. Study 1 [Posttest]: Coefficients from the Regression of Posttest on Group

\begin{tabular}{|c|c|c|c|}
\hline Difference Between Groups & Model 1 & Model 2 & Model 3 \\
\hline Posttest & $\begin{array}{l}.216 \\
.65)\end{array}$ & $\begin{array}{l}-.084 \\
.57)\end{array}$ & $\begin{array}{l}-.069 \\
.60)\end{array}$ \\
\hline Pretest & - & $\begin{array}{l}.385^{*} \\
(.08)\end{array}$ & $\begin{array}{l}.387^{*} \\
(.10)\end{array}$ \\
\hline Level (U/G) & - & - & $\begin{array}{l}.523 \\
(.72)\end{array}$ \\
\hline \#Years at UVA & - & - & $\begin{array}{l}-.094 \\
. .25)\end{array}$ \\
\hline \#Reading Courses Taken & - & - & $\begin{array}{l}.517 \\
(1.06)\end{array}$ \\
\hline Age $3(25+)$ & - & - & $\begin{array}{l}-1.741 * \\
(.76)\end{array}$ \\
\hline Age $1(18-20)$ & - & - & $\begin{array}{l}.362 \\
(.96)\end{array}$ \\
\hline Major 1 (Elem) & - & - & $\begin{array}{l}.280 \\
(.78)\end{array}$ \\
\hline Major 2 (Sped) & - & - & $\begin{array}{l}-.075 \\
(1.37)\end{array}$ \\
\hline Comfort Vocab & - & - & $\begin{array}{l}-.143 \\
(.30)\end{array}$ \\
\hline Comfort IVI & - & - & $\begin{array}{c}-.720 \\
(.37)\end{array}$ \\
\hline Intercept & $\begin{array}{l}24.80 \\
(.46)\end{array}$ & $\begin{array}{l}17.50 \\
(1.44)\end{array}$ & $\begin{array}{l}18.94 \\
(2.87)\end{array}$ \\
\hline$R^{2}$ & .001 & .223 & .287 \\
\hline Adjusted $R^{2}$ & -.009 & .207 & .199 \\
\hline Number of observations & 101 & 101 & 101 \\
\hline
\end{tabular}

Note: Standard errors are reported in parentheses and represent robust standard errors (Huber White). $N=101 .{ }^{*}$ indicates significance at the $95 \%$ level, $p<.05$. 
The simple regression analysis of Model 1 revealed that assigned group did not significantly predict differences in posttest scores, $b=.216, t(100)=.326, p=.745,95 \%$ CI $[-1.098,1.531]$. The regression coefficient $(B=.216)$ was not statistically significant, meaning there were no significant differences on posttest scores between the reading and video group $(p=.745)$. Specifically, those in the treatment group, on average, scored .216 points higher on the posttest than the control group.

Model 2 also shows no significant differences on posttest scores between each group, $b=-.084, t(100)=-.142 p=.887,95 \% \mathrm{CI}[-1.255,1.087]$. Controlling for the pretest variable in Model 2, the mean difference in posttest scores between the treatment and control group is -.084 . However, there were significant differences from the pretest scores to posttest scores, $b=.385, t(100)=5.29, p<.01,95 \%$ CI $[0.240,0.529]$. These results suggest that all participants significantly improved their knowledge from pretest to posttest, but there is no treatment effect on groups. A t-test comparing pretest to posttest further supports the findings that everyone improved significantly: $t(100)=14.46, \mathrm{p}<$ $.01)$. The mean difference of all participants between pretest and posttest is 5.54 points; the pretest mean was 19.36 and the posttest mean was 24.91 .

Model 3, with all predictors added, also showed no significant differences on posttest scores between each group $b=-.069, t(100)=-.114, p=.909,95 \%$ CI $[-1.264$, 1.126]. Controlling for all variables in Model 3, the mean difference in posttest scores between the treatment and control group is -.069. Although, like Model 2, Model 3 continues to show significant differences between pretest scores and posttest scores $b=$ $.387, t(100)=4.73, p<.01,95 \% \mathrm{CI}[0.224,0.549]$, suggesting that everyone improved significantly on the assessment of vocabulary knowledge. When adding covariates, the 
unstandardized coefficient for group did not change much; treatment effects were robust to including all baseline covariates in the model.

Model 3, which controls for all variables, indicates a significant positive relationship between baseline characteristic of participants aged 25 or older (i.e., Age 3) and the posttest outcome. These findings do not greatly affect results, as there are no significant differences on post outcomes for Study 1.

\section{Vocabulary Maintenance Test}

Table 6 presents maintenance test results from three regression models and reports the coefficient and standard error on treatment effects among groups, as well as $p$ values from a t-test of coefficients to confirm results. Model 1 refers to simple regression results using maintenance test scores as the dependent variable and holding treatment groups constant. Model 2 includes multiple regression results after adding an additional predictor, pretest scores, as another control covariate with maintenance test performance as the dependent variable. Model 3 includes all baseline covariates as predictors. The standard errors in Table 6 decrease or stay relatively the same with each adjusted model giving us reason to believe treatment effects were due to the intervention and not outside factors.

Table 6. Study 1 [Maintenance]: Coefficients from the Regression of Maintenance Test on Group

\begin{tabular}{llll}
\hline Difference Between Groups: & Model 1 & Model 2 & Model 3 \\
\hline Maintenance & .167 & -.215 & -.371 \\
& $(.67)$ & $(.54)$ & $(.54)$ \\
Pretest & - & $.490^{*}$ & $.497^{*}$ \\
& & $(.07)$ & $(.08)$ \\
Level (U/G) & - & - & 1.05
\end{tabular}




$\begin{array}{llll}\text { \#Years at UVA } & - & - & .583^{*} \\ & & & (.29) \\ \text { \#Reading Courses Taken } & - & - & -.180 \\ & & & (.77) \\ \text { Age 3 }(25+) & - & - & -.361 \\ & & & (.96) \\ \text { Age 1 (18-20) } & - & - & 1.668^{*} \\ & & & (.80) \\ \text { Major 1 (Elem) } & - & - & -.610 \\ & & & (.69) \\ \text { Major 2 (Sped) } & - & - & .439 \\ & & & (.84) \\ \text { Comfort Vocab Pre } & - & - & -.475 \\ & & & (.28) \\ \text { Comfort IVI Pre } & - & - & .050 \\ & & & (.29) \\ \text { Intercept } & & 15.07 & 14.29 \\ R^{2} & 24.37 & (1.36) & (2.20) \\ \text { Adjusted } R^{2} & . .478) & .343 & .318 \\ \text { Number of Observations } & .001 & .330 & 101 \\ & -.990 & 101 & \end{array}$

Note: Standard errors are reported in parentheses and represent robust standard errors (Huber White). $N=101$. * indicates significance at the 95\% level, $p<.05$.

Like posttest results, the simple regression analysis of Model 1 revealed that assigned treatment group did not significantly predict differences in maintenance scores, $b=.167, t(100)=.246, p=.806,95 \% \mathrm{CI}[-1.181,1.516]$. The regression coefficient $(B=$ .167) was not statistically significant, meaning there were no significant differences on maintenance scores between the reading and video group $(p=.806)$. The mean 
maintenance score of the treatment group was 24.37 and the mean score of the control group was only .167 points less at 24.54 .

Model 2 also shows no significant differences on maintenance scores between each group, $b=-.215, t(100)=-.386 p=.700,95 \%$ CI $[-1.318,0.889]$. Controlling for the pretest variable in Model 2, the mean difference in maintenance scores between the treatment and control group is -.215 . However, there were significant differences from the pretest scores to maintenance scores, $b=.190, t(100)=7.153, p<.01,95 \% \mathrm{CI}$ $[0.354,0.626]$. As we would suspect from the trend with posttest scores previously discussed, these results suggest that all participants significantly improved their knowledge from pretest to maintenance, but there is no treatment effect on groups.

Model 3, with all predictors added, also showed no significant differences between treatment groups on maintenance scores, $b=-.371, t(100)=-.666, p=.507$, 95\% CI [-1.478, 0.736]. Controlling for all variables in Model 3, the mean difference in maintenance scores between the treatment and control group is -.371. Although, like Model 2, Model 3 continues to show significant differences between pretest scores and maintenance scores, $b=.497, t(100)=6.57, p<.01,95 \%$ CI [0.347, 0.648], suggesting that everyone improved significantly from pretest to the maintenance test, which occurred three weeks after intervention. When adding covariates, the unstandardized coefficient for group decreased, but did not change much; treatment effects were robust to including all baseline covariates in the model. In addition, when controlling for all variables, Model 3 indicates a positive relationship between two baseline characteristics (i.e., Number of Years at UVA and Age 1) and the maintenance test outcome. 
A t-test comparing posttest to maintenance reveals no significant differences of scores between the posttest to the maintenance test given three weeks later: $t(100)=$ $1.744, \mathrm{p}=.084)$. The mean difference of all participants between posttest and maintenance is very slight: 0.45 points; the posttest mean was 24.91 and the maintenance mean was 24.45. Therefore, participants scored relatively the same (with a slight decrease in performance) from posttest to maintenance, suggesting they retained their knowledge three weeks after the intervention.

\section{Comfort Teaching Vocabulary}

Table 7 presents regression results that examined treatment group differences on a scale measuring anticipated comfort-level of teaching vocabulary to children after receiving the intervention. Model 1 revealed that assigned treatment group did not significantly predict differences in level of comfort teaching vocabulary, $b=-.168, t(100)$ $=-1.18, p=.240,95 \%$ CI $[-0.450,0.114]$. The mean level of comfort teaching vocabulary score of the treatment group was 4.60 (on a scale where 1 is not comfortable and 6 is the very comfortable) and the mean score of the control group was only .168 points less at 4.44 .

Table 7. Study 1 [Comfort Vocab]: Coefficients from the Regression of Comfort Teaching Vocabulary on Group

\begin{tabular}{llll}
\hline Difference Between Groups: & Model 1 & Model 2 & Model 3 \\
\hline Comfort Vocab Post & -.168 & -.172 & -.208 \\
& $(.14)$ & $(.13)$ & $(.12)$ \\
Comfort Vocab Pre & - & $.260^{*}$ & $.313^{*}$ \\
& & $(.07)$ & $(.08)$ \\
Comfort IVI Pre & - & - & $.163^{*}$
\end{tabular}


Level (U/G)

\#Years at UVA

\#Reading Courses Taken

Age $3(25+)$

Age 1 (18-20)

Major 1 (Elem)

Major 2 (Sped)

Intercept

$R^{2}$

Adjusted $R^{2}$

Number of Observations
-

.209

$-.024$

$-.134$

(.21)

.111

.145

.113

$.409 *$

3.59

3.08

(.28)

.135

.117

.238

.153

101

101

Note: Standard errors are reported in parentheses and represent robust standard errors (Huber White). $N=101$.

* indicates significance at the $95 \%$ level, $p<.05$.

Model 2 and Model 3 show coefficients did not change much when control covariates are added. Model 2 shows no significant differences on level of comfort teaching vocabulary between treatment groups, $b=-.172, t(100)=-1.28, p=.200,95 \%$ CI $[-0.438,0.093]$. However, there were significant differences between recorded level of comfort teaching vocabulary prior to the intervention and comfort level post intervention, $b=.260, t(100)=3.70, p<.01,95 \%$ CI [0.121, 0.399]. Similarly, Model 3 shows no significant differences on level of comfort teaching vocabulary between 
treatment groups, $b=-.208, t(100)=-1.56, p=.122,95 \%$ CI $[-0.472,0.057]$. Significant differences were found between level of comfort prior to intervention and post, $b=.313$, $t(100)=4.15, p<.01,95 \%$ CI $[0.163,0.463]$. Model 2 and 3 demonstrate that participant comfort level increased after intervention, regardless of being in the treatment or control group, and therefore regardless of the form of instruction provided. In addition, when controlling for all variables, Model 3 indicates significant positive relationship between the outcome of comfort teaching vocabulary and the following baseline characteristics: (a) level of comfort teaching vocabulary prior to the intervention (i.e., Comfort Vocab Pre), (b) level of comfort teaching IVI prior to the intervention (i.e., Comfort IVI Pre), and (c) participants majoring in special education (i.e., Major 2).

\section{Comfort Teaching Intensifying Vocabulary Intervention}

Table 8 shows regression results of comfort-level teaching the specific vocabulary intervention known as Intensifying Vocabulary Instruction (IVI) post intervention. Model 1 shows that treatment group did not significantly predict differences in level of comfort teaching IVI, $b=.240, t(100)=1.15, p=.249,95 \%$ CI $[-0.171,0.651]$. The treatment group mean level of comfort teaching IVI was 4.0 on a scale of 1 to 6 and the control group mean was just .24 points higher at 4.24.

Table 8. Study 1 [Comfort IVI]: Coefficients from the Regression of Comfort Teaching IVI on Group

\begin{tabular}{llll}
\hline Difference Between Groups: & Model 1 & Model 2 & Model 3 \\
\hline Comfort IVI Post & .240 & .263 & .247 \\
& $(.20)$ & $(.20)$ & $(.20)$ \\
Comfort IVI Pre & - & $.260^{*}$ & $.394^{*}$ \\
& & $(.09)$ & $(.09)$ \\
Comfort Vocab Pre & - & - & .120
\end{tabular}




\begin{tabular}{|c|c|c|c|}
\hline Level (U/G) & - & - & $\begin{array}{l}.085 \\
(.27)\end{array}$ \\
\hline \#Years at UVA & - & - & $\begin{array}{l}.136 \\
(.07)\end{array}$ \\
\hline \#Reading Courses Taken & - & - & $\begin{array}{l}.066 \\
(.27)\end{array}$ \\
\hline Age $3(25+)$ & - & - & $\begin{array}{l}.141 \\
(.29)\end{array}$ \\
\hline Age $1(18-20)$ & - & - & $\begin{array}{l}.783 * \\
(.29)\end{array}$ \\
\hline Major 1 (Elem) & - & - & $\begin{array}{l}-.117 \\
(.29)\end{array}$ \\
\hline Major 2 (Sped) & - & - & $\begin{array}{l}.145 \\
(.27)\end{array}$ \\
\hline Intercept & $\begin{array}{l}4.00 \\
(.14)\end{array}$ & $\begin{array}{l}3.59 \\
(.23)\end{array}$ & $\begin{array}{l}2.23 \\
(.57)\end{array}$ \\
\hline $\begin{array}{l}R^{2} \\
\text { Adjusted } R^{2} \\
\text { Number of Observations }\end{array}$ & $\begin{array}{l}.013 \\
.003 \\
101\end{array}$ & $\begin{array}{l}.058 \\
.038 \\
101\end{array}$ & $\begin{array}{l}.145 \\
.050 \\
101\end{array}$ \\
\hline
\end{tabular}

Note: Standard errors are reported in parentheses and represent robust standard errors (Huber White). $N=101$. * indicates significance at the $95 \%$ level, $p<.05$.

Model 2 and Model 3 show coefficients remained relatively the same after adding control covariates. Model 2 shows no significant differences on comfort level teaching IVI between groups, $b=.263, t(100)=1.29, p=.199,95 \%$ CI [-0.141, 0.667].

Significant differences were found between level of comfort teaching IVI prior to intervention and after the intervention, $b=.260, t(100)=2.14, p=.034,95 \%$ CI $[0.020$, 0.501]. Likewise, Model 3 shows no significant differences on level of comfort teaching IVI between treatment and control groups, $b=.247, t(100)=1.20, p=.233,95 \%$ CI [- 
$0.161,0.655]$. There are significant differences on level of comfort teaching IVI between pre and post intervention scores, $b=.394, t(100)=2.90, p<.01,95 \%$ CI $[0.124,0.663]$. In conclusion, regardless of treatment group, on average, all participants' level of comfort teaching IVI increased significantly from prior to after receiving intervention. In addition, when controlling for all variables, Model 3 indicates a significant positive relationship between the outcome of comfort teaching IVI and the following baseline characteristics: (a) comfort teaching IVI prior to the intervention (i.e., Comfort IVI Pre) and (b) participants who were between the ages of 18-20 (i.e., Age 1).

\section{Conclusion}

The results for all outcome measures (posttest, maintenance test, survey of comfort teaching vocabulary, and survey of comfort teaching IVI) are reported in Table 9. The most parsimonious and therefore optimal model for treatment effects is Model 2 because including the additional covariates in Model 3 did not greatly help or change coefficients. Coefficients and standard errors from simple regression analyses Model 2 are reported as well as t-statistics to examine treatment and control group differences on each outcome. Because $p$ values are all above .05 , it can be suggested that group assignment had no significant effect on any of the outcomes measured in Study 1. When we apply Bonferroni Correction for multiple outcomes, all outcomes still remain nonsignificant (where the adjusted alpha level is $.05 / 4=.0125$ ).

Table 9. Study 1 Unstandardized Regression for the Prediction of Outcome Scores from Group Assignment

\begin{tabular}{llllll}
\hline Group & $B$ & $\mathrm{SE}$ & $t$ & $p$ & $95.0 \% \mathrm{CI}$
\end{tabular}

Posttest

$-0.0840 .577$

$-0.1420 .885$

$-1.2551 .087$ 


$\begin{array}{lllllll}\text { Maintenance } & -0.215 & 0.543 & -0.386 & 0.693 & -1.318 & 0.889 \\ \text { Comfort Teaching Vocab } & -0.172 & 0.132 & -1.289 & 0.193 & -0.438 & 0.093 \\ \text { Comfort Teaching IVI } & 0.263 & 0.201 & 1.292 & 0.192 & -0.141 & 0.667\end{array}$

Note: $N=101$. Total possible points for Posttest and Maintenance test is 30. Total possible points for Comfort Teaching Vocabulary and Comfort Teaching IVI is 6.0. Each outcome reflects the model (i.e., Model 2) that controls for participant pretest scores. Standard errors are robust (Huber White).

\section{Results for Study 2: Teacher Practice}

The purpose of Study 2 was to look at the effects of treatment on actual teaching ability. Forty-nine preservice teachers were randomly assigned to one of two experimental groups. The conditions for each group were exactly the same as conditions in Study 1, including a video plus CAP group and a reading group. Unlike Study 1, Study 2 was an experimental posttest-only design. We assume there are no significant differences between groups prior to being given the intervention since participants were from the same academic course across two semesters and were randomly assigned. Additionally, Table 4 presents results from descriptive statistics, a t-test, and an Omnibus f-test holding three baseline covariates constant to look at potential differences among groups. Baseline covariates included (a) the number of years at the university, (b) major 1 (elementary), and (c) major 2 (special education). The means of each treatment group are very similar on each covariate: The mean number of years at the university for the video plus CAP group is 2.7 where the mean for the reading group is slightly higher, 3.04; the mean percent of those in the video group who are majoring in elementary education is $70 \%$ where the mean percent in the reading group majoring in elementary education is $68 \%$; and last, the mean percent of those in the video group majoring in 
special education is $25 \%$ where the mean percent in the reading group majoring in special education is $28 \%$. T-test $p$ values for each covariate are much higher than .05 , indicating that our assessment of similar group means was accurate, and that there were no significant differences between groups on any baseline covariate. A joint test of significance (Omnibus f-test) also showed no significant differences between treatment groups $(\mathrm{F}(48)=.792, p=.505)$.

Following the treatment intervention of either watching the video plus CAP or reading, each participant was observed teaching vocabulary once. They were instructed to teach vocabulary during storybook reading and to reinforce vocabulary in an afterreading activity. Therefore, there are three dependent variables that measure teacher practice, including (a) the percent of IVI practices used during reading, (b) the percent of IVI practices used after reading, and (c) the total IVI practices including both during and after reading. In addition, I measured participants' comfort level teaching vocabulary after intervention and assessed their vocabulary instructional knowledge using the same 30-item multiple-choice posttest used in Study 1. Simple regression procedures were conducted on each dependent variable. Adjusted or multiple regression procedures were not used due to the small sample size and lack of baseline covariate data collected.

\section{Percent of IVI Practices During Reading}

Simple regression procedures examined differences between groups in the percentage of practices associated with IVI used during a reading activity. The dependent variable was the percent of IVI practices during reading (\%during) and the treatment condition (group) was held constant. Table 10 presents results for all outcome measures from the regression and reports the coefficient and standard error on treatment 
effects among groups. The simple regression analysis revealed that the treatment group significantly predicted differences teaching during reading, $b=.131, t(48)=3.675, p<$ $.01,95 \%$ CI $[0.059,0.203]$. The mean difference in outcome scores between the treatment and control group is .131. The group of preservice teachers who watched the video plus CAP used significantly more evidence-based practices during their vocabulary lesson than preservice teachers who read the same content. The mean percent of evidence-based practices during reading lessons for the video plus CAP group was significantly higher $(M=.83$, or $83 \%)$ than the reading group $(M=.70$, or $70 \%)$. Therefore, the video plus CAP group scored on average 13\% higher than the reading group. When we apply Bonferroni Correction for multiple outcomes, the three practicerelated outcomes (i.e., \% During, \% After, and \% Total) still remain significant (where the adjusted alpha level is $.05 / 5=.01)$.

Table 10. Study 2 [All Outcomes] Coefficients from the Regression of Post-Outcomes on Group

Difference Between Groups: $\quad B(\mathrm{SE}) \quad N$

$\begin{array}{lll}\text { Comfort Teaching Vocab } & \begin{array}{l}0.000 \\ (0.28)\end{array} & 48 \\ & \begin{array}{l}0.208 \\ (0.95)\end{array} \\ \text { Posttest } & 0.131^{*} & 48 \\ & (0.03) & 49 \\ \text { \% During } & 0.194^{*} & \\ & (0.04) & 47 \\ \text { \% After } & 0.174^{*} & \\ & (0.03)\end{array}$

Note: Standard errors are reported in parentheses. 
* indicates significance at the 95\% level, $p<.01$ (Bonferroni Correction, .05/5=.01).

\section{Percent of IVI Practices After Reading}

Like the during-reading portion of the vocabulary lesson, a regression analysis of the percent of IVI practices demonstrated during the after-reading activity revealed significant differences among groups. The group assignment significantly predicted teaching differences after reading, $b=.194, t(46)=4.5, p<.01,95 \%$ CI $[0.107,0.281]$. The mean difference in outcome scores between the treatment and control group is .194. It should be noted that two participants did not include an after-reading activity during their vocabulary instruction; therefore, the number of participants for this outcome measure decreased from $N=49$ to $N=47$. This issue of attrition is further discussed in the next section as it affects results of both the percent of EBPs after reading and total. The group of preservice teachers who watched the video plus CAP used significantly more IVI practices during the after-reading activity portion than preservice teachers who read the same content. The mean percent of IVI practices during reading lessons for the video plus CAP group was significantly higher $(M=.86$, or $86 \%)$ than the reading group $(\mathrm{M}=.66$, or $66 \%)$. Therefore, the video plus CAP group scored on average $19 \%$ higher than the reading group. Results for all outcome measures are reported in Table 10.

\section{Percent of IVI Practices Total (During + After)}

As would be expected from the results of the during-reading and after-reading portions of vocabulary lessons, participants in the video plus CAP group used significantly more IVI practices as a whole throughout the entire lesson than participants who read. Group assignment significantly predicted teaching outcomes of the entire vocabulary lesson, $b=.174, t(46)=4.83, p<.01,95 \% \mathrm{CI}[0.101,0.246]$. The mean 
difference in outcome scores between the treatment and control group is .174 . The mean percent of IVI practices used throughout the entire vocabulary lesson was significantly higher for the group who watched the video plus CAP $(\mathrm{M}=.85$, or $85 \%)$ than the group who read a script of the same content $(\mathrm{M}=.67$, or $67 \%)$. Overall, the video plus CAP group used an average of $17 \%$ more IVI-related practices than participants in the reading group.

\section{Attrition}

Previously mentioned, three participants did not complete all follow-up measures that were asked of them. Specifically, when asked to teach a vocabulary lesson post intervention, two participants taught vocabulary words during reading only, and did not include an after-reading activity. Therefore, two participants did not have scores for two post-intervention outcomes: Percent of IVI practices after reading and percent of IVI practices total. Each participant was assigned to a different group- one to the treatment and one to the control group. Both participants attended the university for three years and majored in education (one elementary and one special education). Their vocabulary posttest scores were very similar with only one point difference. Based on baseline covariate information, it is my assumption that these two participants are not very different from one another. Participant 1 was in the control group (reading) and scored $17 / 30$ on the vocabulary knowledge posttest, $67 \%$ IVI practices during reading, and declared feeling somewhat comfortable (level 3) on the comfort-teaching-vocabulary scale after the intervention. Participant 2 was in the treatment group (video plus CAP) and scored slightly higher than Participant 1 , with a score of $18 / 30$ on the vocabulary knowledge posttest, 78\% IVI practices during reading, and indicated comfortable (level 
4) on the comfort-teaching-vocabulary scale post intervention. Table 11 shows each participant's baseline covariate and outcome scores compared to the mean of their treatment group. Participant 1 and 2 scored lower than the average of their assigned groups on three outcomes: Posttest, percent of IVI practices used during reading, and comfort teaching vocabulary.

Table 11. Study 2 Attrition Participant Comparisons with Means of Group

\begin{tabular}{|c|c|c|c|c|c|c|}
\hline & Group & Major & \#Yrs & Posttest & \% During & ComfortVocab \\
\hline Participant 1 & Read & Sped & 3.0 & 17.00 & $67 \%$ & 3.00 \\
\hline Read Group Means & & & 3.0 & 23.29 & $70 \%$ & 4.54 \\
\hline Participant 2 & Video & Elem & 3.0 & 18.00 & $78 \%$ & 4.00 \\
\hline Video Group Means & & & 2.7 & 23.50 & $83 \%$ & 4.54 \\
\hline
\end{tabular}

Note: Posttest maximum possible score is 30 points. Level of comfort teaching vocabulary ranged from 1 to 6 with 6 being the most comfortable. \#Yrs = The number of years at the university; \% During $=$ The percentage of evidence-based vocabulary practices used during storybook reading; ComfortVocab $=$ Comfort level teaching vocabulary on a scale from 1-6.

Additionally, a third participant completed all vocabulary lesson parts, but did not complete the vocabulary posttest or the comfort-teaching-vocabulary scale. Table 12 compares regression results with the full sample (i.e., with attrition) to regression results after eliminating participants with missing outcome data (i.e., without attrition). The coefficients are very similar with participant data removed, and the same outcomes are statistically significant. Since there are not huge differences between regression analyses with and without attrition, the fact that these participants did attrite does not have a great effect on results. The people who had attrition are not really that different from the 
people who remained in the sample completely, and therefore do not seem to be driving results in one way or another.

Table 12. Study 2: Comparison of Regression Results with Attrition and Without Attrition

\begin{tabular}{llllll}
\hline Group & $N$ & $B$ & $\mathrm{SE}$ & $p$ & $\mathrm{R}^{2}$ \\
\hline $\begin{array}{c}\text { \% During } \\
\text { With Attrition }\end{array}$ & 49 & 0.131 & 0.03 & $0.001^{*}$ & 0.223 \\
$\quad$ Without Attrition & 46 & 0.140 & 0.03 & $0.000^{*}$ & 0.246
\end{tabular}

Note: This table shows a comparison of results from the full sample including three participants with missing data (i.e., With Attrition) and results after eliminating the three participants with missing data (i.e., Without Attrition).

\section{Vocabulary Posttest}

Participating preservice teachers in Study 2 were given the same 30-item multiple-choice posttest that was given in Study 1 to assess knowledge of vocabulary instruction. Paralleling results of Study 1, there were no significant differences between groups on the vocabulary posttest, $b=.208, t(47)=.218, p<.829,95 \% \mathrm{CI}[-1.717$, 2.134]. This finding is also evident from examining the means of each group on the posttest; video plus CAP $M=23.5$; reading $M=23.3$. The video plus CAP group scored an average of .2 points higher than the reading group.

\section{Comfort Teaching Vocabulary}

Following the intervention, participants were asked on a scale of 1 through 6 , with 6 being very comfortable, how comfortable they felt teaching vocabulary to a future group of students. There were no significant differences between groups on the measure of comfort, $b=.000, t(47)=.000, p<1.0,95 \%$ CI $[-0.581,0.581]$. The average of both groups was the same $(M=4.5)$ indicating that regardless of treatment intervention, on average participants felt moderately comfortable teaching vocabulary. 


\section{Correlation Between Knowledge and Practice}

Pearson Correlation was weak between posttest and the total number of evidencebased practices used in a vocabulary lesson $(r=.226)$. The weak correlation indicates that test performance, or demonstration of vocabulary instruction knowledge, does not predict teaching ability or use of evidence-based practices.

\section{Conclusion}

The results for all outcome measures of Study 2 (Comfort Teaching Vocabulary, Posttest, \% During, \% After, and \% Total) are reported in Table 13. Coefficients and standard errors from simple regression analyses are reported as well as t-statistics to examine treatment and control group differences on each outcome. The $p$ values indicate no significant differences between treatment groups on the level of comfort teaching vocabulary and on the vocabulary knowledge posttest. However, there were significant differences between treatment and control group on the number of IVI practices used teaching a vocabulary lesson $(p<.001)$ during each part of the lesson- during reading, after-reading, and total.

Table 13. Study 2 [All Outcomes] Simple Regression Analyses and t-statistics

\begin{tabular}{lllllll}
\hline Group & $B$ & SE & $t$ & $p$ & $95.0 \%$ CI \\
\hline Comfort Vocab & 0.000 & 0.288 & 0.000 & 1.000 & -0.581 & 0.581 \\
Posttest & 0.208 & 0.956 & 0.218 & 0.829 & -1.717 & 2.134 \\
\% During & 0.131 & 0.036 & 3.675 & $0.001^{*}$ & 0.059 & 0.203 \\
\% After & 0.194 & 0.043 & 4.500 & $0.000^{*}$ & 0.107 & 0.281 \\
\% Total & 0.174 & 0.036 & 4.825 & $0.000^{*}$ & 0.101 & 0.246 \\
\hline
\end{tabular}

Note: $N=49 .{ }^{*} p<.01$ (Bonferroni Correction of $.05 / 5=.01$ ) 
To further investigate observed group differences and determine which groups significantly outperformed the others on each outcome measure, a Bonferroni Correction was used to control for a Type 1 error using five comparisons, or five outcome measures (e.g., Comfort Teaching Vocab, Posttest, $\%$ During, $\%$ After, and $\%$ Total; $a=.05 / 5=$ $.01)$. Three outcomes remain significant with $p$ values less than .01: $\%$ During, $\%$ After, and $\%$ Total. Therefore, with $99 \%$ confidence, we have $1 \%$ probability that our findings were due to chance and not treatment; we are confident that vocabulary instruction differences were attributed to the treatment. Given non-significant differences on baseline covariates (e.g., number of years at the university, major 1, and major 2) and using two cohorts taking the same education course, the observed teaching differences between treatment and control group can be attributed to the video plus CAP intervention.

\section{Summary of Results for Study 1 and Study 2}

Table 14 presents a summary of overall regression results that look for group differences for both Study 1 and Study 2. In summary, regression results from Study 1 and Study 2 indicate no significant differences between treatment and control groups on knowledge of vocabulary instruction as measured by the multiple-choice posttest and maintenance test (see Table 14). Additionally, both studies showed no significant differences between groups on the level of comfort teaching vocabulary or teaching the specific practice of Intensifying Vocabulary Intervention. The only significant differences between groups were found in Study 2 results on the outcomes that looked at actual teaching ability (e.g., \% During, \% After, and \% Total). Preservice teachers who 
were assigned to watch the video plus CAP, used significantly more IVI practices during vocabulary instruction than preservice teachers who read the same content.

To help interpret practical significance, I calculated effect sizes for each outcome by dividing the beta coefficient by the standard deviation of the control group for each corresponding outcome. In Study 2, the treatment group scored 0.07 standard deviations larger than the control group on the outcome measure of percentage of IVI practices during reading (i.e., \% During); 0.03 standard deviations more than the control group on the outcome measure of percentage of IVI practices after-reading (i.e., \% After); and 0.02 standard deviations more than the control group on the outcome of total IVI practices (i.e., \% Total). Effect sizes are small despite statistical significance on these outcome measures for Study 2; the practical significance of these small effect sizes is discussed further in section V. Study 1 effect sizes are very small (three effect sizes are negative), as is expected with no significant differences between groups on each outcome.

However, Study 1 did have a larger effect size for the level of comfort teaching IVI post intervention (i.e., Comfort Teaching IVI) indicating that the treatment group scored .28 standard deviations larger than the control group. Regardless, there were no significant differences at the Bonferroni correction level $(p<.01)$.

Table 14. Summary of Results from Study 1 and Study 2

\begin{tabular}{llll}
\hline Treatment (Group) & $B$ & $S E$ & ES
\end{tabular}

Posttest

Study 1

Study 2

Maintenance

Study 1

Study 2

$\begin{array}{lll}-0.084 & 0.577 & -0.024 \\ 0.208 & 0.956 & 0.059\end{array}$

$-0.215$

0.543

$-0.059$ 
Comfort Teaching Vocab

Study 1

Study 2

Comfort Teaching IVI

Study 1

Study 2

\% During

Study 1

Study 2

$\%$ After

Study 1

Study 2

$\%$ Total

Study 1

Study 2
$-0.172$

0.000

0.132

0.288

$-0.258$

0.000

0.263

0.201

0.280

-

$0.131^{*}$

0.036

0.068

$-$

$0.194 *$

0.043

0.032

Note: * indicates significance at the $p<.05$ level and the Bonferroni Correction level of $p<.01$. Beta Coefficients, Standard Errors, and Effect Sizes reported from Study 1 are taken from Model 2 that adjusted for pretest scores. Effect Sizes were calculated by dividing regression coefficients by the standard deviation of the control group.

Therefore, video plus CAPs, created according to Mayer's Cognitive Theory of Multimedia Learning (CTML, 2009) and Brunvand's video production guidelines, can be suggested to enhance teaching ability regarding vocabulary instruction for struggling readers. These findings have important implications to inform future practice as it relates to the development and implementation of instructional technology materials to promote preservice teacher learning of how to teach all students, including students with disabilities. In addition, the results support that Mayer's theoretical model (Mayer, 2001, 2005,2009 ), attention to the cognitive load theory to develop automaticity (Feldon, 2007), and Brunvand's guidelines, may be valid methods to guide production of multimedia instructional materials in this domain. 


\section{CHAPTER V}

\section{DISCUSSION}

The purpose of this study was to evaluate the effects of a multimedia-based instructional tool (video plus CAPs) designed to deliver an evidence-based vocabulary intervention to teacher candidates. Specifically, I measured the effects of video plus CAPs as a teacher education tool on knowledge and teaching ability. This study was needed given the overall poor performance of youth with learning disabilities on measures of reading proficiency, lack of high quality vocabulary instruction occurring in early grades, and the gap in empirical literature on multimedia instruction based on theories of learning to improve vocabulary instruction.

\section{Conclusions}

Study results support the use of video plus CAP as an effective tool to support preservice teacher use of an evidence-based vocabulary intervention. Several conclusions can be drawn from this study with regard to (a) teacher knowledge, (b) comfort teaching, (c) teaching ability, and (d) the advance of research and theory in this domain.

\section{Teacher Knowledge}

Both studies indicated that treatment assignment had no significant effect on teacher knowledge post intervention. Preservice teachers in the treatment group (video plus CAP) did not statistically outperform those in the control group (reading) on the posttest or maintenance test. Significant differences from pretest to posttest indicated 
that all preservice teachers improved their knowledge, regardless of treatment. Therefore both instructional methods--video plus CAP and the reading--can be suggested as effective tools to improve knowledge of effective vocabulary instruction. Additionally, there were no significant group differences from the posttest to the maintenance test, indicating that all participants retained their knowledge weeks after the intervention, regardless of treatment.

The lack of significant differences between the treatment and control conditions is surprising given the research on CAPs and preservice-teacher knowledge to date (Kennedy et al., 2011; Kennedy et al., 2012; Kennedy \& Thomas, 2012; Kennedy et al., 2012). A potential explanation is that the reading was created based on the video plus CAP; it is possible that principles of Mayer's CTML (2009) were embedded in the reading unintentionally. The reading was relatively brief (4 pages), narrowly focused on the topic at hand, and detailed, including scripts of what the teacher should say during each part of the vocabulary lesson. Therefore, though the purpose of the control group was to replicate "typical" instruction given to preservice teachers, it is possible that this reading was much more concise and focused than typical articles and readings provided in teacher education.

Another possible reason why we did not see significant differences between reading and video plus CAP groups on tests of knowledge, is that both instructional formats provided some aspects that teacher education experts recommend. Specifically, in addition to understanding the meanings of reading-related terms, preservice teachers need to know how such components work together and how to explicitly and systematically teach them (Lyon \& Weiser, 2009). With the reading treatment, I aimed 
to accomplish this by including information about vocabulary instruction, as well as written scripts of brief lessons to teach various vocabulary strategies. The video accomplished this by teaching about vocabulary instruction (through CAP) and showing how to actually teach strategies (through video modeling). Additionally, both methods communicated recent research findings that support the vocabulary strategies disseminated (Cunningham et al., 2009). In summary, learning about vocabulary instruction as demonstrated on multiple choice tests, can occur from the multimedia tool, video plus CAP, and a more traditional instructional reading of an informational packet created based on the corresponding video plus CAP.

\section{Comfort Teaching}

Though both Study 1 and Study 2 indicated that all participants' comfort level improved after treatment, there were no significant differences on levels of comfort between the treatment and control groups. Comfort teaching the specific practices of IVI, as measured by Study 1, was also not statistically different between groups. Therefore, like the previous conclusions regarding knowledge, both intervention methods can be suggested as ways to improve the comfort that preservice teachers report feeling about teaching vocabulary.

Past research indicates that increased knowledge of teaching reading results in feelings of better preparedness to teach reading (Al Otaiba \& Lake, 2007). The current research findings show that all preservice teachers improved knowledge of effective vocabulary instruction, and in turn all improved their level of comfort to teach vocabulary. However, such improvements do not necessarily result in improved 
teaching; preservice teachers need to learn how to translate such knowledge into practice in authentic ways (Brownell et al., 2009).

\section{Teacher Practice}

Unlike conclusions regarding teacher knowledge and comfort teaching, there were significant differences in teaching ability between treatment groups post intervention. On all three measures (\% During, \% After, and \% Total), the preservice teachers who watched the video plus CAP used significantly more IVI-related practices than those who read the same content. With just one 30-minute viewing of a video plus CAP, preservice teachers learned to use an average of $88 \%$ IVI practices, compared to the preservice teachers in the reading group who used an average of $67 \%$ IVI practices. These findings indicate that a CAP paired with video modeling that follows Brunvand's (2010) video production guidelines, serves as an effective way to teach how to implement practices that are associated with an evidence-based intervention.

These results align with previous research suggesting that, when taught new instructional strategies, teachers may need to be provided with (a) models of authentic, practical, and concrete practices (Denton, Vaughn, \& Fletcher, 2003; Richards \& Skolits, 2009), (b) opportunities for active learning (Gordon, 2004; Scanlon, Shumaker, \& Deshler, 1994), and (c) evidence of strategy success (e.g., understanding the theory behind the strategy; Richards \& Skolits, 2009). Different from the reading on vocabulary instruction, the video plus CAP tool showed a real teacher modeling effective strategies. Additionally, preservice teachers were given an opportunity to actually try the strategy with children (i.e., active learning). These results are promising and important given the 
need to improve teacher use of evidence-based vocabulary instruction, and the need to find teacher education methods that help translate research into practice.

\section{Overall Conclusions on Knowledge and Practice}

These findings extend previous research (Bos, Mather, Narr, \& Babur, 1999; Brownell et al., 2009; Carlisle, Kelcey, Rowan, \& Phelps, 2011; Carlisle, Correnti, Phelps, \& Zeng, 2009) that found improved knowledge did not directly correlate to improved classroom practice. To illustrate their point, a special education teacher who completed required coursework and licensing exams (and did very well on both) will not necessarily be able to translate knowledge of explicit vocabulary instruction into daily practice, and therefore will not be useful to a student with oral language deficits. With that said, in order for the special education teacher to provide effective practices, he/she does need a solid understanding of definitions, theories, and practices related to reading (Moats, 2009).

The results from this study are important, as Brownell et al. (2009) indicates that teachers need opportunities to situate content knowledge in the task of teaching (i.e., engaged knowledge). Previous research on CAPs (Kennedy et al., 2011; Kennedy \& Thomas, 2012; Kennedy, Ely, et al., 2012; Kennedy, Driver, et al., 2013; Kennedy, Thomas, et al., 2014) demonstrates that CAPs are effective for improving teacher knowledge, and some application of skill in non-teaching situations. The present study extends this line of research by adding the video component, and a better test of skill application by sending participants into the field to implement newly learned strategies in face-to-face instruction with students. Therefore, the current research is the beginning of the necessary bridge between knowledge and practice by incorporating an opportunity for 
preservice teachers to develop engaged knowledge (Phelps \& Schilling, 2004). To illustrate, with one 30-minute viewing of a video plus CAP, preservice teachers significantly improved knowledge of vocabulary instruction and used significantly more IVI practices than the group of peers who read about the same content. Specifically, the video plus CAP group used a total of $88 \%$ IVI practices whereas the reading group used $67 \%$ IVI practices.

It is likely that the video plus CAP group demonstrated certain behaviors significantly more than the reading group because they were able to see a model of a teacher using the practices they were expected to implement. Just as modeling strategies is effective for school-aged children (e.g., Mercer \& Pullen, 2011), modeling for teachers may be an effective method for teaching pedagogical strategies. For example, take the behavior of introducing the storybook prior to reading. The video plus CAP group was able to see an example of questions a teacher might ask or ways to ignite prior knowledge and help children relate to the story, whereas the reading group did not directly observe examples. It appears that the reading group experienced more difficulty (a) providing explicit definitions of target words, (b) reading definitions of target words in the sentence in place of the target word, and (c) asking students to repeat the words. It is probable, and expected based on Bandura's social cognitive theory (1977), that the reading group may have had more difficulty implementing behaviors because they did not see examples of teacher behaviors in action. Another possibility is that preservice teachers in the video plus CAP group learned and recalled more teaching behaviors due to the CAP, which was created following Mayer's CTML (2009) and designed to reduce cognitive load with a means to promote optimal learning. 
Some IVI behaviors may have proved easier to demonstrate than others, and therefore not necessitate seeing a model. For example, both groups consistently exhibited several IVI practices including (a) chose a word-rich story, (b) choose appropriate target words, (c) choose an appropriate number of words to teach, (d) identify target words before reading, (e) read story throughout, (f) use definitions with words students understand, and $(\mathrm{g})$ be encouraging and enthusiastic throughout. Reading about each of these behaviors proved as beneficial as watching video plus CAP. For behaviors that are focused on implementation (i.e., actual teaching and not planning for instruction), and perhaps more difficult to implement, seeing a model led to increased use of effective practices.

\section{Connections with Theory}

Results of this study related to teacher practice indicate that automaticity of practice (Feldon, 2007) may be facilitated via the video plus CAP intervention. Previous research using CAPs did not explicitly pair with video models to support inservice teacher implementation of evidence-based interventions. This study provides preliminary evidence that when a CAP is paired with video modeling that follows Brunvand's (2010) video production guidelines teacher instruction can improve. Therefore, results support that Mayer's CTML (2009), attention to the cognitive load theory to develop automaticity (Feldon, 2007), and Brunvand's guidelines may be valid methods to guide production of multimedia instructional materials in this domain. Results relating to teacher practice provide preliminary evidence that incorporating theories of learning with multimedia instruction in the form of a CAP and video modeling can improve teacher candidate use 
of evidence-based interventions and therefore improve readiness to teach various learners.

In relation to teacher knowledge and teacher comfort, it seems that tying theories of learning and multimedia design to the video plus CAP tool did not seem to make a difference in posttest performance. However, the control group's reading was created based on the video plus CAP to ensure both groups were given equivalent information. Therefore, it is possible that the reading contained some principles to reduce cognitive load (e.g., eliminating extraneous information). Regardless, the reading contained less attention to principles of cognitive learning and multimedia learning than the video plus CAP; therefore we conclude that attention to learning and multimedia theories improves knowledge and comfort teaching, but not to a greater degree than a reading that does not intentionally include such theories.

\section{Limitations}

Findings should be viewed with caution for several reasons. First, although an experimental design was used, only 101 preservice teachers participated in Study 1 and only 49 participated in Study 2. Although these numbers are not far from reasonable in social science research, the participants were enrolled in one university and therefore represent a potentially homogeneous group. Due to these reasons, the generalizability of results is limited. Related, the regression model with all baseline covariates (i.e., Model 3) for Study 1 indicated imbalances between the treatment and control group despite randomization. However, because there were no significant differences on posttest outcomes for Study 1, group differences do not greatly affect results. Furthermore, 
descriptive statistics (see Table 2) further show no significant differences between groups.

Second, the researchers created the tests of knowledge and comfort used in this study. Standardized measures of evidence-based vocabulary instruction knowledge for primary grades do not exist, and therefore were not an option for use in this study. Additionally, the tests consisted of only 30 items. Though the test was piloted with a group of preservice teachers enrolled at a different university to ensure items were not too easy or too difficult, Carlisle and colleagues $(2011 ; 2009)$ have criticized researchercreated instruments in this field. Future research would benefit from Carlisle and colleagues' suggestions on how to improve measurement precision.

Third, though there were significant differences between groups on outcome measures that examined teacher practice, the low effect sizes for each related outcome pose a question about practical significance. There is a lack of comparative literature that examines video modeling to teach use of effective practices. It is possible that the treatment did not have a big effect because the treatments were not very different. Specifically, the content between the video plus CAP and the reading was very similar, both including the matching scripts and parallel information. Regardless, I trust video plus CAP to hold practical importance for teacher education efforts for two reasons: (a) there were statistically significant differences between treatment groups on outcomes related to teacher practice, and (b) the treatments cost zero dollars to produce.

Fourth, Study 1 and parts of Study 2 were conducted online. The purpose of providing tests and attention to intervention online was to appeal to busy undergraduate students and ensure high participant recruitment. Students were asked to follow the 
university's honor code and were given clear directions on how to complete each task, in an attempt to create a controlled environment as much as possible given the online circumstances. Additionally, tests had a time limit to avoid students taking time to refer back to intervention. Though I am confident that my explicit directions eliminated distractions and opportunities for cheating, when assignments are given online, these risks are possible.

Last, although percent agreement on observations of teaching in Study 2 was high (0.85), only $20 \%$ of the total observations were coded for inter-scorer agreement. In addition, according to Kappa (Cohen, 1960) calculations, three of the ten observations had poor agreement. Though the majority ( $70 \%)$ of double-coded observations scored excellent to fair agreement, results should be viewed with caution due to reliability limitations. The measurement of reliability would have been better had multiple researchers coded a higher percentage of observations, and if the IOA was higher. A potential reason that the IOA was not higher is due to the relative subjectivity of certain observation items. Specifically, the second observer noted being uncertain at times as to what constituted a teacher using a specific practice. For example, one checklist item asked whether the preservice teacher "has children pronounce 2-4 target words prior to reading the story" and at times, the preservice teacher asked the student to pronounce the words, but without student compliance. This was one example when the second observer was unsure whether to mark "yes" or "no." More rigorous training on IVI and use of the IVI fidelity checklist could have avoided confusion, and potentially increased IOA.

\section{Implications}


Given the limited number of studies using multimedia-based methods to improve teacher vocabulary instruction, the implications of this study will hopefully spur ongoing scholarly investigations regarding ways to improve teacher education methods to support use of evidence-based practices with fidelity. Multimedia learning materials (e.g., video plus $\mathrm{CAP}$ ) based on sound learning theory and principles of instructional design provide a context for generalization that is often lacking in teacher education research (Kennedy, Thomas, et al., 2014). As the use of multimedia is studied, teacher education efforts should continue to incorporate instructional design features that support learning theories. Additionally, future research should closely measure design features, such as those used in this study, to support teacher cognition, learning, and automaticity of practice to verify they result in improvements in preservice teacher instruction when integrated with multimedia.

Future research could explore the use of video plus CAP in several ways. This research should be replicated with subject areas other than vocabulary instruction to determine the generalizability of the intervention. Second, it would be interesting to compare the video plus CAP tool to different instructional methods than the control used in this research (reading) to determine whether the tool results in significant improvements in knowledge compared to other "traditional" teacher education methods. Third, researchers should examine the effects of multiple viewings of video plus CAP to determine if teaching fidelity improves with more exposure; we do not yet have a clear indication of how much professional development is enough (Desimone, 2009). Preservice teachers demonstrated an average of $88 \%$ evidence-based vocabulary practices; though this percentage is high, it would be valuable to determine whether 
multiple viewings increase this percentage further. Fourth, researchers should examine the effects of a combination of the approaches compared, reading paired with video plus CAP, on preservice teacher learning and practice. Fifth, video plus CAP could be explored with other participant populations including inservice teachers and families to guide instruction at home. Sixth, including a coaching element with video plus CAP is an important next step; researchers (Kretlow, Cooke, \& Wood, 2011; Richards \& Skolits, 2009) found continuous on-site support and immediate feedback to be a contributing factor in teacher sustainability of evidence-based practices. Last, and most important, researchers should examine effects of video plus CAPs on student learning outcomes over time.

\section{Summary}

There is a compelling need to prepare teachers to use interventions supported with research to be effective for all students, including those who at risk for or with learning disabilities. This research is important to the field of teacher education and special education by adding to the collective knowledge base for designing and delivering effective teacher preparation methods. Video plus CAP may be an efficient method to communicate research-supported interventions to preservice teachers, and support implementation of new practices. This promising multimedia practice, based on theories of learning, deserves further experimental testing and implementation among teacher educators. 


\section{REFERENCES}

Adams, M. J., Bereiter, C., Brown, A., Campione, J., Carruthers, I., Case, R., et al. (2000). Open court reading. Columbus, $\mathrm{OH}$ : SRA.

Al Otaiba, S., \& Lake, V. E. (2007). Preparing special educators to teach reading and use curriculum-based assessments. Read Writ, 20, 591-617.

Baddeley, A. D. (1986). Working memory. Oxford, England: Oxford University Press.

Baker, S. K., Simmons, D. C., \& Kameenui, E. J. (1995). Vocabulary acquisition: Curricular and instructional implications for diverse learners (Technical Report No. 14). Eugene: University of Oregon, National Center to Improve the Tools of Educators.

Bandura, A. (1977). Social learning theory. New York, NY: General Learning Press.

Bandura, A. (1989). Human agency in social cognitive theory. American Psychologist, 9, 1175-1184.

Bandura, A. (1997). Self-efficacy: The exercise of control. New York, NY: W.H. Freeman.

Baumann, J. F., Edwards, E. C., Boland, E., Olejnik, S., \& Kame'enui, E. J. (2003). Vocabulary tricks: Effects of instruction in morphology and context on fifth-grade students' ability to derive and infer word meaning. American Educational Research Journal, 40, 447-494.

Baumann, J. F., Edwards, E. C, Font, G., Tereshinski, C. A., Kame’enui, E. J., \& Olejnik, S. (2002). Teaching morphemic and contextual analysis to fifth-grade students. Reading Research Quarterly, 37, 150-176.

Baumann, J. F., Kame'enui, E. J., \& Ash, G. E. (2003). Research on vocabulary instruction: Voltaire reduux. In J. Flood, D. Lapp, J. R. Squire, \& J. M. Jensen (Eds.), Handbook of research on teaching the English language arts $\left(2^{\text {nd }}\right.$ ed., pp. 752-785). Mahwah, NJ: Erlbaum.

Beck, I., \& McKeown, M. G. (1991). Conditions of vocabulary acquisition. In R. Barr, M. L. Kamil, P. Mosenthal, \& P. D. Pearson (Eds.), Handbook of reading research (Vol. 2, pp. 789-814). New York: Longman.

Beck, I. L., \& McKeown, M. G. (2001). Text Talk: Capturing the benefits of read-aloud 
experiences for young children. Reading Teacher, 55, 10-20.

Beck, I. L., \& McKoewn, M. G. (2007). Increasing young children's oral vocabulary repertoires through rich and focused instruction. Elementary School Journal, 107, 251-271.

Beck, I. L, McKeown, M. G., \& Kucan, L. (2002). Bringing words to life: Robust vocabulary instruction. New York: Guilford.

Biemiller, A. (2001). Teaching vocabulary. Early, direct, and sequential. American Educator, 25, 24-48.

Biemiller, A. (2003). Vocabulary: Needed if more children are to read well. Reading Psychology, 24, 323-335. doi: 10.1080/02702710390227297

Biemiller, A. (2005). Size and sequence in vocabulary development: Implications for choosing words for primary grade vocabulary instruction. In A. Hiebert \& M. Kamil (Eds.), Teaching and Learning vocabulary: Bringing research to practice (pp. 223-242). Mahwah, NJ: Erlbaum.

Biemiller, A. (2006). Vocabulary development and instruction: A prerequisite for school learning. In D. K. Dickinson \& S. B. Neuman (Eds.), Handbook of early literacy research, Vol. 2 (pp. 41-51). New York: Guilford.

Biemiller, A., \& Boote, C. (2006). An effective method for building vocabulary in primary grades. Journal of Educational Psychology, 98, 44-62.

Biemiller, A., \& SLonim, N. (2001). Estimating root word vocabulary growth in normative and advantaged populations: Evidence for a common sequence of vocabulary acquisition. Journal of Educational Psychology, 93, 298-520.

Birman, B., Le Floch, K. C., Klekorka, A., Ludwig, M., Taylor, J., Walters, K., et al. (2007). State and local implementation of the No Child Left Behind Act: Vol 2. Teacher quality under NCLB: Interim report. Washington, DC: U.S. Department of Education; Office of Planning, Evaluation and Policy Development; Policy and Program Studies Service.

Bishop, A. G., Brownell, M. T., Klinger, J. K., Leko, M. M., \& Galman, S. A. C. (2010). Differences in beginning special education teachers: The influence of personal attributes, preparation, and school environment on classroom reading practices. Learning Disability Quarterly, 33, 75-92.

Borko, H., Jacobs, J., Eiteljorg, E., \& Pittman, M. E. (2008). Video as a tool for fostering productive discussions in mathematics professional development. Teaching and Teacher Education, 24, 417-436. 
Bos, C. S., \& Anders, P. L. (1990). Effects of interactive vocabulary instruction on the vocabulary learning and reading comprehension of junior-high learning disabled students. Learning Disability Quarterly, 13, 31-42.

Bos, C. Mather, N., Dickson, S., Podhajski, B., \& Chard, D. (2001). Perceptions and knowledge of preservice and inservice educators about early reading instruction. Annals of Dyslexia, 51, 97-120.

Bos, C. S., Mather, N., Narr, R. F., \& Babur, N. (1999). Interactive, collaborative professional development in early literacy instruction: Supporting the balancing act. Learning Disabilities Research \& Practice, 14, 227-238.

Brady, S., Gillis, M., Smith, T., Lavalette, M., Liss-Bronstein, L., Lowe, E., North, W., Russo, E., \& Wilder, T. D. (2009). First grade teachers' knowledge of phonological awareness and code concepts: Examining gains from an intensive form of professional development and corresponding teacher attitudes. Read Writ, $22,425-455$.

Brabham, E. G., \& Lynch-Brown, C. (2002). Effects of teachers reading-aloud styles on vocabulary acquisition and comprehension of students in early elementary grades. Journal of Educational Psychology, 94, 465-473.

Bransford, J., Kinzer, C. K., Risko, V. J., Rowe, D., \& Vye, N. (1989). Designing invitations to thinking: Some initial thoughts. In S. McCormick, J. Zutell, P. L., Scharer, \& P. R. O'Keefe (Eds.), Cognitive and social perspectives for literacy research and instruction: Thirty-eighth yearbook of The National Reading Conference (Vol. 38, pp. 35-54). Chicago, IL: National Reading Conference.

Bransford, J., Brown, L., \& Cocking, R. C. (2000). How people learn: Brain, mind, experience, and school. Washington, DC: National Academy Press.

Brown, J. S., Collins, A., \& Duguid, P. (1989). Situated cognition and the culture of learning. Educational Researcher, 18, 32-42.

Brownell, M. T., Bishop, A. G., Gersten, R., Klinger, J. K., Penfield, R. D., Dimino, J., ... Sindelar, P. T. (2009). The role of domain expertise in beginning special education teacher quality. Exceptional Children, 75, 391-411.

Brownell, M. T., Ross, D. D., Colon, E. P., \& McCallum, C. L. (2005). Critical features of special education teacher preparation: A comparison with general teacher education. Journal of Special Education, 38, 242-253.

Brunvand, S. (2010). Best practices for producing video content for teacher education. Contemporary Issues in Technology and Teacher Education, 10, 247-256.

Brunvand, S., \& Fishman, B. (2006). Investigating the impact of the availability of 
scaffolds on preservice teacher noticing and learning from video. Journal of Educational Technology Systems, 35, 151-174.

Bryant, D. P., Goodwin, M., Bryant, B. R., \& Higgins, K. (2003). Vocabulary instruction for students with learning disabilities: A review of the research. Learning Disability Quarterly, 26, 117-128.

Carlisle, J. F., Correnti, R., Phelps, G., \& Zeng, J. (2009). Exploration of the contribution of teachers' knowledge about reading to their students' improvement in reading. Read Writ, 22, 457-486.

Carlisle, J. F., Kelcey, B., Rowan, B., \& Phelps, G. (2011). Teachers' knowledge about early reading: Effects on students' gains in reading achievement. Journal of Research on Educational Effectiveness, 4, 289-321.

Carpenter, T. P, Fennema, E., Peterson, P. L., Chiang, C. P., \& Loef, M. (1989). Using knowledge of children's mathematics thinking in classroom teaching: An experimental study. American Educational Research Journal, 26, 499-531.

Chandler, P., \& Sweller, J. (1991). Cognitive load theory and the format of instruction. Cognition and Instruction, 8, 293-332.

Chun, M. M., \& Jiang, Y. (1998). Contextual cueing: Implicit learning and memory of visual context guides spatial attention. Cognitive Psychology, 36, 28-71.

Cicchetti, D. V. (1994). Guidelines, criteria, and rules of thumb for evaluating normed and standardized assessment instruments in psychology. Psychological Assessment, 6, 284-290.

Clark, R. E. (2009). Translating research into new instructional technologies for higher education: The active ingredient process. Journal of Computers in Higher Education, 21, 4-18.

Clark, R. E., \& Estes, F. (2008). Turning research into results: A guide to selecting the right performance Solutions (2nd ed.). Greenwich Conn: Information Age Publishers.

Clewell, B. C., Campbell, P. B., \& Perlman, L. (2004). Review of evaluation studies of mathematics and science curricula and professional development models. Washington, DC: Urban Institute.

Cohen, J. (1960). A coefficient of agreement for nominal scales. Educational and Psychological Measurement, 20, 37-46.

Coltheart, M., \& Prior, M. (2007). Learning to read in Australia (Occasional Paper 1/2007) Acton: Academy of the Social Sciences in Australia. 
Cognition and Technology Group at Vanderbilt. (1990). Anchored instruction and its relationship to situated cognition. Educational Researcher, 19, 2-11.

Condus, M. M., Marshall, K. J., \& Miller, S. R. (1986). Effects of the keyword mnemonic strategy on vocabulary acquisition and maintenance by learning disabled children. Journal of Learning Disabilities, 19, 609-613.

Cook, B. G., \& Schirmer, B. R. (2003). What's special about special education: Overview and analysis. Journal of Special Education, 37, 200-205.

Coyne, M., McCoach, D. B., \& Kapp, S. (2007). Teaching vocabulary to kindergarten students at risk of reading difficulties: A comparison of rich instruction, basic instruction, and incidental exposure. Learning Disabilities Quarterly, 30, 74-88.

Coyne, M. D., McCoach, D. B., Loftus, S., Zipoli Jr., R., \& Kapp, S. (2009). Direct vocabulary instruction in kindergarten: Teaching for breadth versus depth. The Elementary School Journal, 110, 1-18.

Coyne, M., Simmons, D., Kame'enui, E., \& Stoolmiller, M. (2004). Teaching vocabulary during shared storybook readings: An examination of differential effects. Exceptionality, 12, 145-162.

Cradler, J., Freeman, M., Cradler, R., \& McNabb, M. (2002). Research implications for preparing teachers to use technology. Learning \& Leading with Technology, 30, 50-54.

Cunningham, A. E., Perry, K. E., Stanovich, K. E., \& Stanovich, P. J. (2004). Disciplinary knowledge of k-3 teachers and their knowledge calibration in the domain of early literacy. Annals of Dyslexia, 54, 139-167.

Cunningham, A. E., \& Stanovich, K. E. (1997). Early reading acquisition and its relation to reading experience and ability ten years later. Developmental Psychology, 33, 934-945.

Cunningham, A. E., Zibulsky, J., Stanovich, K. E., \& Stanovich, P. J. (2009). How teachers would spend their time teaching language arts. Journal of Learning Disabilities, 42, 418-430. Doi: 10.1177/0022219409339063

Darling-Hammond, L. (2010). Teacher education and the American future. Journal of Teacher Education, 61, 35-47.

DeFord, D. E. (1985). Validating the construct of theoretical orientation in reading instruction. Reading Research Quarterly, 20, 351-36.

DeLeeuw, K., \& Mayer, R. E. (2008). A comparison of three measures of cognitive load: 
Evidence for separable measures of intrinsic, extraneous, and germane load. Journal of Educational Psychology, 100, 223-224.

Denton, C. A., Vaughn, S., \& Fletcher, J. M. (2003). Bringing research-based practice in reading intervention to scale. Learning Disabilities Research \& Practice, 18, 201-211.

Desimone, L. M. (2009). Improving impact studies of teachers' professional development: Toward better conceptualizations and measures. Educational Researcher, 38, 181-199. Doi: 10.3102/0013189X08331140

Dieker, L. A., Lane, H. B., Allsopp, D. H., O’Brien, C., Butler, T. W., Kyger, M., Lovin, L., \& Fenty, N. S. (2009). Evaluating video models of evidence-based instructional practices to enhance teacher learning. Teacher Education and Special Education, 32, 180-196.

Dingle, M. P., Brownell, M. T., Leko, M. H., Boardman, A. G., \& Haager, D. (2011). Developing effective special education reading teachers: The influence of professional development, context, and individual qualities. Learning Disability Quarterly, 34, 87-103.

Dunn, L. M., \& Dunn, L. M. (1997). Peabody Picture Vocabulary Test-III. Circle Pines, $\mathrm{MN}$ : American Guidance Service.

Dymond, S. K., \& Bentz, J. L. (2006). Using digital videos to enhance teacher preparation. Teacher Education and Special Education, 29, 98-112.

Ebbers, S. M., \& Denton, C. A. (2008). A root awakening: Vocabulary instruction for older students with reading difficulties. Learning Disabilities Research \& Practice, 23, 90-102.

Egel, A. L., \& Barthold, C. H. (2010). Structural equation modeling. In G. R. Hancock, \& R. O. Mueller (Eds.), The reviewer's guide to quantitative methods in the social sciences (pp. 357-370). New York: Routledge.

Feldon, D. F. (2007). Cognitive load and classroom teaching: The double-edged sword of automaticity. Educational Psychologist, 42, 123-137.

Fleiss, J. L. (1981). Statistical methods for rates and proportions. NY: Wiley.

Friel, S. N., \& Carboni, L. W. (2000). Using video-based pedagogy in an elementary mathematics methods course. School Science and Mathematics, 100, 118-127.

Gersten, R., Vaughn, S., Deshler, D., \& Schiller, E. (1997). What we know about using research findings: Implications for improving special education practice. Journal of Learning Disabilities, 30, 466-476. 
Graves, M. F. (2006). Building a comprehensive vocabulary program. New England Reading Association Journal, 42, 1-7.

Graves, M. F., \& Silverman, R. (2010). Interventions to enhance vocabulary development. In A. McGill-Franzen \& R. L. Allington (Eds.), Handbook of reading disability research (pp. 315-325). New York, NY: Routledge.

Gomez, L. M., Sherin, M. G., Griesdorn, J., \& Finn, L. (2008). Creating social relationships: The role of technology in preservice teacher preparation. Journal of Teacher Education, 59, 117-131. Doi: 10.1177/0022487107314001

Grossman, P. (2005). Research on pedagogical approaches in teacher education. In M. Cochran-Smith \& K. M. Zeichner (Eds.), Studying teacher education: The report of the AERA panel on research and teacher education (pp. 425-476). Mahwah, NJ: Lawrence Erlbaum.

Grossman, P. (2008). Responding to our critics: From crisis to opportunity in research on teacher education. Journal of Teacher Education, 59, 10-23.

Haladyna, T. M., Downing, S. M., \& Rodriguez, M. C. (2002). A review of multiplechoice item-writing guidelines for classroom assessment. Applied Measurement in Education, 15, 309-334.

Hammerness, K., Darling-Hammond, L., Grossman, P., Rust, F., \& Shulman, L. S. (2005). The design of teacher education programs. In L. Darling-Hammond \& J. Bransford (Eds.), Preparing teachers for a changing world. San Francisco, CA: Jossey-Bass.

Hart, B., \& Risley, T. R. (1995). Meaningful differences in the everyday experience of young American children. Baltimore: P.H. Brookes.

Hazenberg, S., \& Hulstijn, J. H. (1996). Defining a minimal receptive second-language vocabulary for non-native university students: An empirical investigation. Applied Linguistics, 17, 145-163.

Heilesen, S. B. (2010). What is the academic efficacy of podcasting? Computers \& Education, 55, 1063-1068. Doi: 10.1016/j.compedu.2010.05.002

Heward, W. L. (2003). Ten faulty notions about teaching and learning that hinder the effectiveness of special education. The Journal of Special Education, 26, 186-205.

Hirsch, E. D. (2003). Reading comprehension requires knowledge-of words and the world: Scientific insights into the fourth-grade slump and the nation's stagnant comprehension scores. American Educator, 27, 10-29, 44. 
Jitendra, A. K., Edwards, L. L. Sacks, G., \& Jacobson, L. A. (2004). What research says about vocabulary instruction for students with learning disabilities. Exceptional Children, 70, 299-322.

Johnson, G., Gersten, R., \& Carnine, D. (1987). Effects of instructional design variables on vocabulary acquisition of LD students: A study of computer-assisted instruction. Journal of Learning Disabilities, 20, 206-213.

Jones, M. L. (2009) A study of novice special educators' views of evidence-based practices. Teacher Education and Special Education, 32, 101-120. doi:10.1177/0888406409333777

Joshi, R. M., Binks, E., Hougen, M., Dahlgren, M. E., Ocker-Dean, E., \& Smith, D. L. (2009). Why elementary teachers might be inadequately prepared to teach reading. Journal of Learning Disabilities, 42, 392-402.

Justice, L. M., Meier, J., \& Walpole, S. (2005). Learning new words from storybooks: An efficacy study with at-risk kindergarteners. Language, Speech, and Hearing Services in Schools, 36, 17-32.

Kelcey, B. (2011). Assessing the effects of teachers' reading knowledge on students' achievement using multilevel propensity score stratification. Educational Evaluation and Policy Analysis, 33, 458-482.

Kennedy, M. (1998). Form and substance of inservice teacher education (Research Monograph No. 13). Madison : University of Wisconsin-Madison, National Institute for Science Education.

Kennedy, M. J., \& Deshler, D. D. (2010). Literacy instruction, technology, and students with learning disabilities: Research we have, research we need. Learning Disability Quarterly, 33, 289-298.

Kennedy, M. J., Deshler, D. D., \& Lloyd, J. W. (2013). Effects of multimedia vocabulary instruction on adolescents with learning disabilities. Journal of Learning Disabilities,

Kennedy, M. J., Driver, M. K., Pullen, P. C., Ely, E., \& Cole, M. T. (2013). Improving teacher candidates' knowledge of phonological awareness: A multimedia approach. Computers \& Education, 64, 42-51. doi:10.1016/j.compedu.2013.0.1.010

Kennedy, M. J., Ely, E., Thomas, C. N., Pullen, P. C., Newton, J. R., Ashworth, K., Cole, M. T., \& Lovelace, S. P. (2012). Using multimedia tools to support teacher candidates' learning. Teacher Education and Special Education, 35, 243-257.

Kennedy, M. J., Hart, J. E., \& Kellems, R. O. (2010). Using enhanced podcasts to 
augment limited instructional time in teacher preparation. Teacher Education and Special Education, 34, 87-105.

Kennedy, M. J., Newton, J. R., Haines, S. J., Walther-Thomas, C. S., \& Kellems, R. O. (2012). A triarchic model for teaching introduction to special education : case studies, content acquisition podcasts, and effective feedback. Journal of Technology and Teacher Education, 20, 251-275.

Kennedy, M. J., \& Thomas, C. N. (2012). Effects of content acquisition podcasts to develop preservice teachers' knowledge of positive behavioral interventions and supports. Exceptionality, 20, 1-19.

Kent, A. M., \& Simpson, J. L. (2010). Interactive videoconferencing: Connecting theory to practice for preservice teachers. Journal of Digital Learning in Teacher Education, 27, 12-21.

Kersting, N. B., Givvin, K. B., Sotelo, F. L., \& Stigler, J. W. (2010). Teachers' analyses of classroom video predict student learning of mathematics: Further explorations of a novel measure of teacher knowledge. Journal of Teacher Education, 61, 172181. Doi: $10.1177 / 0022487109347875$

Klingner, J. K., Urbach, J., Golos, D., Brownell, M., \& Menon, S. (2010). Teaching reading in the $21^{\text {st }}$ century: A glimpse at how special education teachers promote reading comprehension. Learning Disability Quarterly, 33, 59-74. doi: $10.1177 / 073194871003300201$

Kirschner, P., Sweller, J., \& Clark, R. E. (2006). Why minimal guidance during instruction does not work: An analysis of the failure of constructivist, discovery, problem-based learning, experiential, and inquiry-based teaching. Educational Psychologist, 41, 75-86.

Klinger, J. K. (2004). The science of professional development. Journal of Learning Disabilities, 37, 248-255.

Klinger, J. K., Urbach, J., Golos, D., Brownell, M., \& Menon, S. (2010). Teaching reading in the $21^{\text {st }}$ century: A glimpse at how special education teachers promote reading comprehension. Learning Disability Quarterly, 33, 59-74.

Kosnik, C., \& Beck, C. (2008). We taught them about literacy but what did they learn? The impact of a preservice teacher education program on the practices of beginning teachers. Studying Teacher Education, 4, 115-128.

Kretlow, A. G., Cooke, N. L., \& Wood, C. L. (2012). Using in-service and coaching to increase teachers' accurate use of research-based strategies. Remedial and Special Education, 33, 348-361. doi:10.1177/0741932510395397

Ku, Y., \& Anderson, R. C. (2003). Development of morphological awareness in Chinese and 
English. Reading and Writing: An Interdisciplinary Journal, 16, 399-422.

Landrum, T. J., Cook, B. G., Tankersley, M., \& Fitzgerald, S. (2007). Teacher perceptions of the useability of intervention information from personal versus data-based sources. Education and Treatment of Children, 30, 27-42. doi:10.1353/etc.2007.0025

Landrum, T. J., \& Tankersley, M. (2004). Science in the schoolhouse : An uninvited guest. Journal of Learning Disabilities, 27, 207-212. doi:10.1177/00222194040370030401

Leko, M. B., \& Brownell, M. T. (2011). Special education preservice teachers' appropriation of pedagogical tools for teaching reading. Exceptional Children, 77, 229-251.

Leko, M. B., Brownell, M. T., Sindelar, P. T., \& Murphy, K. (2012). Promoting special education preservice teacher expertise. Focus on Exceptional Children, 44, 3-16.

Lerner, L. (2003). My psychoanalytic journey. Psychoanalytic Review, 90, 685-698.

Lessen, E., \& Sorensen, C. (2006). Change. Integrating, 38, 45-49.

Levine, A. (2006). Educating School Teachers. Washington, D.C.: Education Schools Project.

Loftus, S. M., Coyne, M. D., McCoach, D. B., Zipoli, R., \& Pullen, P. C. (2010). Effects of a supplemental vocabulary intervention on the word knowledge of kindergarten students at risk for language and literacy difficulties. Learning Disabilities Research \& Practice, 25, 124-136.

Lyon, G. R. (1997, September). NICHD research findings in learning disabilities. Washington, DC: Congressional Printing Office.

Lyon, G. R., \& Weiser, B. (2009). Teacher knowledge, instructional expertise, and the development of reading proficiency. Journal of Learning Disabilities, 42, 475480 .

Mastropieri, M. A., \& Scruggs, T. E. (1998). Constructing more meaningful relationships in the classroom: Mnemonic research into practice. Learning Disabilities Research \& Practice, 13, 138-145.

Mastropieri, M. A., Scruggs, T. E., \& Fulk, B. J. (1990). Teaching abstract vocabulary with the keyword method: Effects on recall and comprehension. Journal of Learning Disabilities, 23, 92-107.

Mastropieri, M. A., Scruggs, T. E., Levin, J. R., Gaffney, J., \& McLoone, B. (1985). Mnemonic vocabulary instruction for learning disabled students. Learning 
Disability Quarterly, 8, 57-63.

Mather, N., Bos., C., \& Babur, N. (2001). Perceptions and knowledge of preservice and inservice teachers about early literacy instruction. Journal of Learning Disabilities, 34, 472-482.

Mayer, R. (2001). Multimedia learning. Cambridge, UK: Cambridge University Press.

Mayer, R. (2004). Should there be a three-strikes rule against pure discovery learning? The case for guided methods of instruction. American Psychologist, 59, 14-19.

Mayer, R. E. (2009). Multi-media learning: Second edition. New York, NY: Cambridge.

Mayer, R. E. \& Johnson, C. I. (2008). Revising the redundancy principle in multimedia learning. Journal of Educational Psychology, 100, pp. 380-386.

Mayer, R., Moreno, R., Boire, M., \& Vagge, S. (1999). Maximizing constructivist learning from multimedia communications by minimizing cognitive load. Journal of Educational Psychology, 91, 638-643.

Maynard, K. L., Pullen, P. C., \& Coyne, M. D. (2010). Teaching vocabulary to first-grade students through repeated shared storybook reading: A comparison of rich and basic instruction to incidental exposure. Literacy Research and Instruction, 49, 209-242.

Merrill, M. D. (1983). Component display theory. In C. M. Reigeluth (Ed.), Instructional design theories and models (pp. 279-282). Hillsdale, NJ: Erlbaum.

McCardle, P., \& Chabra, V. (Eds.). (2004). The voice of evidence in reading research. Baltimore: Paul H. Brookes.

McCutchen, D., Abbott, R. D., Green, L. B., Beretvas, S. N., Cox, S., Potter, N. S., et al. (2002). Beginning literacy: Links among teacher knowledge, teacher practice, and student learning. Journal of Learning Disabilities, 35, 69-86.

McCutchen, D., Green, L., Abbott, R. D., \& Sanders, E. A. (2009). Further evidence for teacher knowledge: Supporting struggling readers in grades three through five. Reading and Writing: An Interdisciplinary Journal, 22, 401-423.

McCutchen, D., Harry, D. R., Cunningham, A. E., Cox, S., Sidman, S., \& Covill, A. E. (2002). Reading teachers' knowledge of children's literature and english phonology. Annals of Dyslexia, 52, 207-228.

Milken Exchange on Educational Technology. (1999). Will new teachers be prepared to teach in a digital age? A national survey on information technology in teacher education. Santa Monica, CA: Author. 
Mitchem, K., Koury, K., Fitzgerald, G., Hollingsead, C., Miller, K., Tsai, H., \& Zha, S. (2009). The effects of instructional implementation on learning with interactive multimedia case-based instruction. Teacher Education and Special Education, 32, 297-318.

Moats, L. C. (1994). The missing foundation in teacher education: Knowledge of the structure of spoken and written language. Annals of Dyslexia, 44, 81-102.

Moats, L. (2009a). Knowledge foundations for teaching reading and spelling. Reading and Writing: An Interdisciplinary Journal, 22, 379-399.

Moats, L. (2009b). Still wanted: Teachers with knowledge of language. Journal of Learning Disabilities, 42, 387-391.

Moats, L. C., \& Foorman, B. R. (2003). Measuring teachers' content knowledge of language and reading. Annals of Dyslexia, 53, 23-45.

Moats, L. C., \& Foorman, B. R. (2008). Literacy achievement in the primary grades in high-poverty schools. In S. Neuman (Ed.), Educating the other America: Top experts tackle poverty, literacy, and achievement in our schools (pp. 91-111). Baltimore: Paul H. Brookes.

Nagy, W. E. (2005). Why vocabulary instruction needs to be long-term and comprehensive. In E. H. Hiebert \& M. L. Kamil (eds.). Teaching and learning vocabulary: Bringing research to practice (pp. 27-44). New York, NY: Routledge.

Nagy, W. E. (2007). Metalinguistic awareness and the vocabulary- comprehension connection. In R. K. Wagner, A. E. Muse, \& K. R. Tannenbaum (Eds.), Vocabulary acquisition: Implications for reading comprehension (pp. 52-77). New York: Guilford.

Nagy, W., Berninger, V. W., \& Abbott, R. D. (2006). Contributions of morphology beyond phonology to literacy outcomes of upper elementary and middle-school students. Journal of Educational Psychology, 98, 134-147.

National Center for Educational Statistics (NCES). (2005). 2009 NAEP reading framework. Washington, DC: Author.

National Center for Education Statistics (NCES). (2013). The nations report card: Reading 2011. Institute of Education Sciences, U.S. Department of Education, Washington, D.C.

National Council on Teacher Quality. (2006). What teacher preparation programs aren't teaching about reading-And what elementary teachers aren't learning. Washington, DC: Author. 
National Reading Panel. (2000). Teaching children to read: An evidence-based assessment of the scientific research literature on reading and its implications for reading instruction: Report of the subgroups. Bethesda, MD: Author.

O’Brien, C., Aguinaga, N. J., Hines, R., \& Hartshorne, R. (2011). Using contemporary technology tools to improve the effectiveness of teacher educators in special education. Rural Special Education Quarterly, 30, 33-40.

Penno, J. F., Wilkinson, I. A., \& Moore, D. W. (2002). Vocabulary acquisition from teacher explanation and repeated listening to stories: Do they overcome the Mathew Effect? Journal of Educational Psychology, 94, 23-33.

Phelps, G., \& Schilling, S. (2004). Developing measures of content knowledge for teaching reading. Elementary School Journal, 105, 31-48.

Podhajski, B., Mather, N., Nathan, J., \& Sammons, J. (2009). Professional development in scientifically based readin instruction: Teacher knowledge and reading outcomes. Journal of Learning Disabilities, 42, 403-417.

Pryor, C. R., \& Bitter, G. G. (2008). Using multimedia to teach inservice teachers: Impacts on learning, application, and retention. Computers in Human Behavior, 24, 2668-2681.

Pullen, P. C., \& Justice, L. M. (2003). Enhancing phonological awareness, print awareness, and oral language skills in preschool children. Intervention in School and Clinic, 39, 87-98.

Pullen, P. C., Tuckwiller, E. D., Ashworth, K., Lovelace, S. P., \& Cash, D. (2011). Implementing intensive vocabulary instruction for students at risk for reading disability. Learning Disabilities Research \& Practice, 26. 145-157.

Pullen, P. C., Tuckwiller, E. D., Konald, T. R., Maynard, K. L., \& Coyne, M. D. (2010). A tiered intervention model for early vocabulary instruction: The effects of tiered instruction for young students at risk for reading disability. Learning Disabilities Research, 25, 110-123.

Quintana, C., Reiser, B. J., Davis, E., Krajcik, J. S., Golan, R., Kyza, E., et al. (2002, October). Evolving a scaffolding design framework for designing educational software. Paper presented at the International Conference of the Learning Sciences, Seattle, WA.

Rath, L. K. (1994). The phonemic awareness of reading teachers: Examining aspects of knowledge. Unpublished doctoral dissertation, Harvard University, Cambridge, MA. 
Reschly, D. J., \& Wood-Garnett, S. (2009). Teacher preparation for response to intervention in middle and high schools. Washington, DC: National Comprehensive Center for Teacher Quality.

Richards, J., \& Skolits, G. (2009). Sustaining instructional change: The impact of professional development on teacher adoption of a new instructional strategy. Research in the Schools, 16, 41-58.

Robinson, L., \& Kelley, B. (2007). Developing reflective thought in preservice educators: Utilizing role-plays and digital video. Journal of Special Education Technology, 22, 31-43.

Saeed, N., Yang, Y., \& Sinnappan, S. (2009). Emerging web technologies in higher education: A case of incorporating blogs, podcasts and social bookmarks in a web programming course based on students' learning styles and technology preferences. Educational Technology \& Society, 12, 98-109.

Salomon, G. (1984). Television is "easy" and print is "tough": The differential investment of mental effort in learning as a function of perceptions and attributions. Journal of Educational Psychology, 76, 647-658.

Santagata, R. (2009). Designing video-based professional development for mathematics teachers in low-performing schools. Journal of Teacher Education, 60, 38-51. doi: $10.1177 / 0022487108328485$

Santagata, R., \& Angelici, G. (2010). Studying the impact of the lesson analysis framework on preservice teachers' abilities to reflect on videos of classroom teaching. Journal of Teacher Education, 61, 339-349.

Santagata, R., Zannoni, C., \& Stigler, J. (2007). The role of lesson analysis in preservice teacher education: An empirical investigation of teacher learning from a virtual video-based field experience. Journal of Mathematics Teacher Education, 10, $123-140$.

Saxe, G.B., Gearhart, M., \& Nasir, N. (2001). Enhancing students' understanding of mathematics: A study of three contrasting approaches to professional support. Journal of Mathematics Teacher Education, 4, 55-79.

Scanlon, D., Schumaker, J. B., \& Deshler, D. D. (1994). Collaborative dialogues between teachers and researchers to create education interventions: A case study. Journal of Educational and Psychological Consultation, 5, 69-76.

Schrader, P., Leu, D., \& Kinzer, C. (2003). Using Internet delivered video cases to support pre-service teachers' understanding of effective early literacy instruction: An exploratory study. Instructional Science, 31, 317-340. 
Scruggs, T. E., Mastropieri, M. A., Bakken, J. P., \& Brigham, F. J. (1993). Reading versus doing: The relative effects of textbook-based and inquiry-oriented approaches to science learning in special education classrooms. The Journal of Special Education, 27, 1-15.

Sherin, M. G. (2004). New perspectives on the role of video in teacher education. In J. Brophy (Ed.), Using video in teacher education (pp. 1-27). New York: Elsevier Science.

Sherin, M. G., \& Han, S. Y. (2004). Teaching learning in the context of a video club. Teaching and Teacher Education, 20, 163-183. doi:10.1016/j.tate.2003.08.001

Sherin, M. G. \& van Es, E. A. (2009). Effects of video club participation on teachers' professional vision. Journal of Teacher Education, 60, 20-37.

Silverman, R. (2007a). Vocabulary development of English-language and English-only learners in kindergarten. The Elementary School Journal, 107, 365-383. doi:10.1086/516669

Silverman, R. (2007b). A comparison of three methods of vocabulary instruction during read-alouds in kindergarten. The Elementary School Journal, 108, 97-113. doi:10.1086/525549

Silverman, R., \& Candrell, J. D. (2010). Vocabulary practices in prekindergarten and kindergarten classrooms. Reading Research Quarterly, 45, 318-340.

Sindelar, P. T., Brownell, M. T., \& Billingsley, B. (2010). Special education teacher education research: Current status and future directions. Teacher Education and Special Education, 33, 8-24.

Snell, M. E. (2003). Applying research to practice: The more pervasive problem? Research \& Practice for Persons with Severe Disabilities, 28, 143-147. doi: $10.2511 /$ rpsd.28.3.143

Spear-Swerling, L. (2009). A literacy tutoring experience for prospective special educators and struggling second graders. Journal of Learning Disabilities, 42, 431-443. doi.org/10.1177/0022219409338738

Spear-Swerling, L., \& Brucker, P. O. (2004). Preparing novice teachers to develop basic reading and spelling skills in children. Annals of Dyslexia, 54, 332-364.

Spear-Swerling, L., Brucker, P. O., \& Alfano, M. P. (2005). Teachers' literacy-related knowledge and self-perceptions in relation to preparation and experience. Annals of Dyslexia, 55, 266-295.

Spear-Swerling, L., \& Cheesman, E. (2012). Teachers' knowledge base for implementing 
response-to-intervention models in reading. Read Writ, 25, 1691-1723.

Spencer, E. J., Schuele, C. M., Guillot, K. M., \& Lee, M. W. (2008). Phonemic awareness skill of speech-language pathologists and other educators. Language, Speech, and Hearing Services in the Schools, 39, 512-520.

Spooner, F., Knight, V., Lo, Y., \& Wood, W. (2007). Preparing teachers in severe disabilities across wide geographical areas using videoconferencing technology. Rural Special Education Quarterly, 26, 16-25.

Stahl, S.A., \& Nagy, W. (2006). Teaching word meanings. Mahwah, NJ: Erlbaum.

Steiner, D., \& Rozen, S. (2004). Preparing tomorrow's teachers: An analysis of syllabi from a sample of America's schools of education. In F. M. Hess, A. J. Rotherham, \& K. Walsh (Eds.), A qualified teacher in every classroom? Appraising old answers and new ideas (pp. 119-148). Cambridge, MA: Harvard University Press.

Stotsky, S. (2009). Licensure tests for special education teachers: How well they assess knowledge of reading instruction and mathematics. Journal of Learning Disabilities, 42, 464-474. Doi: 10.1177/0022219409338740

Stump, C. S., Lovitt, T. C., Fister, S., Kemp, K., Moore, R., \& Schroeder, B. (1992). Vocabulary intervention for secondary-level youth. Learning Disability Quarterly, 15, 207-222.

Sweller, J. (1988). Cognitive load during problem solving: Effects on learning. Cognitive Science, 12, 257-285.

Sweller, J. (1999). Instructional design in technical areas. Camberwell, Australia: ACER Press.

Sweller, J. (2004). Instructional design consequences of an analogy between evolution by natural selection and human cognitive architecture. Instructional Science, 32, 931.

Sweller, J., Kirschner, P. A., \& Clark, R. E. (2007). Why minimally guided teaching techniques do not work: A reply to commentaries. Educational Psychologist, 42, 115-121.

Sykes, G., Bird, T., \& Kennedy, M. (2010). Teacher education: Its problems and some prospects. Journal of Teacher Education, 61, 464-476. Doi: $10.1177 / 0022487110375804$

Tomesen, M., \& Aarnoutse, C. (1998). Effects of an instructional program for deriving' word meanings. Educational Studies, 24, 107-128. 
Wagner, R.K., Muse, A.E., \& Tannenbaum, K.R. (2007). Vocabulary acquisition: Implications for reading comprehension. New York: Guilford.

Walsh, B. A., \& Blewitt, P. (2006). The effect of questioning style during storybook reading on novel vocabulary acquisition of preschoolers. Early Childhood Education Journal, 33, 273-278.

Walsh, K., Glaser, D., \& Wilcox, D. D. (2006). What education schools aren't teaching about reading and what elementary teachers aren't learning. Washington, DC: National Council on Teacher Quality.

Washburn, E. K., Joshi, R. M., \& Binks-Cantrell, E. S. (2011a). Teacher knowledge of basic language concepts and dyslexia. Dyslexia, 17, 165-183.

Washburn, E. K., Joshi, R. M., \& Binks-Cantrell, E. S. (2011b). Are preservice teachers prepared to teach struggling readers? Annals of Dyslexia, 61, 21-43.

Wasik, B. A., \& Bond, M. A. (2001). Beyond the pages of a book: Interactive book reading and language development in preschool classrooms. Journal of Educational Psychology, 93, 243-250.

Wasik, B. A., Bond, M. A., \& Hindman, A. (2006). The effects of a language and literacy intervention on head start children and teachers. Journal of Educational Psychology, 98, 63-74.

Wayne, A. J., Yoon, K. S., Zhu, P., Cronen, S., \& Garent, M. S. (2008). Experimenting with teacher professional development: Motives and methods. Educational Researcher, 37, 469-479.

Weiderholt, J. L., \& Bryant, B. R. (2001). Gray oral reading test $\left(4^{\text {th }}\right.$ ed.). Austin, TX: Pro-Ed.

Wilson, S. M., Floden, R. E., \& Ferrini-Mundy, J. (2002). Teacher preparation research: An insider's view from the outside. Journal of Teacher Education, 53, 190-204.

Woodcock, R. (1998). Woodcock reading mastery test-revised. Circle Pines, MN: American Guidance Service.

Wysocki, K., \& Jenkins, J. R. (1987). Deriving word meanings through morphological generalization. Reading Research Quarterly, 22, 66-81.

Yoon, K. S., Duncan, T., Lee, S. W.-Y., Scarloss, B., \& Shapley, K. (2007). Reviewing the evidence on how teacher professional development affects student achievement (Issues \& Answers Report, REL 2007-No.033). Washington, DC: U.S. Department of Education, Institute of Education Sciences, National Center for Education Evaluation and Regional Assistance, Regional Educational 
Laboratory Southwest.

Yoon, K. S., Duncan, T., Lee, S., \& Shapley, K. (2008, March). The effects of teachers' professional development on student achievement: Findings from a systematic review of evidence. Paper presented at the Annual Meeting of the American Educational Research Association, New York, NY.

Zeichner, K. (2006). Reflections of a university-based teacher educator on the future of college- and university-based teacher education. Journal of Teacher Education, $57,326-340$. 
Appendix A

CAP Production Steps 


\begin{tabular}{|c|c|}
\hline $\begin{array}{c}\text { Mayer's } \\
\text { Instructional } \\
\text { Design } \\
\text { Principles } \\
\text { (2009) }\end{array}$ & $\begin{array}{c}\text { CAP [Content Acquisition Podcast] Production Steps } \\
\text { For Delivery of Content }\end{array}$ \\
\hline \multicolumn{2}{|r|}{ Preparation } \\
\hline $\begin{array}{l}\text { - Coherence } \\
\text { - Segmenting }\end{array}$ & $\begin{array}{l}\text { Step 1.0: Identify a clearly defined and coherent topic of interest. } \\
\text { 1.1 Select only the most critical content to include in the CAP. }\end{array}$ \\
\hline $\begin{array}{l}\text { - Coherence } \\
\text { - Segmenting } \\
\text { - Signaling } \\
\text { - Pretraining }\end{array}$ & $\begin{array}{l}\text { Step 2.0: Create 'standard' PowerPoint slides (heading and bulleted } \\
\text { supporting points) for critical content. } \\
\text { 2.1 Create a clear PowerPoint title page slide } \\
\text { 2.2 Separate critical content so each slide presents only one piece of } \\
\text { discrete information and key descriptors. } \\
\text { 2.3 Eliminate extraneous content from slides and planned comments. } \\
\text { 2.4 Determine and implement a logical numbering or hierarchical } \\
\text { ordering system for key ideas throughout slides when presenting } \\
\text { multifaceted concepts } \\
\text { 2.5 Make PowerPoint speaker notes as appropriate; print a copy of } \\
\text { slides for reference when recording podcast narration. }\end{array}$ \\
\hline \multicolumn{2}{|r|}{ Production } \\
\hline $\begin{array}{l}\text { - Multimedia } \\
\text { - Spatial } \\
\text { Contiguity } \\
\text { - Redundancy } \\
\text { - Coherence }\end{array}$ & $\begin{array}{l}\text { Step 3.0 Replace 'standard' text-heavy slides one-by one with images } \\
\text { that represent the content as closely as possible. For example: A slide } \\
\text { that introduces reading comprehension strategies might include a } \\
\text { photo of a puzzled-looking child holding a book. } \\
\text { 3.1 Select one eye-catching image per key idea. Use } \\
\text { google.com/images, bing.com/images or another internet search engine to } \\
\text { find copyright-free photos or other images. } \\
\text { 3.2 Select large images that fill most of the available slide space } \\
\text { without losing clear visual resolution } \\
\text { 3.3 Avoid cluttered images with embedded text or distracting } \\
\text { details. } \\
\text { 3.4 For slides where you plan to insert text to emphasize key terms } \\
\text { or ideas, make three copies of the appropriate slide and keep them in order } \\
\text { in your presentation. }\end{array}$ \\
\hline
\end{tabular}




\begin{tabular}{|c|c|}
\hline $\begin{array}{l}\text { - Redundancy } \\
\text { - Spatial } \\
\text { Contiguity } \\
\text { - Coherence }\end{array}$ & $\begin{array}{l}\text { Step 4.0: Insert text over images by using 'insert text box' on the } \\
\text { second of the three slides. The first and third slide should be free of } \\
\text { text. } \\
\text { 4.1 Select one word or a short phrase ( } 3-4 \text { words) to highlight the } \\
\text { topic of the slide to be typed into the text box. Using full sentences is not } \\
\text { advised. Use clear and concise verbiage. } \\
4.2 \text { Use } 40 \text { point or larger font size and widely-used type styles; } \\
\text { select text color that is easily readable given the contrast with the } \\
\text { background images and colors. [NOTE: The text box "fill color" tool } \\
\text { make be used to ensure good contrast between images and text.] } \\
\text { 4.3: Centrally locate text boxes either in the middle of the slide or } \\
\text { near a major image element. } \\
\text { 4.4 Limit viewers' need to move their eyes across the podcast } \\
\text { screen or to multiple locations on any given slide; use the same principle } \\
\text { when selecting appropriate pictures. }\end{array}$ \\
\hline $\begin{array}{l}\text { - Modality } \\
\text { - Temporal } \\
\text { Contiguity } \\
\text { - Coherence } \\
\text { - Multimedia } \\
\text { - Redundancy }\end{array}$ & $\begin{array}{l}\text { Step 5.0: Prepare and time your slide narration so it coincides with } \\
\text { the appropriate on-screen text. For example, when recording a } \\
\text { presentation about making pizza: } \\
\text { 5.1 Create three identical slides that adhere to the aforementioned } \\
\text { steps. Insert a text box (See Steps } 3.0-4.4 \text { above) in the second of three } \\
\text { identical slides that has the words "add cheese". } \\
\text { 5.2 Begin narrating these slides (See Step 6.0). With Slide } 1 \text { of } 3 \\
\text { on the screen say, "The next step in making pizza is...", then hit "Enter" } \\
\text { to advance to the second slide already prepared with the text box and say, } \\
\text { "add cheese," (narration will match text on the screen) hit "Enter," and } \\
\text { finish narration on this element of making a pizza while slide } 3 \text { (without } \\
\text { any text, but same picture) is on screen. } \\
\text { 5.3 Repeat this process for every key CAP term/concept to be } \\
\text { addressed in the presentation. Not every picture representing a concept or } \\
\text { piece of information needs additional text-reserve use of text for the } \\
\text { most essential concepts/pieces of information within your CAP. }\end{array}$ \\
\hline $\begin{array}{l}\text { - Multimedia } \\
\text { - Coherence } \\
\text { - Modality } \\
\text {-Personalization, } \\
\text { Voice, and } \\
\text { Image } \\
\text { - Segmenting }\end{array}$ & $\begin{array}{l}\text { Step 6.0: Finalize slides and familiarize yourself with the written } \\
\text { narrative before recording narration. Save your file. } \\
\text { 6.1 Under PowerPoint pull-down menu, click 'Slide Show', and } \\
\text { then, 'Rehearse Timings." } \\
\text { 6.2 Rehearse narration; hit enter to advance through the slides. } \\
\text { Note the total length of your narration when done. } \\
\text { 6.3 PowerPoint will ask if you want it to automatically link the } \\
\text { amount of time you spent on each slide for later use. CLICK YES. } \\
\text { 6.4 Practice recording podcast several times until comfortable and } \\
\text { confident with the flow of the CAP. If it is longer than } \\
\text { 3-5 minutes (shorter is fine), or if more than three-five concepts are } \\
\text { presented, divide the CAP content into two or more podcasts (e.g., } \\
\text { Learning Strategies [LS] Part I, LS Part II). } \\
\text { 6.5 Save the file as a movie. Select the quality of playback } \\
\text { (highest quality is recommended) }\end{array}$ \\
\hline
\end{tabular}




\begin{tabular}{|c|c|}
\hline $\begin{array}{l}\text { - Personalization, } \\
\text { Voice, and } \\
\text { Image } \\
\text { - Multimedia } \\
\text { - Modality }\end{array}$ & $\begin{array}{l}\text { Step 7.0: Import saved .ppt movie file into your choice of iMovie } \\
\text { (MAC) or Windows MovieMaker (PC). } \\
7.1 \text { There are several options for recording narration and linking to } \\
\text { your movie-there is no 'correct' way. Recording narration within } \\
\text { PowerPoint is possible, but is frequently unreliable (based on experience } \\
\text { with Office } 2008 \text { or previous versions). An easy way for novices to } \\
\text { record narration following the preceding steps is Apple's iMovie or } \\
\text { Window's Movie Maker programs. } \\
7.2 \text { Drag the file into the video production timeline (at bottom of } \\
\text { screen in both iMovie and Movie Maker). } \\
7.3 \text { Ensure your computer's built in microphone or external mic is } \\
\text { functioning properly and at an appropriate volume. Record a test } \\
\text { statement to confirm audio level prior to narration. } \\
\quad 7.4 \text { Record narration in a room free from background noise or } \\
\text { other distractions. Preview your recording. If sound is distorted or } \\
\text { otherwise imperfect, diagnose the problem (you were too close to } \\
\text { microphone, etc.) and re-record. } \\
7.5 \text { Speak in a clear, engaging voice; record in front of a mirror or } \\
\text { with another person to create a more natural-sounding recording. Use } \\
\text { good posture, smiling, and hand gestures can also improve the quality of } \\
\text { vocal recordings. } \\
7.6 \text { Listen to your recording for unnecessary pauses (um's or } \\
\text { other dead air). If they are noticeable/distracting, re-record your Pre- } \\
\text { CAP. } \\
7.7 \text { Save/Export your finished video as a quicktime or windows } \\
\text { media file. }\end{array}$ \\
\hline \multicolumn{2}{|r|}{ Publishing } \\
\hline & $\begin{array}{l}\text { Step 8.0 Upload your saved video to the web } \\
\text { 8.1 Upload your CAP to course management websites (e.g., } \\
\text { BlackBoard) or other file-sharing sites (e.g., www.vimeo.com; } \\
\text { www.youtube.com). }\end{array}$ \\
\hline
\end{tabular}

\section{Appendix B}

Multiple-Choice Pretest/Posttest/Maintenance Test 
By taking this test, you are agreeing to participate in this Vocab Study as outlined in the Consent Form (provided on the Collab site under Resources).
A. I agree
B. I decline

Are you an undergraduate or graduate student?
A. Undergraduate
B. Graduate

What is your undergraduate major?

How many years have you studied at UVA (including this year)?
How old are you?
A. $18-20$
B. $21-24$
C. $25-27$
D. $28+$ 
What program are you majoring in with Curry?
A. Administration \& Supervision
B. Counselor Education
C. Communication Disorders
C D. Curriculum \& Instruction (Teaching \& Learning)
E. Clinical \& School Psychology
F. Early Childhood Special Education
G. Educational Psychology
H. Elementary Education
I. Gifted Education
J. English Education
$\mathrm{K}$. Foreign Language
L. Higher Education
M. Instructional Technology
N. Mathematics Education
O. Reading Education
P. Science Education
Q. Special Education-Elementary
R. Special Education-Secondary
S. Speech Pathology \& Audiology
T. Teacher Education

Have you had experience working with students, (such as tutoring in a school or substitute teaching)?
A. Yes
B. No 
Circle the letter(s) for any reading courses you have taken, or are currently taking at UVA:

$\Gamma$ A. 5221 Reading Development

B. 5222 Reading Development for Special

Populations

C. 5300 Language Block

$\Gamma$ D. 5480 2nd Lang Acquisition

$\Gamma$ E. 5710 Content Area Reading

F. 5730 Diagnosis \& Remediation: Prek-2

[ G. 7700 Foundations of Reading Instruction

H. 7720 Word Study: Language Structure \&

Phonics

[I. 7886 Comp of Text

ГJ. 8995 Practicum- Reading Clinic

Are you planning to teach:

A. Early childhood students

B. Elementary students

C. Secondary students

D. Not planning to teach

Are you planning to teach in a:

A. General education setting

B. Special education setting

C. Not planning to teach 
Given you have a future teaching profession, how important is the ability to teach vocabulary for your students' success?
A. 1 (not important)
B. 2
C. 3
D. 4
C. 5
F. 6 (very important)

How comfortable do you feel teaching vocabulary?

A. 1 (not comfortable)

B. 2

C. 3

D. 4

E. 5

F. 6 (very comfortable)

How comfortable do you feel teaching a strategy called, Intensifying Vocabulary Intervention (IVI)?
A. 1 (not comfortable)
B. 2
C. 3
D. 4
E. 5
F. 6 (very comfortable) 
How many vocabulary words should a teacher try to teach during one lesson?
C. 1
B. $2-4$
C. 5-6
D. 7

When teaching vocabulary, teachers should...

C. A. use dictionary definitions to teach word meanings

B. encourage students to come up with word meanings

C. Cefine word meanings with language students understand

C D. have students come up with a sentence using the word correctly

Which statement is true about vocabulary instruction?
A. Instruction that includes word-learning

strategies is more effective than incidental word learning.

B. English Language Learners acquire

c. vocabulary best from indirect word learning (e.g., listening to others use vocabulary words in sentences).

C. When using the following teaching methods, teachers should use one method at

a time- (a) teaching words in context, and (b) teaching words with student-friendly definitions).

D. After reading a book to introduce new vocabulary words to struggling students, the

teacher should wait one day to do additional word-learning activities to not overload student cognitive resources. 
To help poor readers learn new vocabulary words, a beginning step teachers should do is...

A. teach words within contexts.

B. have students write the new words.

C C. ask students to sound out the words and predict their meanings.

D. have students draw a picture of what they think the word means.

Children acquire vocabulary by...

A. receiving direct instruction.

B. being directly taught words and listening to adults use words in conversation.

C. looking at synonyms of new vocabulary words.

C D. comparing dictionary definitions to studentfriendly definitions.

$<p>$

Which is NOT\&nbsp; a good activity to do with struggling readers after reading a book in which you introduced a new vocabulary word? $</ p>$
A. show examples of the word
B. show non-examples of the word
C. C. have them try to say the word in a sentence
C D. have them read the sentence in the book with the word multiple times

Circle the statement that is NOT true. At the end of vocabulary activities, the teacher should,
A. Say, "what was the word we talked about?"
B. Check for student learning
C. Say, "use this word at home"
D. Say, "what does the word mean?" 
What should students use/do independently to determine word meanings?

A. Use dictionaries or other reference aids

B. Listen to vocabulary through conversations among adults

C. Learn student-friendly definitions from the teacher

C D. Read sentences in a book that make word meaning clear

Vocabulary words should be taught:

A. Indirectly

B. Passively

C. Incidentally

D. Explicitly

Which of the following will help children become independent word learners?

c A. Using context clues and understanding morphology

C B. Understanding morphology and having phonological awareness

C. Learning syllabication rules

D. Using word parts and knowing vowel patterns

Vocabulary instruction is necessary

A. To sound out words

B. To bring meaning to print

C. To review known words

D. To segment sounds in words 
What is an example of learning vocabulary indirectly? Someone says...

A. "The word blustery means very windy"

B. "Can you believe this weather? What a blustery day"

C C. "If a baby cries quietly, we could also say the baby whimpers"

C D. "The definition of whimper is a series of low sounds expressive of discontent"

As a teacher, what should you say when doing a vocabulary lesson with poor readers? (The target vocabulary word is shown in italics).
A. "The word blustery means very windy"
B. "Can you believe the weather? What a blustery day"
c. "Why do you think he whimpers?"
$C$ D. "The word whimper means a series of low sounds expressive of discontent"

Which is not an example of direct instruction in vocabulary?

c. A. Clear and carefully planned instruction of vocabulary words

B. Teaching word learning strategies

C. Teaching vocabulary through conversation

D. Teaching students to use word parts to figure out meanings (prefixes and suffixes) 
When teaching vocabulary, you should choose books with these kinds of words:

C. A. Words of mature language users such as glorious, cruel, or drowsy

B. Words students likely know

C C. Content specific words such as isotope or polygon

D. Low frequency words that are specific to a

story students' are reading such as ukulele or sombrero

When teaching vocabulary, you should also choose these kinds of words:

C. A. Words that students may need to understand their science lesson

B. Words those are typically difficult to pronounce

c. C. Transition words such as however and whereas

C. D. Words that you think students will use in the future

What are tier 1 words?

A. Low frequency and content specific words

B. Words that don't occur often in written and spoken language

C. Difficult words to learn

D. Words students probably already know

What is an example of a tier 3 word?
A. Ball
B. And
C. Economics
D. Fortunate 
What is an example of a tier 2 word?

A. Triumphant

B. Isotope

c. Orange

D. Crepe

What is an example of a tier 1 word?
A. Shore
B. Tromp
c. Parallel
D. Picture

If you are introducing a new word, "essential", the best way to define it is...

A. "Discipline is essential in an army"

B. "Pertaining to the essence of something"

c. "Pretty crucial"

D. "Most important"

In the following sentence, what word should you select to teach?

"The carnivore snoozes in his dark, quiet cave."
A. Carnivore
B. Snoozes
C. Quiet
D. Cave 
When learning vocabulary words, students should...

$\checkmark$ A. Look up words in the dictionary before reading the book that introduces the word

$C$ B. Write sentences with vocabulary words embedded in them

$\mathrm{C}$. Engage with words in various settings

D. Learn words in isolation before learning them in context

When learning vocabulary words, struggling students should NOT...

A. Be taught new words with words the teacher thinks they know

B. Be asked to give inappropriate or nonexamples of words

C. Refer to definitions from reference aids

C D. Be exposed to new vocabulary words too many times (over 10) per day

Prior to reading a book with new vocabulary words, a teacher should NOT

C. A. Get students to engage with the story by tapping into what they already know

B. Mention the new words and ask students to listen for them in the story

C. Ask students to predict word meanings

D. Activate prior knowledge of students

When you teach a word within a sentence, you should...

A. Skip the word, keep reading, and have students figure out the meaning

B. Prompt students to spell the word

C C. Say the meaning of the word within the sentence

D. Have students say the word multiple times 
After you introduced new vocabulary words in a story, what would be helpful for struggling students who need extra help learning the words?

ᄃ. A. Have students write the meaning of each word multiple times

B. Give students an informal assessment to determine their understanding

c. Give examples of words with pictures

D. Have students reread the story on their own

An effective vocabulary lesson includes these' aspects, except...

C. A. Sophisticated words that they are not likely to use on their own

B. Teacher reads the words' meaning in the story's sentence

C. Provide tools for students to learn word meanings independently

D. Interact with the word in different contexts

Which statement is true?

C. Atudents less frequently acquire vocabulary from hearing others

B. Studies have determined that explicit instruction is more effective for upper grades

C. Children need to be exposed to books that

they can read on their own when learning vocabulary words

D. Students are likely to learn more from

$\checkmark$ direct teacher instruction than indirect learning (e.g., hearing their parents use words) 
Which is/are helpful to do after introducing vocabulary words in a storybook?

- A. Show students examples of a word's meaning

$\Gamma$ B. Ask students to relate the word to their life

$\Gamma$ C. Have students identify non-examples of a word's meaning

$\Gamma$ D. Have students say the word in a complete sentence

What are tier 2 words?

A. Words of mature language users and

words that can be explained with already known words

B. Words that could be explained with already

known words and are most commonly used in spoken language

C. Receptive vocabulary words

D. Subject-specific words of mature language users 


\title{
Appendix C
}

\author{
IVI Fidelity Checklist
}

\section{Fidelity of During-Reading IVI Implementation}

Name:

Observer:

Book:

Read Aloud:

\begin{tabular}{|l|l|l|}
\hline \multicolumn{1}{|c|}{ Behaviors } & No & Yes \\
\hline 1. Chose "word-rich" story & & \\
\hline $\begin{array}{l}\text { 2. Target words chosen are appropriate (important, } \\
\text { useful, difficult) }\end{array}$ & & \\
\hline 3. Instructor identifies target words. & & \\
\hline $\begin{array}{l}\text { 4. Instructor chooses the right \# of words to teach } \\
\text { (2-4 per lesson) }\end{array}$ & & \\
\hline $\begin{array}{l}\text { 5. Instructor has children pronounce 2-4 "magic } \\
\text { words" prior to the reading of the story. }\end{array}$ & \\
\hline $\begin{array}{l}\text { 6. Instructor tells students to raise their hands when } \\
\text { they hear a magic word. }\end{array}$ & \\
\hline 7. Instructor discussed text prior to reading. & \\
\hline 8. Instructor reads story throughout & \\
\hline $\begin{array}{l}\text { 9. As instructor reads, instructor acknowledges } \\
\text { raised hands when children hear word or prompts } \\
\text { them if students don't raise hands (majority of the } \\
\text { time- yes or no?) }\end{array}$ & & \\
\hline $\begin{array}{l}\text { 10. Instructor provides an explicit definition of each } \\
\text { target word when it appears in the storybook. }\end{array}$ & & \\
\hline $\begin{array}{l}\text { 11. Instructor uses "kid friendly" definitions, with } \\
\text { words they understand (not dictionary) }\end{array}$ & & \\
\hline $\begin{array}{l}\text { 12. Instructor immediately reads definition of the } \\
\text { target word back within the sentence in which the } \\
\text { target word appears. }\end{array}$ & & \\
\hline 13. Instructor asks students to repeat the target word. & & \\
\hline $\begin{array}{l}\text { 14. Instructor is encouraging and enthusiastic about } \\
\text { word learning throughout the lesson }\end{array}$ & \\
\hline $\begin{array}{l}\text { 15. Students were actively engaged in word learning } \\
\text { (they SAW and USED words in different contexts) }\end{array}$ & & \\
\hline
\end{tabular}




\begin{tabular}{|l|l|l|}
\hline 16. Instructor taught word-learning strategies & & \\
\hline 17. Discussed text during and after reading & & \\
\hline $\begin{array}{l}\text { 18. Instructor helped students relate to words with } \\
\text { prior knowledge/experiences }\end{array}$ & & \\
\hline
\end{tabular}

\section{Fidelity of IVI Implementation After-Reading Activities}

\begin{tabular}{|l|l|l|l|l|}
\hline \multicolumn{1}{|c|}{ Behaviors } & Word A & Word B & Word C & Word D \\
\hline $\begin{array}{l}\text { 1. Instructor chooses at least one after- } \\
\text { reading activity (e.g., } \\
\text { Example/Nonexample, Making } \\
\text { Sentences, or Relating to Experiences). }\end{array}$ & & & & \\
\hline $\begin{array}{l}\text { Which activity (e.g., } \\
\text { Example/Nonexample, Making } \\
\text { Sentences, or Relating to Experiences): }\end{array}$ & & & & \\
\hline & & & \\
\hline $\begin{array}{l}\text { 2. Instructor has and uses appropriate } \\
\text { materials necessary }\end{array}$ & & & \\
\hline $\begin{array}{l}\text { 3. Instructor introduces word (e.g., "one } \\
\text { word you learned in the story is....). }\end{array}$ & & & & \\
\hline $\begin{array}{l}\text { 4. Instructor prompts students to say } \\
\text { word until all do. }\end{array}$ & & & & \\
\hline $\begin{array}{l}\text { 5. Instructor says kid friendly definition } \\
\text { of word and has students repeat } \\
\text { definition. }\end{array}$ & & & & \\
\hline $\begin{array}{l}\text { 6. Instructor administers after-reading } \\
\text { activity for word. }\end{array}$ & & & & \\
\hline $\begin{array}{l}\text { 7. Instructor prompts students to use } \\
\text { word in complete sentences. }\end{array}$ & & & & \\
\hline $\begin{array}{l}\text { 8. Instructor is encouraging and } \\
\text { enthusiastic about word learning } \\
\text { throughout the activity for word }\end{array}$ & & & & \\
\hline $\begin{array}{l}\text { 9. Students were actively engaged in } \\
\text { word learning (e.g., they respond, repeat, } \\
\text { answer, participate) }\end{array}$ & & & & \\
\hline $\begin{array}{l}\text { 10. Instructor repeats or incorporates } \\
\text { word 1's definition throughout/ multiple } \\
\text { exposures to the word and definition. }\end{array}$ & & & & \\
\hline $\begin{array}{l}\text { 11. Instructor brings the activity to a } \\
\text { close by saying, "what was the word we } \\
\text { talked about?" and students respond. }\end{array}$ & & & & \\
\hline
\end{tabular}


12. Instructor ends the activity by saying, "what does word mean?" and students respond.

\section{Comments:}




\section{Appendix D}

\section{Control Group Reading}

Effective Practices for Vocabulary Instruction: Intensifying Vocabulary Instruction (IVI)

Paige C. Pullen and Emily Ely

University of Virginia 


\section{Why is Vocabulary Instruction Important?}

The reading achievement of students in the United States is concerning. Approximately $35 \%$ of students in the fourth grade are reading below basic levels of achievement and are unable to read grade level material effectively.

In later elementary grades, reading achievement is measured through reading comprehension. This makes sense given that the purpose for reading is to understand what you read. Research suggests that comprehension scores are highly correlated with vocabulary knowledge. Research also suggests that the relationship between vocabulary and reading comprehension increases over time.

For these reasons, it is critical to begin vocabulary instruction in early childhood, especially for children who may be at an increased risk for reading failure.

\section{Vocabulary Learning in the Early Grades}

Many children, especially those from impoverished backgrounds, enter their formal schooling with significant deficits in their vocabulary (Biemiller, 2001; Coyne et al., 2004; Hart \& Risley, 2003; Hirsch, 2003; National Research Council, 1998).

Research tells us that vocabulary is mostly acquired indirectly, and some vocabulary must be taught directly. Oral conversation is the primary resource for young children's acquisition of vocabulary. Over time, however, conversations become less-effective sources for new vocabulary as they typically contain only the most common words (Cunningham \& Stanovich, 1988). Likewise, the books that young children read for themselves characteristically contain only words children recognize aurally, offering limited vocabulary-development opportunities.

Several groups of researchers have been investigating the effects of direct, explicit vocabulary instruction for students at multiple grade levels (Beck \& McKeown, 2007; Beck, McKeown, \& Omanson, 1987; Coyne et al., 2004; Loftus, Coyne, McCoach, Zipoli, \& Pullen, 2010; Pullen, Tuckwiller, Konold, Maynard, \& Coyne, 2010).

Findings from these studies suggest that rich vocabulary instruction results in greater word learning for children than incidental vocabulary learning and provide clear evidence that vocabulary can be taught effectively. 


\section{Effective Vocabulary Practices}

\section{PRIOR TO INSTRUCTION}

\begin{tabular}{|c|l|}
\hline PRACTICE & \multicolumn{1}{c|}{ EXPLANATION } \\
\hline \multirow{2}{*}{$\begin{array}{c}\text { Choose the } \\
\text { right }\end{array}$} & $\begin{array}{l}\text { As children have listening and speaking abilities that are better } \\
\text { developed than their reading and writing skills, books beyond the } \\
\text { child's own independent reading ability that are read aloud are the } \\
\text { best source for vocabulary development (Beck \& McKeown, } \\
\text { 2007). Books above the child's reading level are typically more } \\
\text { complex and have richer language than those the child can read } \\
\text { alone, and opportunities to use language during interactive, rich, } \\
\text { dialogic discussion that is part of shared reading activities further } \\
\text { contribute to vocabulary acquisition (Senechal, 1997; Whitehurst } \\
\text { et al., 1999). }\end{array}$ \\
\cline { 2 - 3 } & Choose a word-rich story with multiple Tier Two words. \\
\cline { 2 - 3 } & $\begin{array}{l}\text { Select books with appealing pictures and engaging stories to best } \\
\text { hold the child's attention (Coyne et al., 2004). }\end{array}$ \\
\hline
\end{tabular}

What are appropriate words to teach? There are three tiers of words, but you should use your limited instruction time to teach words that will provide the highest utility for students.

\section{PRACTICE
EXPLANATION}

\begin{tabular}{|c|l|}
\hline \multirow{2}{*}{$\begin{array}{c}\text { Choose the } \\
\text { right }\end{array}$} & $\begin{array}{l}\text { Beck and colleagues (2002) advise choosing words that students } \\
\text { are less likely to learn through grade-level material, words that } \\
\text { are more sophisticated synonyms of already-familiar words or } \\
\text { concepts. Teach two to four words using already-familiar words } \\
\text { and concepts. These words are called Tier Two words (e.g., } \\
\text { "devour"). }\end{array}$ \\
\cline { 2 - 3 } WORDS & $\begin{array}{l}\text { The other tiers of words consist of Tier One words (i.e., words } \\
\text { your students likely already know, such as "nice") and Tier Three } \\
\text { words (i.e., lower frequency words that are often content specific } \\
\text { and you don't see or use often, such as "isotope"). }\end{array}$ \\
\cline { 2 - 3 } & Choose words that students are likely to see, find interesting, and \\
\hline
\end{tabular}


use in the future.

\section{PRACTICE}

INTRODUCE WORDS

\section{EXPLANATION}

Before you begin reading the book you chose, introduce the target vocabulary words.

Mention the target words, prompt students to say the words with you, and tell the students to listen for the words as you read the story.

It is also important to ignite student prior knowledge and past experiences; help them relate to the story.

\section{Example:}

Say, I want you to listen for a few magic words in the story. Slumbering. Say it with me...slumbering. Blustery. Say it with me...blustery. Raise your hand when you hear these magic words.

\section{DURING READING / VOCABULARY INSTRUCTION}

- Rich instruction includes explaining words in child-friendly ways, giving multiple examples in multiple contexts and requiring students to identify appropriate and inappropriate uses of the word (Beck \& McKeown, 2007).

- When you come across a target word in the story, provide a child-friendly definition. Also, incorporate the word's definition into the story's sentence. For example, if the target word is "whimpers" and the sentence is "the bear whimpers," you could say, "another way to say this sentence is to say, the bear cries quietly."

- Teach word learning strategies so that students will eventually be able to figure out word meanings on their own. For example, you could teach them how to use (1) word parts, such as prefixes, suffixes, and base words, to figure out word meanings; (2) context clues to figure out word meanings (e.g., pictures or other parts of the sentence), (3) reference aids (e.g., dictionaries and thesauruses). Note: Students need to be explicitly taught how to use these reference aids and when teaching new word meanings, dictionary definitions should not be used. 


\section{Example:}

If children raise their hands...

Oh, good. Some of you raised your hands! What word did you hear? (Children Respond) Yes, slumbering. "In a cave in the woods, a slumbering bear sleeps through the party in his very own lair."

If children do not raise their hands...

I think I heard one of our magic words. Listen and raise your hand when you hear our magic word slumbering. "In a cave in the woods, a slumbering bear sleeps through the party in his very own lair." What word did you hear? (Children Respond) Yes, slumbering.

Then add...

Slumbering means sleeping. Now I'll say the sentence again with a word that means slumbering. "In a cave in the woods, a sleeping bear sleeps through the party in his very own lair." (Point to the picture.) In the picture you can see that bear is slumbering inside of his lair while the other animals have a party. Everyone say slumbering.

\section{ATTER-READING ACTIVITIES}

- Researchers have explored providing follow-up activities or review of vocabulary. These strategies require children to interact more actively with the words and in various contexts (Coyne et al., 2004; Wasik \& Bond, 2001 ), with the goal of promoting depth of vocabulary processing that allows students to make connections to the word and process it in new contexts (Stahl \& Fairbanks, 1986).

- Several activities that provide students with opportunities to use and interact with target words in meaningful ways involve students making connections between target words and real-world contexts. These activities include recognizing examples and nonexamples of the target words, creating sentences using target words, and relating word meanings to personal experiences. These activities can be implemented within a tiered instructional format. 


\begin{tabular}{|l|}
\hline \multicolumn{1}{|c|}{ A tiered instructional format could look like this: } \\
\hline Reading Activity \\
1) Introduce and teach target vocabulary words to all students through storybook \\
reading; \\
\hline $\begin{array}{l}\text { After-Reading Activity } \\
\text { 2) For students who do not produce sufficient learning, intensify instruction by } \\
\text { increasing frequency, duration, or reduce group size; }\end{array}$ \\
\hline $\begin{array}{l}\text { Another After-Reading Activity } \\
\text { 3) For students who continue to be unresponsive, provide even more intense and } \\
\text { individualized instruction on the vocabulary words. }\end{array}$
\end{tabular}

For all after-reading activities, introduce the word(s) you will be reviewing:

\section{PRACTICE \\ EXPLANATION}

[Show students cover of book].

Say, when we read this book, we talked about some magic words that we found in the story. Now we are going to play some more

INTRODUCE games with these magic words. During our games, if you think the

After-

Reading answer to my question is "yes", show me your "thumbs up" like Activities this. (Model a "thumbs up.") If you think the answer is "no" show me your "thumbs down" like this (Model "thumbs down.")

[Show students the picture of slumbering from the story].

One word you learned in the story is slumbering. Everybody say slumbering. Say this after me: slumbering means sleeping. 


\section{Examples of After-Reading Activities:}

\section{(1) EXAMPLES and NON-EXAMPLES}

[Show two pictures of someone slumbering, and one picture that does not represent slumbering.]

One at a time, ask, Does this picture show a slumbering person? Students respond; clarify why they are correct or incorrect.

Continue with each picture.

\section{(2) RELATING to EXPERIENCES}

[Show three pictures that demonstrate slumbering.]

Hold up one picture. The lion in this picture is slumbering, or sleeping. This picture reminds me of a time when I saw a lion slumbering at the zoo.

Select a student and ask, tell me about a time that you saw an animal slumbering.

Continue with each picture

\section{(3) MAKING SENTENCES}

[Give each student an animal puppet.]

Let's look at some animals that are slumbering, or sleeping. Everyone will have a turn to say something about their animal using our magic word, slumbering.

Model [with a bear puppet]. My turn first. The bear is slumbering because he is tired from walking through the woods. Act out the puppet bear to show a slumbering bearpretend he is slumbering.

Prompt students to say something about their different animal using the magic word slumbering. 


\begin{tabular}{|l|l|}
\multicolumn{1}{c|}{ PRACTICE } & \multicolumn{1}{c|}{ EXPLANATION } \\
\hline \multirow{3}{*}{ CLOSURE } & Briefly review the target words and check for understanding. \\
\cline { 2 - 2 } & $\begin{array}{l}\text { Say, Everyone, what is the magic word(s) we have been talking } \\
\text { about? What does it mean? }\end{array}$
\end{tabular}

\section{Conclusion}

The intent of this chapter is to provide a means for future teachers to translate specific vocabulary research into actual practice. Studies on these vocabulary practices were implemented in two states and several different schools. In all cases, teachers were enthusiastic about learning the activities as they translated the activities to meet their student needs, using other storybooks and varying target words (Pullen, Tuckwiller, Ashworth, Lovelace, \& Cash, 2011). 


\section{Appendix E}

\section{Directions Sent in Email to Complete Tasks Online}

[Email sent to the Experimental Group]:

Below are the next tasks for the Vocab Study, due by this Friday, March 8. You will find a link to a video that talks about and models vocabulary practices that have been supported with research to be effective for struggling elementary students.

Directions:

- Watch the video ONE TIME in ONE sitting- straight through (about 25 minutes).

- Please watch in a silent space, alone, so that you can devote your full attention to it.

- Make sure you allot time after to immediately take the multiple choice posttest on collab.

- Do NOT take the posttest while watching the video; take the posttest after when the video is complete and closed.

- Do NOT receive or give any aid while reading and while taking the posttest.

- Tip: To the bottom right of the video you'll see "HD". Make sure HD is OFF. Click HD to turn it on or off- the video will have fewer pauses if HD is off.

- Make sure your internet connection is good or the video will continually pause.

In summary, please watch the video, and immediately after take the posttest by this Friday, March 8.

In a few weeks, you will be reminded to take a maintenance test. After that, you will receive credit for participating!

LINK to video:

http://vimeo.com/52186714

[Email sent to the Control Group]:

Attached is the next task for the Vocab Study, due by this Friday, March 8. You will find a paper describing vocabulary practices that have been supported with research to be effective for struggling elementary students.

Directions:

- Read this thoroughly in ONE sitting.

- You can take notes if you wish.

- Please read in a silent space, alone, so that you can devote your full attention to the paper.

- Make sure you allot time after to immediately take the multiple choice posttest on collab. 
- Do not receive or give any aid while reading and while taking the posttest.

In summary, please read the attachment, and immediately after take the posttest by this Friday, March 8.

In a few weeks, you will be reminded to take a maintenance test. After that, you will receive credit for participating! 


\section{Appendix F}

\section{IVI Script Followed to Create Video-Modeling}

\section{Teacher: Point to the title on the cover. Say:}

The title of this story is Bear Snores On. The story was written by Karma Wilson and the pictures were drawn by Jane Chapman. I want you to be good listeners while I read the story. We'll talk about it after I finish. Listen to hear about how a tired bear makes new friends. It looks like the animals are awake, but bear is sleeping. Do you ever sleep if you're really tired when other people around you are talking?

\section{Introduce the magic words. Say:}

When I read this story, I am going to read and say a lot of words. I want you to listen for a few magic words in the story. Here they are.

Slumbering. Say it with me...slumbering.

Blustery. Say it with me...blustery.

Whimpers. Say it with me...whimpers.

When you hear these words in the story, raise your hand.

\section{Read Bear Snores On}

As you read the story, pause at the following pages to focus on the target vocabulary words.

\section{Slumbering (p. 19)}

\section{If children raise their hands...}

Oh, good. Some of you raised your hands! What word did you hear? (Children Respond) Yes, slumbering. "In a cave in the woods, a slumbering bear sleeps through the party in his very own lair."

\section{If children do not raise their hands...}

I think I heard one of our magic words. Listen and raise your hand when you hear our magic word slumbering. "In a cave in the woods, a slumbering bear sleeps through the party in his very own lair." What word did you hear? (Children Respond) Yes, slumbering.

\section{Then add...}

Slumbering means sleeping. Now I'll say the sentence again with a word that means slumbering. "In a cave in the woods, a sleeping bear sleeps through the party in his very own lair." (Point to the picture.) In the picture you can see that bear is slumbering inside of his lair while the other animals have a party. Everyone say slumbering.

\section{Whimpers (p. 26)}




\section{If children raise their hands...}

Oh, good. Some of you raised your hands! What word did you hear? (Children Respond) Yes, whimpers. "And he whimpers and he moans, he wails and he groans."

\section{If children do not raise their hands...}

I think I heard one of our magic words. Listen and raise your hand when you hear our magic word whimpers. "And he whimpers and he moans, he wails and he groans." What word did you hear? (Children Respond) Yes, whimpers.

\section{Then add...}

Whimpers means makes a quiet unhappy or frightened sound like you are about to start to cry. Now I'll say the sentence again with some words that mean whimpers. "And he makes a quiet unhappy sound and he moans, he wails and he groans." (Point to the picture.) In the picture you can see that bear is unhappy and whimpers because he missed the party. Everyone say whimpers.

\section{Blustery (p. 29)}

If children raise their hands...

Oh, good. Some of you raised your hands! What word did you hear? (Children Respond) Yes, blustery. "Then he spins tall tales through the blustery night."

\section{If children do not raise their hands...}

I think I heard one of our magic words. Listen and raise your hand when you hear our magic word blustery. "Then he spins tall tales through the blustery night." What word did you hear? (Children Respond) Yes, blustery.

\section{Then add...}

Blustery means rough, windy weather. Now I'll say the sentence again with a word that means blustery. "Then he spins tall tales through the windy night." (Point to the picture on page 19.) In the picture you can see that the weather outside of bear's lair is very blustery. Everyone say blustery.

Now that we have finished reading the book, let's play some games with our magic words.

\section{PAUSE:}

After reading the story, you want to reinforce learning of the magic words with various activities or games. For the purpose of showing you different activities, you will see three different after-reading activities, one activity for each vocabulary word. These activities can be used after reading in different ways. The following activities have been supported by research to be effective to teach vocabulary. In a whole class setting, one after-reading activity is sufficient. In a small group setting for students who have low vocabulary and need additional attention, you would conduct two of these after-reading activities per word 
on a different day. You could do the same activity for each word or you could do a different activity for each word.

PAUSE

EXAMPLE/NON-EXAMPLE ACTIVITY (Blustery)

Materials: Students will do thumbs up/down; 3 pictures; book

Say...0ne word you learned in this story is blustery. Everybody say blustery. (Students respond.)

If students do not respond...say, I didn't hear all of our friends say the magic word. Let's try that again; everybody say blustery.

Blustery means windy. Everybody say it after me: blustery means windy. (Students respond.)

Show the picture (pg 19) of blustery in the story. Look at this picture from the story. "It was a blustery night outside." The wind is blowing the snow all around. What is it like outside? (Students respond. Prompt students to answer in a complete sentence.) Yes, blustery. Say it this way: "It was a blustery night outside."

Let's play a game about our magic word blustery. I'm going to ask you a question and I want you to answer by giving me a thumbs up or thumbs down. Thumbs up means YES and thumbs down means NO. Let's practice. "Is it sunny today?"...(if confused with thumbs up/down, review more.)

Show the following pictures to the group:

(Picture 1- blustery ocean) "Does this picture show a blustery day?"

If you held up your yes sign like this, you're right! This picture shows a blustery, or windy, day. "It was a blustery day; the wind was blowing the trees and the ocean."

(Picture 2-calm ocean) "Does this picture show a blustery day?"

If you held up your no sign like this, you're right! This picture doesn't show a blustery day; it shows a still day. The ocean was very still; there was no wind at all.

(Picture 3- child in wind) "Does this picture show a blustery day?"

If you held up your yes sign like this, you're right! This picture shows a blustery, or windy day. It was a blustery day; the wind blew the girl's umbrella inside out and her hat is blowing away because it is so blustery outside!

Everyone, what is the magic word that we have been talking about? (Students respond: blustery.) What does it mean? (Students respond: windy.) 


\section{PAUSE}

\section{MAKING SENTENCES with Puppets (Whimpers) Materials: 2 puppets (bear \& raven) for teacher; $3-4$ puppets for students; book}

Making sentences can be done with puppets or pictures. For this activity, you will see it done with puppets.

We're going to play with puppets to talk about another word you learned in the story. The other word you learned is whimpers. Everybody say whimpers. (Students respond.)

If not all students responded, say... I didn't hear all of our friends say the magic word. Let's all try that again. Everybody say whimpers.

Whimpers means cries quietly. Everyone say it with me: whimpers means cries quietly. (Students respond.)

Show students the picture of whimpers in the story. Look at this picture from the story, "The bear whimpers and he moans." The bear whimpers, or cries quietly. What does the bear do? (Students respond.) Prompt students to answer in complete sentence. Yes, whimpers. Say it this way: "The bear whimpers or cries quietly."

Give each student a puppet.

Let's look at some animals who whimper, or cry. Everyone will have a turn to say something about their animal using our magic word, whimpers.

(Puppet 1- Bear) My turn first. "The bear whimpers because he got all wet in the rain." (Use bear puppet to model whimpering.)

(Puppet 2- Raven) Here's another animal who whimpers. "Raven whimpers when he can't find his nest." (Use puppet to model a lost raven whimpering.)

Student name, it's your turn to say something about this animal using our magic word whimpers.

Now it's your turn to saying something about your puppet using the magic word whimpers.

Have each student take turns making up a sentence using the puppet as a prop. Provide prompting as necessary.

Everyone, what is the magic word that we have been talking about? (Students respond: whimpers.) What does it mean? (Students respond: to cry quietly.)

PAUSE 


\section{RELATING TO EXPERIENCES with pictures (slumbering) Materials: 3 pictures, book}

One of the words we learned in this story is slumbering. Everybody say slumbering. (Students respond.)

If not all students responded, say... I didn't hear all of our friends say the magic word. Let's all try that again. Everybody say slumbering.

Slumbering means sleeping. Everyone say it with me: slumbering means sleeping. (Students respond.)

Show the picture of slumbering in the story. Look at this picture from the story. Bear is slumbering while the other animals have a party. The bear is slumbering, or sleeping. What is the bear doing? (Students respond.) Prompt students to answer in a complete sentence. Yes, slumbering. Say it this way: Bear is slumbering, or sleeping.

Now I'm going to ask you some more questions about our magic word slumbering. Listen to what I say. You will each have a turn.

(Picture 1- Lion slumbering)

Hold up the picture. The lion in this picture is slumbering, or sleeping. This picture reminds me of a time when I saw a lion slumbering in its home at the zoo. (Remove picture). Select a student and ask: Tell me about a time that you saw an animal slumbering. (Prompt as necessary.)

(Picture 2- Man and child slumbering)

Hold up the picture. The man and the child in this picture are slumbering, or sleeping together on the couch. This picture reminds me of a time when I was very tired and slumbered with my grandpa in his chair. (remove picture.) Select a different student and ask: Tell me about a time when you were slumbering with someone in your family. (Prompt as necessary.)

(Picture 3- baby sleeping)

Hold up the picture. In this picture, the baby is slumbering, or sleeping. This picture reminds me of a time when I held my slumbering baby cousin for the first time. (remove picture.) Select a different student and ask: Tell me about a time that you held or saw a slumbering baby. (Prompt as necessary.)

Everyone, what is the magic word that we have been talking about? (Students respond: slumbering.) What does it mean? (Students respond: slumbering means sleeping) 